UNIVERSIDADE DE SÃO PAULO ESCOLA DE ENGENHARIA DE SÃO CARLOS DEPARTAMENTO DE ENGENHARIA DE ESTRUTURAS

CLASSIFICAÇÃO ESTRUTURAL DE PEÇAS DE MADEIRA DE PINUS ELLIOTTII UTILIZANDO O MÓDULO DE ELASTICIDADE OBTIDO PELO MÉTODO DE ONDAS LONGITUDINAIS DE TENSÃO 



\title{
CLASSIFICAÇÃO ESTRUTURAL DE PEÇAS DE MADEIRA DE PINUS ELLIOTTII UTILIZANDO O MÓDULO DE ELASTICIDADE OBTIDO PELO MÉTODO DE ONDAS LONGITUDINAIS DE TENSÃO
}

\author{
VERSÃO CORRIGIDA
}

A versão original encontra-se na Escola de Engenharia de São Carlos

\begin{abstract}
Dissertação apresentada ao Departamento de Engenharia de Estruturas da Escola de Engenharia de São Carlos, Universidade de São Paulo, como parte dos quesitos necessários para obtenção do título de Mestre em Engenharia Civil (Estruturas).
\end{abstract}

Orientador: Prof. Dr. Antônio Alves Dias 
AUTORIZO A REPRODUÇÃO TOTAL OU PARCIAL DESTE TRABALHO, POR QUALQUER MEIO CONVENCIONAL OU ELETRÔNICO, PARA FINS DE ESTUDO E PESQUISA, DESDE QUE CITADA A FONTE.

Andrade Junior, Jairo Ribas de

A553c Classificação estrutural de peças de madeira de Pinus elliottii utilizando o módulo de elasticidade obtido pelo método de ondas longitudinais de tensão / Jairo Ribas de Andrade Junior; orientador Antônio Alves Dias. São Carlos, 2016.

Dissertação (Mestrado) - Programa de Pós-Graduação em Engenharia Civil (Bngenharia de Estruturas) e Area de Concentração em Estruturas -- Escola de Engenharia de São Carlos da Universidade de Săo Paulo, 2016.

1. Classificação estrutura da madeira. 2. Ensaio năo-destrutivo. 3. Madeira laminada colada. 4. Construção industrializada. 5. Woodframe. I. Título. 


\section{FOLHA DE JULGAMENTO}

Candidato: Engenheiro JAIRO RIBAS DE ANDRADE JUNIOR.

Título da dissertação: "Classificação estrutural de peças de madeira de pinus elliottii utilizando o módulo de elasticidade obtido pelo método de ondas longitudinais de tensāo".

Data da defesa: 12.12 .2016$.

\section{Comissão Julgadora:}

Prof. Dr. Antonio Alves Dias (Orientador)

(Escola de Engenharia de São Carlas/EESC)

Prof. Titular Carlito Calil Junior

(Escola de Engenharia de São Carlos/EESC)

Prof. Dr. Almir Sales

(Universidade Federal de São Carlos/UFSCar)
Resultado:

Aprovado

A.PROU ADO

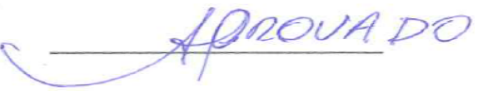

Coordenador do Pragrama de Pós-Graduação em Engenharia Civil (Engenharia de Estruturas):

Prof. Tifular Humberto Breves Coda

Presidente da Comissão de Pós-Graduação: Prof. Associado Luís Fernando Costa Alberto 

Aos meus pais Jairo e Sônia pela educação e estrutura e a minha esposa Aline pelo apoio e carinho... 



\section{AGRADECIMENTOS}

Primeiramente a Deus por toda a saúde e oportunidades.

Aos meus pais Jairo e Sonia pelos ensinamentos e direcionamento durante toda a minha vida e aos meus irmãos Cláudia, Patrick e Vanessa.

A minha esposa Aline pela paciência, amor, apoio e carinho em todos os momentos.

Ao meu amigo e Prof. Dr. Guilherme Corrêa Stamato pelo acompanhamento profissional e dia a dia.

Ao meu orientador Prof. Dr. Antônio Alves Dias pelo direcionamento e elucidações na elaboração do trabalho.

Aos amigos e profissionais do LaMEM pelos serviços realizados ao longo do trabalho e estrutura disponibilizada.

Aos professores e ao Departamento de Engenharia Civil (Estruturas) da USP de São Carlos (EESC-USP) pela estrutura e base fornecidas para a formação.

A Associação da Indústria Madeireira de Capão Bonito (ASSIM) por ceder o equipamento para realização dos ensaios dinâmicos.

A todos que de maneira indireta torceram pelo meu sucesso em completar mais esta etapa de formação. 



\section{RESUMO}

ANDRADE JUNIOR, J. R. Classificação estrutural de peças de madeira de Pinus elliottii utilizando o módulo de elasticidade obtido pelo método de ondas longitudinais de tensão. 2016. 126 p. Dissertação (Mestrado em Engenharia Civil (Estruturas)) - Escola de Engenharia de São Carlos, Universidade de São Paulo, São Carlos, 2016.

A classificação estrutural de peças de madeira possibilita melhor utilização do material, separando as peças de acordo com a sua resistência estimada. Nesse processo é feita a classificação visual, de grande importância no caso de madeiras do gênero pinus, e a classificação mecânica por meio de testes não destrutivos com objetivo de estimar o módulo de elasticidade. Com esse objetivo, além de ensaios de flexão estática, podem ser aplicados métodos dinâmicos baseados em medições das frequências naturais e densidade do material para a determinação do módulo de elasticidade da madeira. Nesse sentido o objetivo deste trabalho foi avaliar a eficiência do aparelho portátil Brookhuis Micro Timber Grader (MTG) na estimativa do módulo de elasticidade por meio de ensaios não-destrutivos de vibração longitudinal. Para tanto, foi utilizado um lote de peças estruturais de madeira da espécie Pinus elliottii classificado visualmente. Os resultados obtidos por esse aparelho foram comparados com os resultados de módulo de elasticidade obtidos em ensaio de flexão estática. Tendo em vista a sua praticidade, é recomendável a utilização deste método para a classificação estrutural de peças serradas de madeira. A classificação visual agregada a classificação mecânica são essenciais para a utilização do Pinus em vigas laminadas coladas, construções industrializadas de madeira e do sistema construtivo em woodframe.

Palavras-chave: Classificação estrutural da madeira. Ensaio não-destrutivo. Madeira Laminada Colada. Construção industrializada. Woodframe. 



\begin{abstract}
ANDRADE JUNIOR, J. R. Structural grading of Pinus elliottii timber using the modulus of elasticity obtained by longitudinal stress wave method. 2016. 126 p. Dissertation (M. Sc. in Civil Engineering (Structures)) - School of Engineering of São Carlos, University of São Paulo, São Carlos, 2016.

The structural grading of wood allows better use of the material, sorting the specimen according to their estimated strength. In this process the visual grading is a fundamental matter in use of the structural Pinus elliottii and also the mechanical grading obtained by nondestructive methods in order to estimate the modulus of elasticity. For this purpose, in addition to the static bending tests, dynamic methods based on measurement of the natural frequencies and density of the material to determining the modulus of elasticity (MOE) of timber can be applied. The objective of this study was to evaluate the efficiency of portable device Brookhuis Micro Timber Grader (MTG) in estimating the modulus of elasticity by non-destructive testing of longitudinal vibration. It was used structural pieces of wood species Pinus elliottii rated visually. The results obtained by this device was compared with the modulus of elasticity results obtained in static bending tests. Given its convenience and low cost, it is recommended to use this method for structural grading of timber sawn pieces. The visual and stress grading are essencial for the use of Pines in glued laminated timber, industrilization timber constructions and woodframe constructions.
\end{abstract}

Keywords: Structural Timber Grading. Non-destructive Examination. Glued Laminated Timber. Industrialization Construction. Woodframe. 


\section{LISTA DE FIGURAS}

Figura 1 - Definição de planos e eixos de simetria elástica para uma peça retangular de madeira .....................29

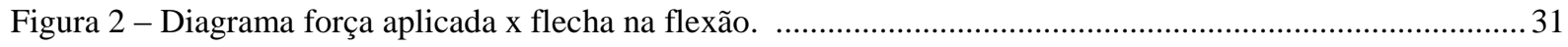

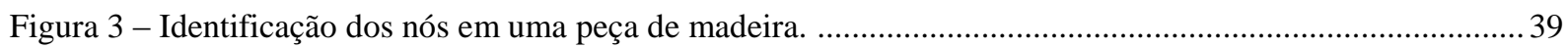

Figura 4 - Medida da inclinação das fibras de uma peça de madeira. .......................................................... 40

Figura 5 - Esquemático da estrutura microscópica da madeira. ............................................................... 43

Figura 6 - Tipos de vibração mecânica: (a) flexional, (b) longitudinal, (c) torcional. .......................................48

Figura 7 - Modos de vibração com vários graus de liberdade: (a) um grau, (b) $n$ graus ................................. 48

Figura 8 - Deslocamento e alongamento de uma barra na vibração longitudinal............................................52

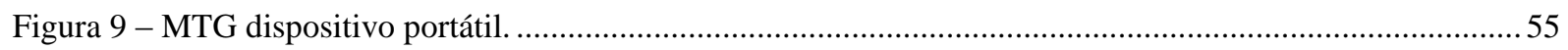

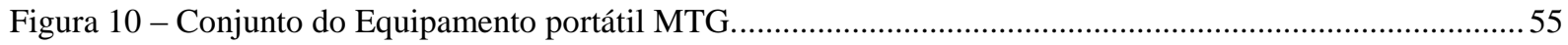

Figura 11 - Medições do módulo de elasticidade com o MTG utilizando ativador interno. ................................57

Figura 12 - Medições do MOE com o MTG utilizando ativador externo. …..................................................58

Figura 13 - Lote de 260 peças de 45x105x2500mm de Pinus elliottii.......................................................65

Figura 14 - Medidor de umidade por contato M52 Marrari. .............................................................................66

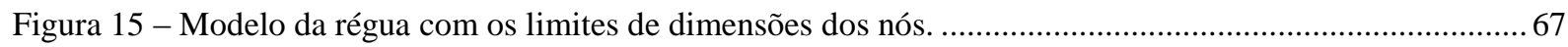

Figura 16 - Medição de um nó de borda com a régua adaptada...................................................................67

Figura 17 - Computador com bluetooth e software de aquisição de dados. .................................................68

Figura 18 - Posicionamento do MTG para obtenção do MOE estimado e display do aparelho.........................68

Figura 19 - Detalhe do apoio rotulado e do sistema de aplicação da carga......................................................69

Figura 20 - Montagem do ensaio estático para obtenção do MOE e MOR .......................................................69

Figura 21 - Esquemático dos espaçamentos para ensaio da peça de 45x105mm...........................................70

Figura 22 - Valores Característicos de MOE de acordo com a NBR7190. ........................................................8 82

Figura 23 - Valores Característicos de MOR de acordo com a NBR7190 ..................................................... 82

Figura 24 - Diagrama de dispersão e reta de regressão entre o MOE e o $\mathrm{E}_{\mathrm{MTG}}$ do lote completo........................84

Figura 25 - Gráfico dos resíduos contra valores estimados para o MOE do lote completo. .................................84

Figura 26 - Gráfico de probabilidade normal dos resíduos para o $\mathrm{E}_{\mathrm{MTG}}$ do lote completo.................................85

Figura 27 - Diagrama dispersão e reta de regressão entre o MOE e o $\mathrm{E}_{\mathrm{MTG}}$ da Classe SS................................8 86

Figura 28 - Gráfico dos resíduos contra valores estimados para o $\mathrm{E}_{\mathrm{MTG}}$ - Classe SS .....................................86

Figura 29 - Gráfico de probabilidade normal dos resíduos para o $\mathrm{E}_{\mathrm{MTG}}$ da Classe SS....................................86

Figura 30 - Diagrama dispersão e reta de regressão entre o MOE estático e o $\mathrm{E}_{\mathrm{MTG}}$ da Classe S1....................87

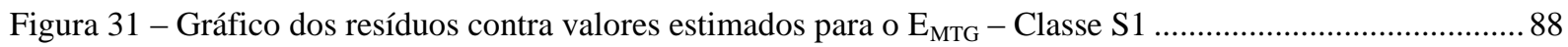

Figura 32 - Gráfico de probabilidade normal dos resíduos para o $\mathrm{E}_{\mathrm{MTG}}$ da Classe $\mathrm{S} 1$.....................................8 88

Figura 33 - Diagrama dispersão e reta de regressão entre o MOE e o $\mathrm{E}_{\mathrm{MTG}}$ da Classe S2 ..............................89

Figura 34 - Gráfico dos resíduos contra valores estimados para o $\mathrm{E}_{\mathrm{MTG}}$ - Classe S2 ...................................89

Figura 35 - Gráfico de probabilidade normal dos resíduos para o $\mathrm{E}_{\mathrm{MTG}}$ da Classe $\mathrm{S} 2$..................................... 90

Figura 36 - Diagrama dispersão e reta de regressão entre o MOE e o $\mathrm{E}_{\mathrm{MTG}}$ da Classe S3...............................90

Figura 37 - Gráfico dos resíduos contra valores estimados para o $\mathrm{E}_{\mathrm{MTG}}$ - Classe S3 .................................. 91

Figura 38 - Gráfico de probabilidade normal dos resíduos para o $\mathrm{E}_{\mathrm{MTG}}$ da Classe $\mathrm{S} 3$................................... 91 
Figura 39 - Diagrama de dispersão e reta de regressão entre o MOE e o $\mathrm{E}_{\mathrm{DIN}}$ do lote completo......

Figura 40 - Gráfico dos resíduos contra valores estimados para o $\mathrm{E}_{\mathrm{DIN}}$ para o lote completo. ..........................93

Figura 41 - Gráfico de probabilidade normal dos resíduos para o $\mathrm{E}_{\mathrm{DIN}}$ do lote completo. ...............................94

Figura 42 - Diagrama de dispersão e reta de regressão entre o MOE na flexão estática e o $\mathrm{E}_{\mathrm{DIN}}$ - Classe SS.... 95

Figura 43 - Gráfico dos resíduos contra valores estimados para o $\mathrm{E}_{\mathrm{DIN}}$ - Classe SS................................... 95

Figura 44 - Gráfico de probabilidade normal dos resíduos para o $\mathrm{E}_{\mathrm{DIN}}$ - Classe SS. ................................... 95

Figura 45 - Diagrama de dispersão e reta de regressão entre o MOE na flexão estática e o $\mathrm{E}_{\mathrm{DIN}}$ - Classe S1.... 96

Figura 46 - Gráfico dos resíduos contra valores estimados para o $\mathrm{E}_{\mathrm{DIN}}$ - Classe S1................................... 97

Figura 47 - Gráfico de probabilidade normal dos resíduos para o $\mathrm{E}_{\mathrm{DIN}}$ - Classe S1.................................... 97

Figura 48 - Diagrama de dispersão e reta de regressão entre o MOE estático e o $E_{\text {DIN }}$ - Classe S2 ...................98

Figura 49 - Gráfico dos resíduos contra valores estimados para o $\mathrm{E}_{\mathrm{DIN}}$ - Classe S2 .................................. 98

Figura 50 - Gráfico de probabilidade normal dos resíduos para o $\mathrm{E}_{\mathrm{DIN}}$ - Classe S2 ..................................... 99

Figura 51 - Diagrama de dispersão e reta de regressão entre o MOE e o $E_{\text {DIN }}$ - Classe S3........................... 100

Figura 52 - Gráfico dos resíduos contra valores estimados para o $\mathrm{E}_{\mathrm{DIN}}$ - Classe S3.................................. 100

Figura 53 - Gráfico de probabilidade normal dos resíduos para o $\mathrm{E}_{\mathrm{DIN}}$ - Classe S3.................................... 100

Figura 54 - Diagrama de dispersão e reta de regressão entre o MOE e o MOR do lote completo...................... 102

Figura 55 - Gráfico dos resíduos contra valores estimados para o MOR para o lote completo........................ 102

Figura 56 - Gráfico de probabilidade normal dos resíduos para o MOR do lote completo. ............................. 103

Figura 57 - Diagrama de dispersão e reta de regressão entre o MOE e o MOR - Classe SS. .......................... 104

Figura 58 - Gráfico dos resíduos contra valores estimados para o MOR - Classe SS.................................. 104

Figura 59 - Gráfico de probabilidade normal dos resíduos para o MOR - Classe SS. .................................. 104

Figura 60 - Diagrama de dispersão e reta de regressão entre o MOE na flexão estática e o MOR - Classe S1. 105

Figura 61 - Gráfico dos resíduos contra valores estimados para o MOR - Classe S1.................................. 106

Figura 62 - Gráfico de probabilidade normal dos resíduos para o MOR - Classe S1.................................. 106

Figura 63 - Diagrama de dispersão e reta de regressão entre o MOE e o MOR - Classe S2 .......................... 107

Figura 64 - Gráfico dos resíduos contra valores estimados para o MOR - Classe S2 .................................. 107

Figura 65 - Gráfico de probabilidade normal dos resíduos para o MOR - Classe S2 .................................. 108

Figura 66 - Diagrama de dispersão e reta de regressão entre o MOE e o MOR - Classe S3........................... 109

Figura 67 - Gráfico dos resíduos contra valores estimados para o MOR - Classe S3..................................... 109

Figura 68 - Gráfico de probabilidade normal dos resíduos para o MOR - Classe S3................................... 109

Figura 69 - Diagrama de dispersão e reta de regressão entre o MOE e a Densidade aparente do lote completo. 111

Figura 70 - Gráfico dos resíduos contra valores estimados para a Densidade aparente para o lote completo. ... 111

Figura 71 - Gráfico de probabilidade normal dos resíduos para a Densidade do lote completo....................... 112

Figura 72 - Diagrama de dispersão e reta de regressão entre o MOE e a Densidade aparente - Classe SS........ 113

Figura 73 - Gráfico dos resíduos contra valores estimados para a Densidade aparente - Classe SS................ 113

Figura 74 - Gráfico de probabilidade normal dos resíduos para a Densidade aparente - Classe SS. …........... 113

Figura 75 - Diagrama de dispersão e reta de regressão entre o MOE e a Densidade aparente - Classe S1....... 114

Figura 76 - Gráfico dos resíduos contra valores estimados para a Densidade aparente - Classe S1................ 115

Figura 77 - Gráfico de probabilidade normal dos resíduos para a Densidade aparente - Classe S1................ 115 
Figura 78 - Diagrama de dispersão e reta de regressão entre o MOE e a Densidade aparente - Classe S2 ........116

Figura 79 - Gráfico dos resíduos contra valores estimados para a Densidade aparente - Classe S2 ............... 116

Figura 80 - Gráfico de probabilidade normal dos resíduos para a Densidade aparente - Classe S2 ................ 117

Figura 81 - Diagrama de dispersão e reta de regressão entre o MOE e a Densidade aparente - Classe S3........ 118

Figura 82 - Gráfico dos resíduos contra valores estimados para a Densidade aparente - Classe S3 ................118

Figura 83 - Gráfico de probabilidade normal dos resíduos para a Densidade aparente - Classe S3 ................. 118 


\section{LISTA DE TABELAS}

Tabela 1 - Classes de resistência das coníferas.

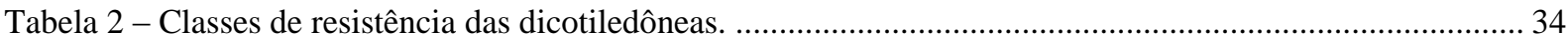

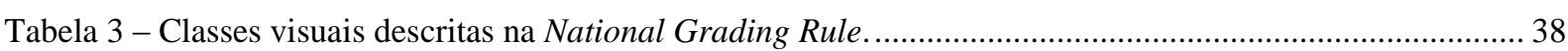

Tabela 4 - Dimensões admitidas dos defeitos em cada classe visual. ............................................................... 40

Tabela 5 - Classes de densidade definidas na ASTM D245-93 ..................................................................... 41

Tabela 6 - Relação entre resistência e o módulo de elasticidade da espécie Abeto da Noruega 40x145 mm

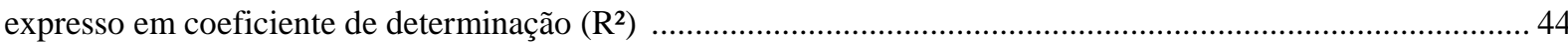

Tabela 7 - Limites das características das peças estruturais para ensaio com o MTG. ........................................58

Tabela 8 - Tolerâncias dos dados de entrada para o Software MTG ............................................................ 58

Tabela 9 - Propriedades mecânicas de peças estruturais de Pinus $s p$.......................................................... 59

Tabela 10 - Propriedades mecânicas de peças estruturais de Pinus oocarpa ......................................................6 60

Tabela 11 - Limitações dos defeitos em cada classe para peças com seção transversal de 45x105mm...............66

Tabela 12 - Quantidade de peças por classe visual. ........................................................................... 71

Tabela 13 - Propriedades das peças da Classe SS................................................................................... 71

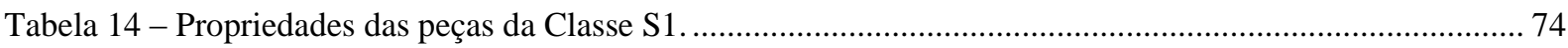

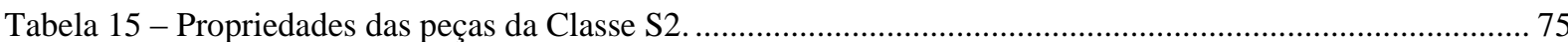

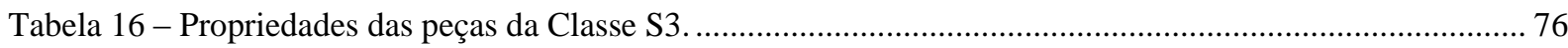

Tabela 17 - Estatística descritiva dos resultados de teor de umidade. ......................................................... 79

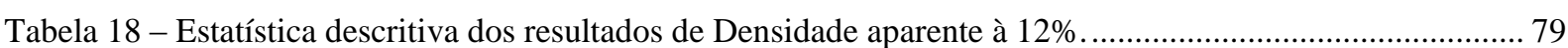

Tabela 19 - Estatística descritiva dos resultados de Módulo de Elasticidade na flexão estática...........................80

Tabela 20 - Estatística descritiva dos resultados de Módulo de Elasticidade obtido pelo MTG..........................80

Tabela 21 - Estatística descritiva dos resultados de MOE Dinâmico................................................................... 80

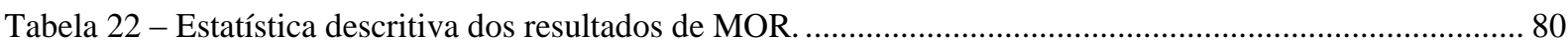

Tabela 23 - Correção do MTG em relação ao MOE estático......................................................................... 81

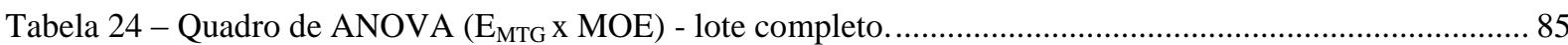

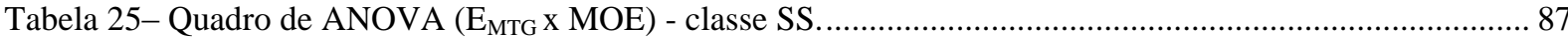

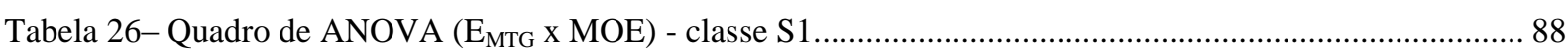

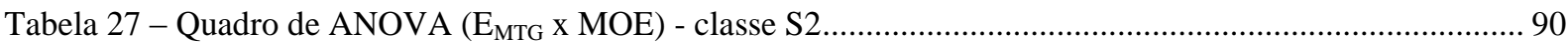

Tabela 28 - Quadro de ANOVA (E $\mathrm{E}_{\mathrm{MTG}} \mathrm{x}$ MOE) - classe S3 ................................................................... 91

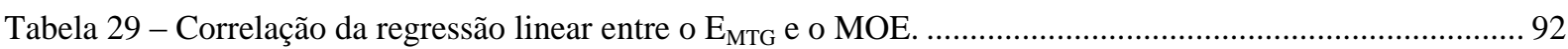

Tabela 30 - Quadro de ANOVA (E

Tabela 31 - Quadro de ANOVA (E

Tabela 32 - Quadro de ANOVA (E

Tabela 33 - Quadro de ANOVA (E

Tabela 34 - Quadro de ANOVA (E

Tabela 35 - Correlação da regressão linear entre o $E_{\text {DIN }}$ e o MOE. ............................................................... 101

Tabela 36 - Quadro de ANOVA (MOR x MOE) - lote completo.................................................................. 103 
Tabela 37 - Quadro de ANOVA (MOR x MOE) - Classe SS. ................................................................ 105

Tabela 38 - Quadro de ANOVA (MOR x MOE) - Classe S1 .................................................................. 106

Tabela 39 - Quadro de ANOVA (MOR x MOE) - Classe S2 ...................................................................... 108

Tabela 40 - Quadro de ANOVA (MOR x MOE) - Classe S3 .................................................................. 110

Tabela 41 - Correlação da regressão linear entre o MOR e o MOE................................................................... 110

Tabela 42 - Quadro de ANOVA (MOE x Densidade) - lote completo.........................................................112

Tabela 43 - Quadro de ANOVA (MOE x Densidade) - Classe SS. .......................................................... 114

Tabela 44 - Quadro de ANOVA (MOE x Densidade) - Classe S1 ............................................................. 115

Tabela 45 - Quadro de ANOVA (MOE x Densidade) - Classe S2 ....................................................... 117

Tabela 46 - Quadro de ANOVA para os dados de MOE pela Densidade aparente - Classe S3...................... 119

Tabela 47 - Correlação da regressão linear entre a Densidade Aparente e o MOE.......................................... 119 


\section{SUMÁRIO}

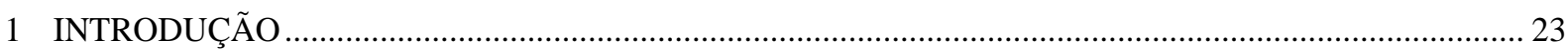

1.1 OBJETIVO

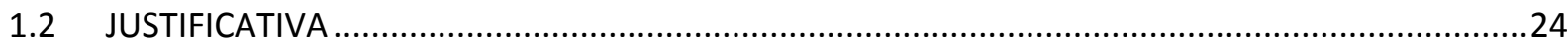

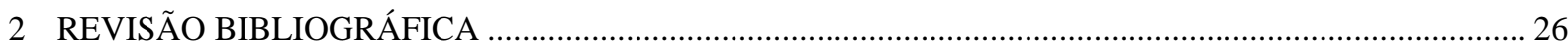

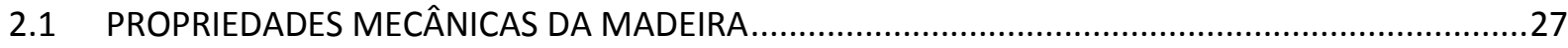

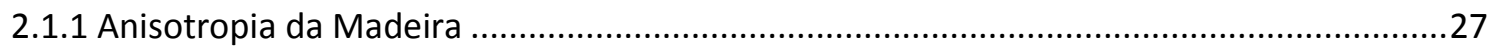

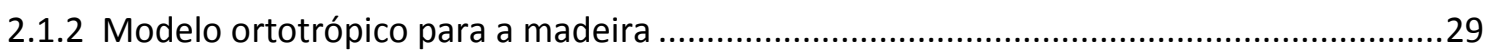

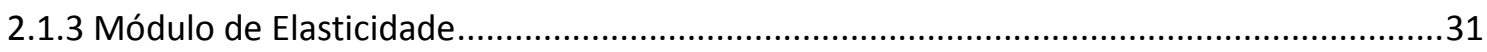

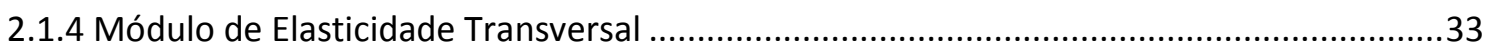

2.1.5 Influência da umidade nas propriedades da madeira .........................................................3

2.1.6 Classes de resistência da NBR 7190/1997 ...........................................................................34

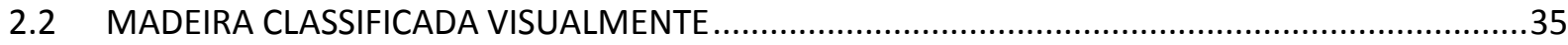

2.2.1 Classificação da madeira estrutural com relação às propriedades mecânicas....................35

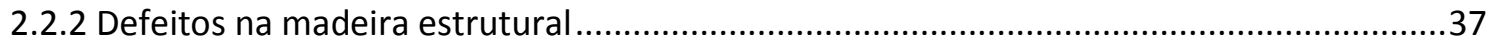

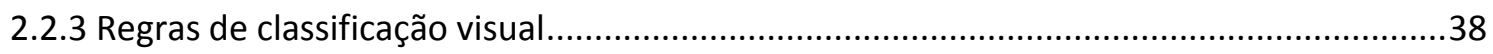

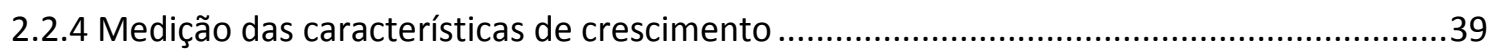

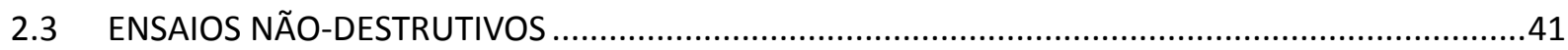

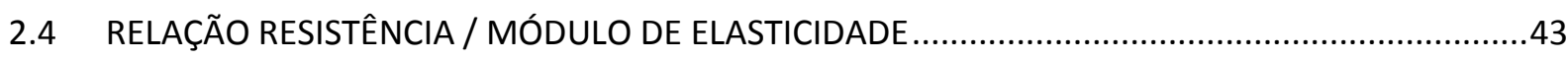

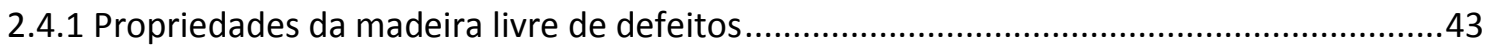

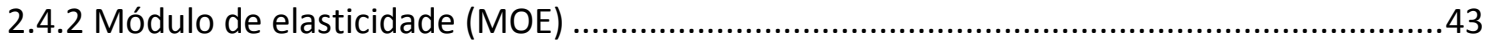

2.4.3 Ensaios de peças em dimensões estruturais ...................................................................44

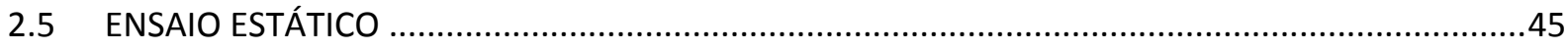

2.5.1 Determinação das constantes elásticas por meio de ensaios estáticos ...............................45

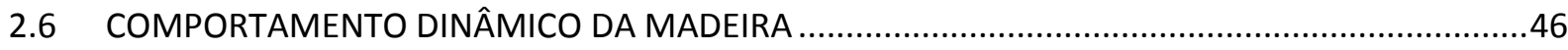

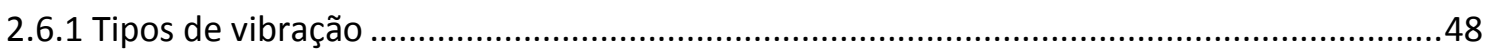

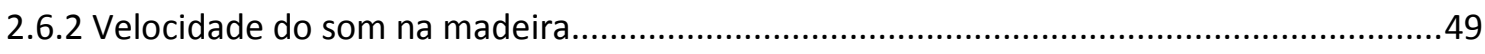

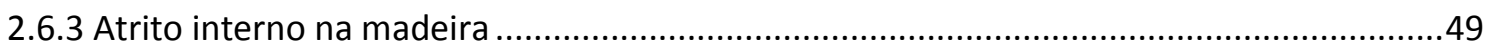

2.6.4 Módulo de elasticidade determinado por vibrações ressonantes ......................................50

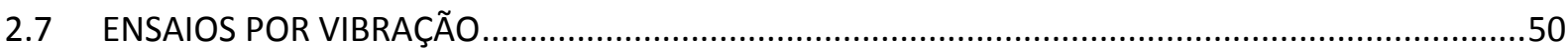

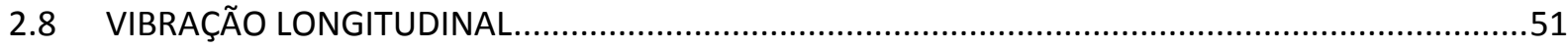

2.9 BROOKHUIS MICROELECTRONICS TIMBER GRADER - MTG .................................................54

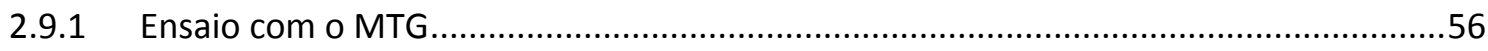


2.9.2 Especificações técnicas. 56

2.10 TRABALHOS TÉCNICO-CIENTÍFICOS SOBRE OBTENÇÃO DE MÓDULO DE ELASTICIDADE PARA

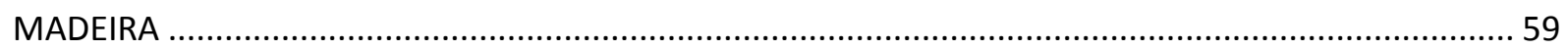

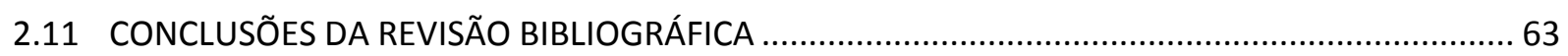

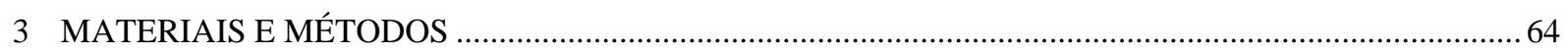

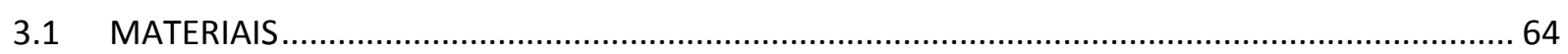

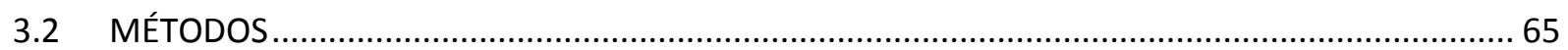

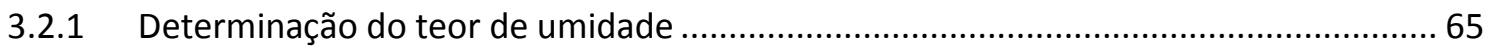

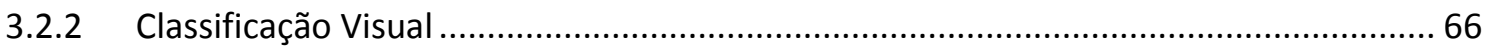

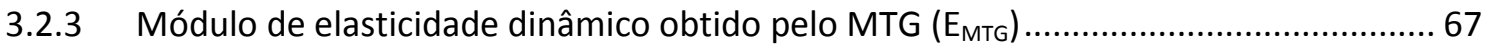

3.2.4 Módulo de elasticidade dinâmico calculado pela frequência natural $\left(E_{D I N}\right)$................. 68

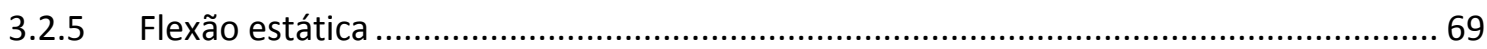

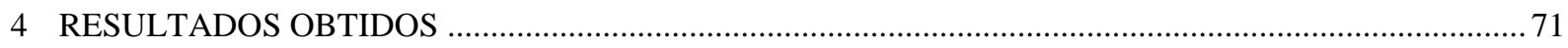

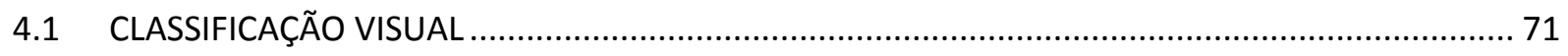

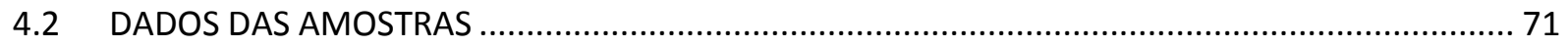

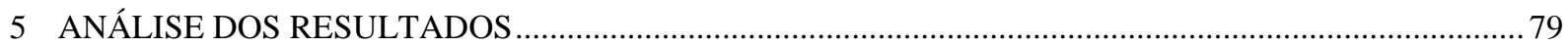

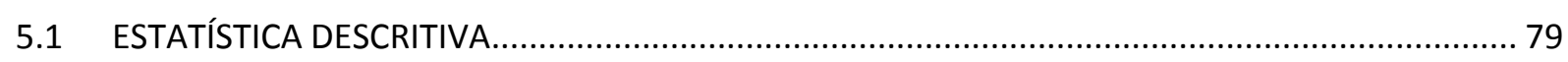

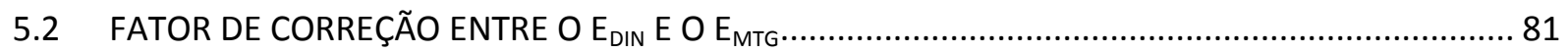

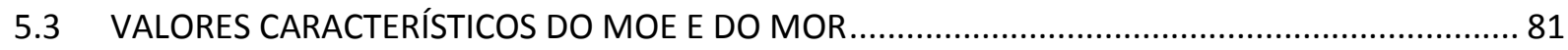

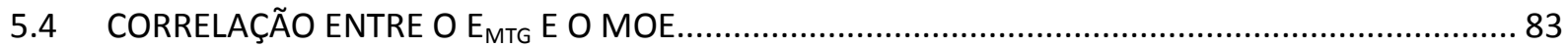

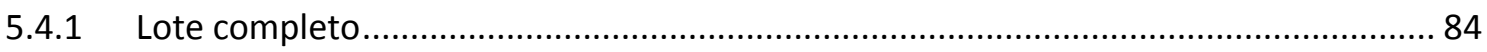

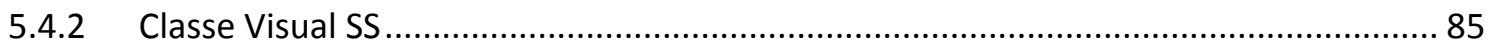

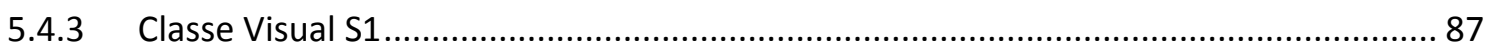

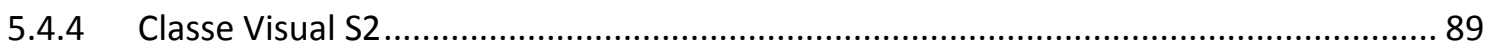

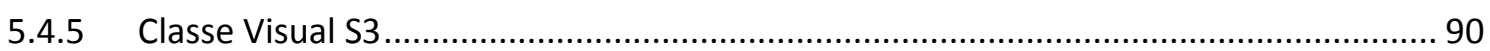

5.4.6 Resumo das Correlações $\mathrm{E}_{\mathrm{MTG}} \times \mathrm{MOE}$

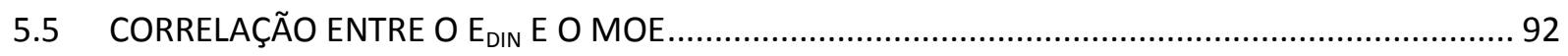

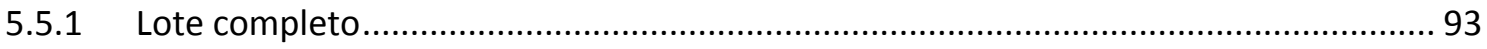

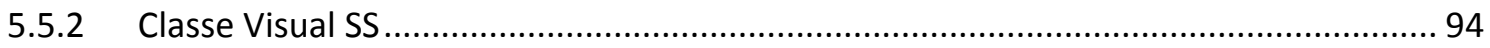

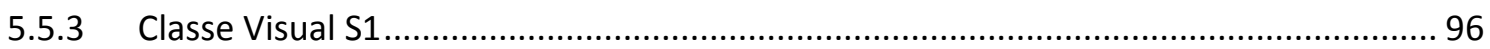

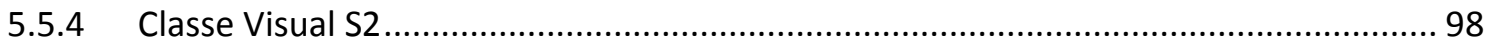

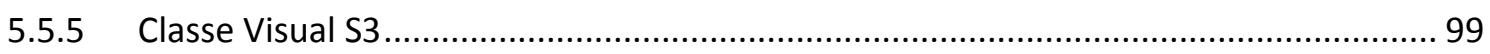

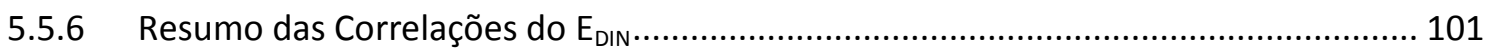

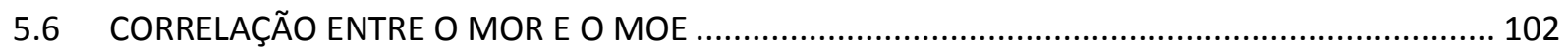

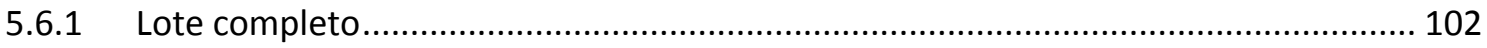




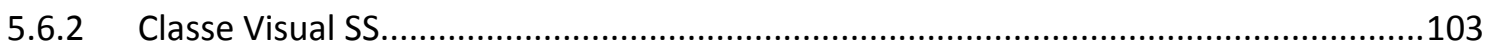

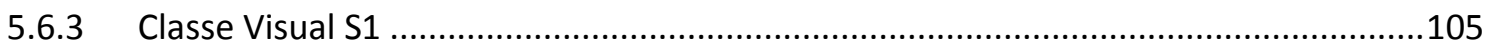

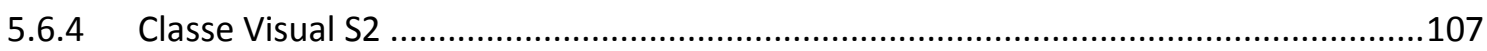

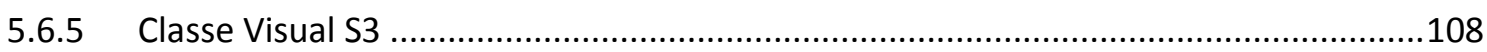

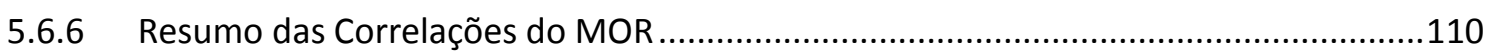

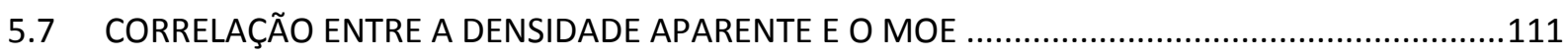

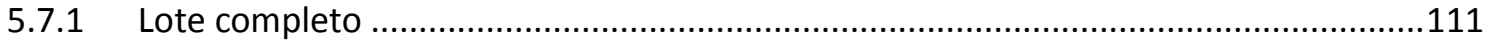

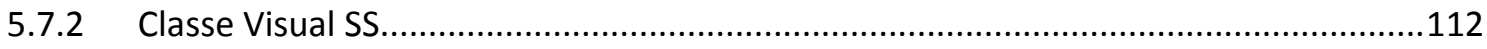

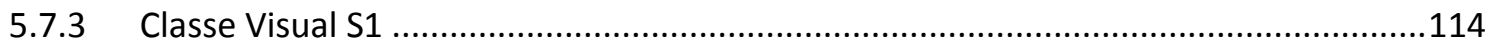

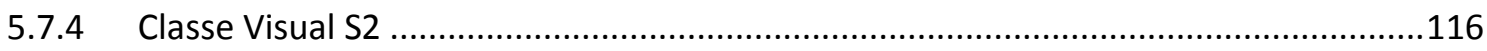

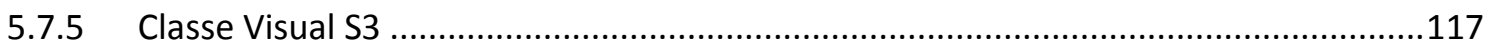

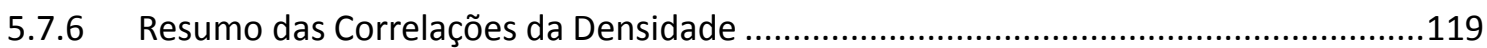

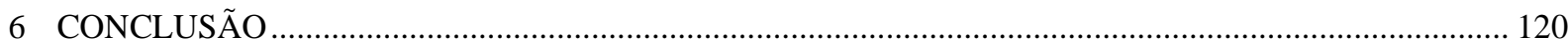

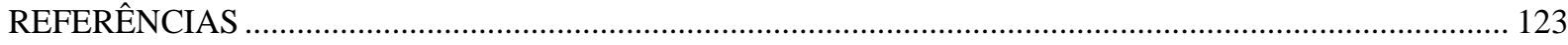





\section{INTRODUÇÃO}

A madeira é um compósito fibroso, que apresenta maior resistência na direção paralela ao eixo longitudinal do tronco. A madeira de dimensões estruturais é um material heterogêneo, com presença de defeitos devido ao crescimento (nós, desvios das fibras, etc.), que reduzem a resistência do material. As peças de madeira serrada do gênero pinus apresentam maior quantidade de defeitos, sendo imprescindível uma classificação mecânica por meio de ensaios não destrutivos.

Um ensaio mecânico não-destrutivo de um material deve ser baseado em correlações conhecidas entre as resistências e outras propriedades que podem ser avaliadas, sem danificar o material. No caso da madeira, a propriedade mecânica que é estimada, na maioria dos casos, é o módulo de elasticidade.

O módulo de elasticidade pode ser obtido por meio de ensaios de flexão estática que são de execução mais difícil e custosa. Métodos dinâmicos como vibração transversal, vibração longitudinal e ultrassom, não destrutivos são uma alternativa para a obtenção do módulo de elasticidade

O aparelho BrookHuis Micro Timber Grader (MTG) é um dispositivo portátil que utiliza o método de vibração longitudinal por ondas de tensão para obtenção do módulo de elasticidade dinâmico da madeira. Através de um software interno, com a seleção da espécie ensaiada, o MTG estima os valores do módulo de elasticidade na flexão estática com correção para $12 \%$ de umidade.

Neste trabalho foi realizado um estudo experimental, em que foram ensaiadas peças de Pinus elliottii, com dimensões estruturais, tanto por ensaio de flexão estática normatizado e também por ensaio dinâmico utilizando o equipamento portátil BrookHuis Microeletronics Timber Grader (MTG), visando a utilização do aparelho portátil na classificação estrutural da madeira. Aliado a uma classificação visual dos defeitos presentes nas peças, o intuito foi estimar o Módulo de Elasticidade na flexão estática a partir de correlações do módulo de elasticidade ( $\mathrm{E}_{\mathrm{MTG}}$ ) obtido com o $\mathrm{MTG}$, do módulo de elasticidade dinâmico $\left(\mathrm{E}_{\mathrm{DIN}}\right)$, do MOR e da densidade aparente da madeira. 


\subsection{OBJETIVO}

O objetivo principal deste trabalho foi avaliar a utilização do método de ensaio não destrutivo, por meio de vibração longitudinal, com o uso do aparelho portátil $M T G$ BrookHuis, para obtenção do módulo de elasticidade de peças estruturais, com vistas à classificação estrutural, utilizando um lote de Pinus elliottii, proveniente do sudoeste paulista.

Também foram avaliadas as correlações entre a resistência à flexão (MOR) e o módulo de elasticidade (MOE), entre o MOE e a densidade aparente e calculados os valores característicos de resistência e de elasticidade do lote.

Os objetivos secundários são:

- classificar visualmente o lote de madeira, segundo as regras do SPIB (Southern Pine Inspection Bureau);

- avaliar o módulo de elasticidade (MOE) das peças por meio de testes de flexão estática; - avaliar os módulos de elasticidade $\mathrm{E}_{\mathrm{MTG}}$ e $\mathrm{E}_{\mathrm{DIN}}$, usando o aparelho MTG, para cada peça; - correlacionar o módulo de elasticidade dinâmico ( $\left.\mathrm{E}_{\mathrm{MTG}}\right)$ com o (MOE) na flexão estática; - correlacionar o módulo de elasticidade dinâmico ( $\left.\mathrm{E}_{\mathrm{DIN}}\right)$ com o (MOE) na flexão estática; - correlacionar a resistência na flexão (MOR) com o módulo de elasticidade (MOE) na flexão estática na maior inércia;

- avaliar a influência da classe visual (presença de defeitos) nas correlações entre os módulos de elasticidade.

\subsection{JUSTIFICATIVA}

A classificação mecânica e a estimativa das propriedades mecânicas da madeira utilizada em estruturas constituem um ponto crítico para o dimensionamento e construção com a espécie Pinus. As peças de madeira com dimensões estruturais contêm defeitos naturais que interferem nas propriedades mecânicas do material, proporcionando comportamentos diferentes dos obtidos nos ensaios de peças pequenas e livres de defeitos.

Países europeus e norte-americanos têm maior desenvolvimento neste setor, com normas de dimensionamento e de ensaio consolidadas, com aplicação de equipamentos inovadores de vibração transversal, vibração longitudinal, ultrassom, entre outros, que podem servir de referência para a estimativa da resistência e do módulo de elasticidade da madeira, 
por meio de ensaios não-destrutivos. A utilização de um equipamento portátil para determinação do módulo de elasticidade (E) por ondas de tensão, torna possível a classificação não-destrutiva "in loco", na serraria, no fornecedor do material ou no recebimento da obra, barateando os custos desta operação e tornando mais confiável a utilização e padronização da madeira em estruturas. A classificação das peças permite uma melhor racionalidade na execução de construções industrializadas, fabricação de vigas laminadas coladas e edificações no sistema construtivo em woodframe. 


\section{REVISÃO BIBLIOGRÁFICA}

Em 2000, as florestas contavam com cerca de 3,9 bilhões de hectares ao redor do mundo, 30\% das terras secas é coberto com árvores. Apesar de várias atividades de conservação, entre 12 e 15 milhões de hectares de floresta são perdidos todo ano. Um total de 3,4 bilhões de $\mathrm{m}^{3}$ de madeira em toras foram derrubados em 2000 ao redor do mundo. Disto, cerca de $45 \%$ foi convertido em madeira comercial (WEGENER, ZIMMER, 2008).

O setor florestal brasileiro tem um grande potencial de fornecimento de matériasprimas para construção de habitações em madeira. A Associação Brasileira de florestas Plantadas (ABRAF) e Indústria Brasileira de Árvores (Ibá) detalham os dados sobre o setor. Das florestas plantadas brasileiras, $72 \%$ são do gênero Eucalyptus e 20,7\% são do gênero Pinus. (ABRAF, 2013)

Levantamento do do Instituto Brasileiro de Árvores (IBA) mostra que em 2014 os plantios de Pinus ocupam 1,588 milhão de hectares, 1,2\% superior a área de 2013 e concentram-se no Paraná (42,4\%), seguidos por Santa Catarina (34,1\%), Rio Grande do Sul 11,6\%, São Paulo 7,8\%, Minas Gerais 2,5\%, e os outros estados somam 1,6\% (IBA, 2015).

A desaceleração da construção civil nacional levou a uma queda de $6,1 \%$ no consumo doméstico de madeira serrada, que passou de 8,51 milhões de metros cúbicos em 2013 para 7,99 milhões de metros cúbicos em 2014. Nesse cenário, a produção de serrados de árvores plantadas atingiu 9,23 milhões de metros cúbicos, recuo de 1,5\% em relação a 2013. As exportações de madeira serrada de árvores plantadas alcançaram 1,24 milhão de metros cúbicos em 2014, um crescimento de 43,6\% em relação a 2013. A demanda global por madeira serrada cresceu $18 \%$ em 2013, em decorrência da melhoria, ainda que modesta, da economia mundial. (IBA, 2015).

A seguir são apresentados os aspectos relevantes de propriedades mecânicas da madeira, da classificação estrutural (visual e mecânica), e de métodos de ensaios pertinentes. 


\subsection{PROPRIEDADES MECÂNICAS DA MADEIRA}

A norma norte-americana American Society for Testing and Materials (ASTM D4761-2002), trata especificamente de ensaios estáticos para peças estruturais, baseada na norma ASTM D198, que detalha os procedimentos de ensaio para madeira serrada na flexão. Vigas com dimensões estruturais são sujeitas à flexão em quatro pontos, bi apoiadas e com a aplicação de cargas em dois pontos, e razão entre vão e espessura da peça entre 18 e 21 vezes. Este tipo de carregamento produz um momento constante, não ocasionando tensão de cisalhamento na seção da viga (BODIG, JAYNE; 1993).

Além dos métodos estáticos para determinar as constantes elásticas da madeira, existem métodos dinâmicos baseados em medições das frequências naturais. $\mathrm{O}$ módulo de elasticidade dinâmico $E_{d}$ pode ser medido utilizando métodos de vibração. Os ensaios de vibração possibilitam a determinação das frequências naturais e do módulo de elasticidade da madeira. Uma vantagem das medições dinâmicas é a curta duração do ensaio. Em geral, o módulo de elasticidade obtido pelos ensaios de vibração é um pouco maior do que os dos ensaios estáticos, mas as diferenças são pequenas, da ordem de 5\% a 15\% (KOLLMANN, 1968).

\subsubsection{Anisotropia da Madeira}

A madeira é um material anisotrópico, ou seja, suas propriedades físicas dependem da direção. Por exemplo, a resistência a tração é 30-50 vezes menor na direção perpendicular às fibras do que na direção paralela às fibras. A razão para isso pode ser observada na anatomia da estrutura das fibras da madeira. Deformações devidas à variação da umidade nas direções perpendiculares às fibras são muito superiores do que na direção paralela às fibras (THELANDERSON, 2003). No caso de materiais anisotrópicos, as relações tensão por deformação são apresentadas com a seguinte notação: 


$$
\left|\begin{array}{l}
\varepsilon_{1} \\
\varepsilon_{2} \\
\varepsilon_{3} \\
\varepsilon_{4} \\
\varepsilon_{5} \\
\varepsilon_{6}
\end{array}\right|=\left|\begin{array}{llllll}
\mathrm{S}_{11} & \mathrm{~S}_{12} & \mathrm{~S}_{13} & \mathrm{~S}_{14} & \mathrm{~S}_{15} & \mathrm{~S}_{16} \\
\mathrm{~S}_{21} & \mathrm{~S}_{22} & \mathrm{~S}_{23} & \mathrm{~S}_{24} & \mathrm{~S}_{25} & \mathrm{~S}_{26} \\
\mathrm{~S}_{31} & \mathrm{~S}_{32} & \mathrm{~S}_{33} & \mathrm{~S}_{34} & \mathrm{~S}_{35} & \mathrm{~S}_{36} \\
\mathrm{~S}_{41} & \mathrm{~S}_{42} & \mathrm{~S}_{43} & \mathrm{~S}_{44} & \mathrm{~S}_{45} & \mathrm{~S}_{46} \\
\mathrm{~S}_{51} & \mathrm{~S}_{52} & \mathrm{~S}_{53} & \mathrm{~S}_{54} & \mathrm{~S}_{55} & \mathrm{~S}_{56} \\
\mathrm{~S}_{61} & \mathrm{~S}_{62} & \mathrm{~S}_{63} & \mathrm{~S}_{64} & \mathrm{~S}_{65} & \mathrm{~S}_{66}
\end{array}\right| \mid \begin{gathered}
\sigma_{1} \\
\sigma_{2} \\
\sigma_{3} \\
\sigma_{4} \\
\sigma_{5} \\
\sigma_{6}
\end{gathered}
$$

Nesta notação, os índices 1,2 e 3 indicam as direções analisadas, que são ortogonais entre si. As distorções $\gamma_{12}, \gamma_{13}$ e $\gamma_{23}$ são representadas por $\varepsilon_{4}, \varepsilon_{5}$ e $\varepsilon_{6}$, respectivamente. As tensões de cisalhamento $\tau_{12}, \tau_{13}$ e $\tau_{23}$ são representadas por $\sigma_{4}, \sigma 5$ e $\sigma_{6}$, respectivamente (BODIG, JAYNE; 1993).

Esta equação matricial também pode ser representada da maneira da Equação (1):

$$
|\varepsilon|=|S| \mid \sigma
$$

A matriz $\mathbf{S}$ é conhecida como matriz compliance ou matriz dos coeficientes de deformabilidade. A inversa da matriz $\mathbf{S}$ é a matriz $\mathbf{C}$, conhecida por matriz das constantes de elasticidade ou dos coeficientes de rigidez, conforme a Equação (2).

$$
|\sigma|=|\mathrm{C}||\varepsilon|
$$

Dos 36 elementos da matriz $\mathbf{S}, 21$ são independentes, e a matriz é simétrica $\left(\mathrm{S}_{\mathrm{ij}}=\right.$ $\mathrm{S}_{\mathrm{ji}}$ ). Deve-se lembrar que, para materiais isotrópicos, são apenas 2 elementos independentes. Os elementos $S_{\mathrm{ij}}$ têm o seguinte significado:

a) quando $\mathrm{i}=\mathrm{j}=1,2$ ou 3, são constantes que relacionam a tensão normal $\sigma$ com a deformação $\varepsilon$, para cada direção, como mostra a Equação (3):

$$
\mathrm{S}_{\mathrm{ii}}=\frac{1}{\mathrm{E}_{\mathrm{i}}}
$$

b) A Equação (4) apresenta os valores do $\mathrm{Sij}$, quando i = 1, 2 ou 3 e j = 1, 2 ou 3, sendo $\mathrm{i} \neq \mathrm{j}$, constantes relacionadas às deformações transversais na direção $\mathrm{j}$ quando se aplicam tensões normais na direção i: 


$$
S_{i j}=\frac{-v_{i j}}{E_{i}}=S_{j i}=\frac{-v_{j i}}{E_{j}}
$$

c) A Equação (5), apresenta os valores $\operatorname{Sij}$, quando $\mathrm{i}=\mathrm{j}=4,5$ ou 6, constantes que relacionam a tensão normal $\tau$ com a distorção $\gamma$, para cada plano:

$$
\mathrm{S}_{\mathrm{ii}}=\frac{1}{\mathrm{G}_{\mathrm{i}}}
$$

d) Quando i = 4, 5 ou 6 e j = 1, 2 ou 3, $S_{\text {ij }}$ relaciona uma deformação linear com uma tensão de cisalhamento, ou vice-versa.

e) Quando $\mathrm{i}=4,5$ ou 6 e $\mathrm{j}=4,5$ ou 6 , para $\mathrm{i} \neq \mathrm{j}, \mathrm{S}_{\mathrm{ij}}$ relaciona uma distorção em determinado plano com uma tensão de cisalhamento que atua em outro plano perpendicular.(BODIG, JAYNE; 1993).

\subsubsection{Modelo ortotrópico para a madeira}

A madeira pode ser considerada um material ortotrópico, com três eixos de simetria elástica, caracterizados pelas direções longitudinal, tangencial e radial. O eixo longitudinal $L$ é paralelo às fibras. $\mathrm{O}$ eixo radial $R$ é normal aos anéis de crescimento (perpendicular às fibras na direção radial). E o eixo tangencial $T$ é perpendicular às fibras, mas tangente aos anéis de crescimento. Estes eixos estão apresentados na Figura 1.

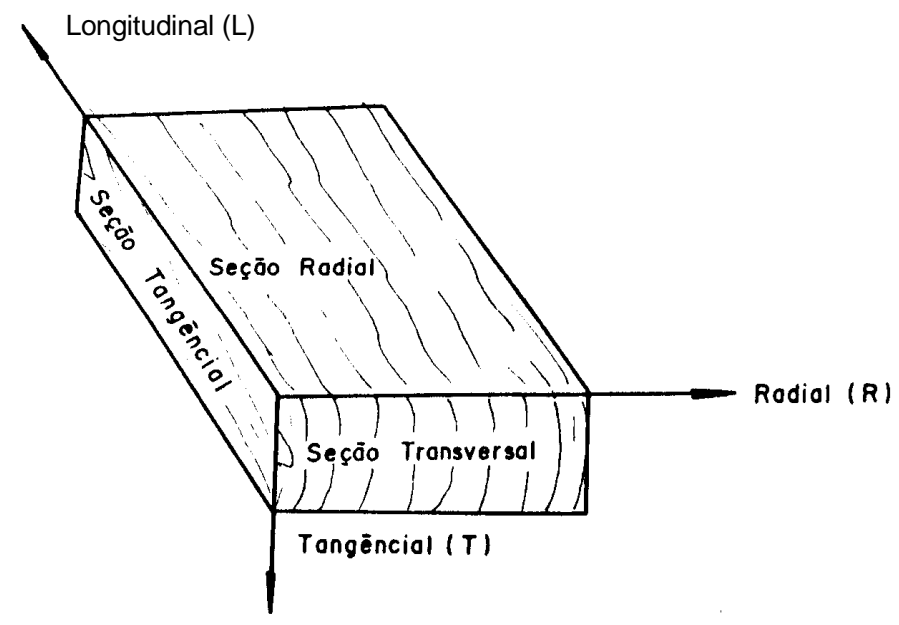

Figura 1 - Definição de planos e eixos de simetria elástica para uma peça retangular de madeira (Fonte: BODIG \& JAYNE, 1993) 
Se as direções $\mathbf{1}, \mathbf{2}$ e $\mathbf{3}$ forem coincidentes com as direções $\mathbf{L}, \mathbf{T}$ e $\mathbf{R}$, respectivamente, teremos a seguinte matriz dos coeficientes de deformação, $\mathbf{S}$.

$$
\mathbf{S}=\left|\begin{array}{cccccc}
\mathrm{S}_{11} & \mathrm{~S}_{12} & \mathrm{~S}_{13} & 0 & 0 & 0 \\
\mathrm{~S}_{21} & \mathrm{~S}_{22} & \mathrm{~S}_{23} & 0 & 0 & 0 \\
\mathrm{~S}_{31} & \mathrm{~S}_{32} & \mathrm{~S}_{33} & 0 & 0 & 0 \\
0 & 0 & 0 & \mathrm{~S}_{44} & 0 & 0 \\
0 & 0 & 0 & 0 & \mathrm{~S}_{55} & 0 \\
0 & 0 & 0 & 0 & 0 & \mathrm{~S}_{66}
\end{array}\right|
$$

Obs: os índices 4, 5 e 6 são referentes ao cisalhamento nos planos perpendiculares aos planos LT, LR e TR, respectivamente.

Substituindo os termos $\mathrm{S}_{\mathrm{ii}}$ por constantes elásticas usuais de Engenharia, e empregando a notação referente aos eixos $\mathbf{L}, \mathbf{T}$ e $\mathbf{R}$, obtém-se as seguintes relações entre tensões e deformações (BODIG, JAYNE; 1993).:

$$
\left\{\begin{array}{c}
\varepsilon_{\mathrm{L}} \\
\varepsilon_{\mathrm{T}} \\
\varepsilon_{\mathrm{R}} \\
\gamma_{\mathrm{LT}} \\
\gamma_{\mathrm{LR}} \\
\gamma_{\mathrm{TR}}
\end{array}\right\}=\left|\begin{array}{cccccc}
\frac{1}{\mathrm{E}_{\mathrm{L}}} & -\frac{v_{\mathrm{TL}}}{\mathrm{E}_{\mathrm{T}}} & -\frac{v_{\mathrm{RL}}}{\mathrm{E}_{\mathrm{R}}} & 0 & 0 & 0 \\
-\frac{v_{\mathrm{LT}}}{\mathrm{E}_{\mathrm{L}}} & \frac{1}{\mathrm{E}_{\mathrm{T}}} & -\frac{v_{\mathrm{RL}}}{\mathrm{E}_{\mathrm{R}}} & 0 & 0 & 0 \\
-\frac{v_{\mathrm{LR}}}{\mathrm{E}_{\mathrm{L}}} & -\frac{v_{\mathrm{TR}}}{\mathrm{E}_{\mathrm{T}}} & \frac{1}{\mathrm{E}_{\mathrm{R}}} & 0 & 0 & 0 \\
0 & 0 & 0 & \frac{1}{\mathrm{G}_{\mathrm{LT}}} & 0 & 0 \\
0 & 0 & 0 & 0 & \frac{1}{\mathrm{G}_{\mathrm{LR}}} & 0 \\
0 & 0 & 0 & 0 & 0 & \frac{1}{\mathrm{G}_{\mathrm{TR}}}
\end{array}\right|\left\{\begin{array}{c}
\sigma_{\mathrm{L}} \\
\sigma_{\mathrm{T}} \\
\sigma_{\mathrm{R}} \\
\tau_{\mathrm{LT}} \\
\tau_{\mathrm{LR}} \\
\tau_{\mathrm{TR}}
\end{array}\right\}
$$

As constantes elásticas da madeira, no modelo ortotrópico, são os módulos de elasticidade longitudinais segundo as três direções $\left(E_{L}, E_{T}, E_{R}\right)$, os módulos de elasticidade transversais segundo os três planos definidos pelas direções principais $\left(G_{L T}, G_{L R}, G_{T R}\right)$ e os coeficientes de Poisson $\left(v_{L T}, v_{T L}, v_{L R}, v_{R L}, v_{T R}, v_{R T}\right)$. De acordo com a Equação (6), destas constantes, apenas nove são independentes, pois:

$$
\frac{v_{L T}}{E_{L}}=\frac{v_{T L}}{E_{T}} \quad ; \quad \frac{v_{L R}}{E_{L}}=\frac{v_{R L}}{E_{R}} \quad ; \quad \frac{v_{R T}}{E_{T}}=\frac{v_{R T}}{E_{R}}
$$


É importante observar que o coeficiente de Poisson $v_{\mathrm{ij}}$ é a relação entre a deformação na direção $j$ e a deformação na direção $i$, para a tensão normal aplicada na direção $i$ (BODIG, JAYNE; 1993).

\subsubsection{Módulo de Elasticidade}

O Módulo de Elasticidade da madeira na norma NBR7190/1997 é definido por meio de um corpo de prova isento de defeitos e com pequenas dimensões, submetido à compressão paralela $\left(\mathrm{E}_{\mathrm{c} 0, \mathrm{~m}}\right)$.

O módulo de elasticidade $\left(E_{L}\right)$ pode ser determinado pela flexão, ao invés de um teste de compressão axial. No caso de relações entre o vão livre e a altura das peças $(\mathrm{L} / \mathrm{h})$ menores que 18, as tensões de cisalhamento apresentam uma influência significativa nas deformações das peças, levando o MOE à um valor inferior se não forem computadas as deformações devido as tensões de cisalhamento. (ROCCO, 1983)

O módulo de elasticidade da madeira obtido na flexão é definido no trecho linear do diagrama força x deslocamento, conforme a Figura 2. (ASSOCIAÇÃO BRASILEIRA DE NORMAS TÉCNICAS, 1997).

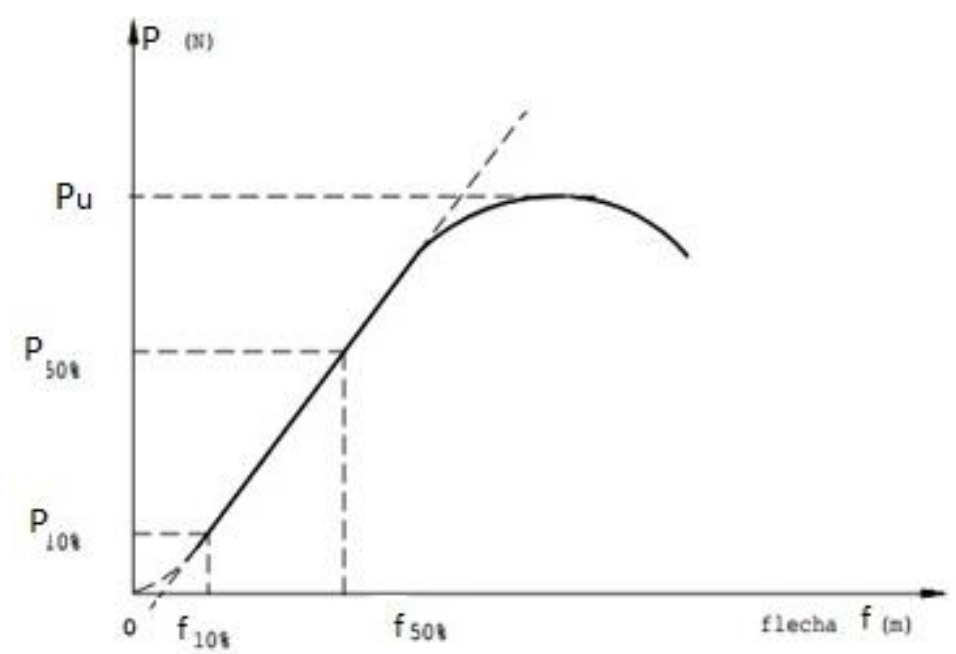

Figura 2 - Diagrama força aplicada x flecha na flexão. (Fonte: NBR 7190/1997, Anexo B)

O módulo de elasticidade deve ser determinado pela inclinação da reta secante à curva força aplicada (P) x flecha no meio do vão (f) (Figura 2), definida pelos pontos $\left(\mathrm{P}_{10 \%}\right.$; $\left.\mathrm{f}_{10 \%}\right)$ e $\left(\mathrm{P}_{50 \%} ; \mathrm{f}_{50 \%}\right)$, correspondentes respectivamente a $10 \%$ e $50 \%$ da força máxima $\left(\mathrm{P}_{\mathrm{u}}\right)$, determinada no ensaio, sendo dada pela Equação (7): 


$$
E_{M}=\frac{\left(P_{50 \%}-P_{10 \%}\right) \cdot l^{3}}{\left(f_{50 \%}-f_{10 \%}\right) \cdot 4 \cdot b \cdot h^{3}}
$$

Sendo:

$E_{M}=$ Módulo de elasticidade na flexão;

$P_{50 \%}=$ Força aplicada equivalente a $50 \%$ da força máxima;

$P_{10 \%}=$ Força aplicada equivalente a $10 \%$ da força máxima;

$l=$ vão livre entre os apoios;

$f_{50 \%}=$ deformação no centro do vão com aplicação de 50\% da carga máxima;

$f_{10 \%}=$ deformação no centro do vão com aplicação de $10 \%$ da carga máxima;

$b=$ largura da peça ensaiada;

$h=$ altura da peça ensaiada;

Os três módulos de elasticidade são indicados como Módulo de Elasticidade Longitudinal paralelo ao eixo, Módulo Radial e Módulo Tangencial relativo aos eixos da madeira. Os coeficientes elásticos variam entre as espécies de madeira, e também com a variação do teor de umidade e com o peso específico (KRETSCHMANN, 2010a).

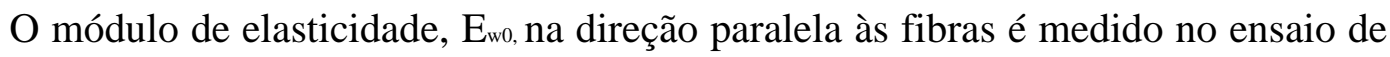
compressão paralela às fibras e o módulo de elasticidade $E_{w 90}$ na direção normal às fibras é medido no ensaio de compressão normal às fibras (ASSOCIAÇÃO BRASILEIRA DE NORMAS TÉCNICAS, 1997).

Segundo a NBR7190/1997, na falta de determinação experimental específica, permite-se adotar a Equação (8), para o valor do módulo de elasticidade normal as fibras, com base no módulo de elasticidade paralelo às fibras:

$$
E_{w 90}=\frac{1}{20} \cdot E_{w 0}
$$

A caracterização do módulo de elasticidade das madeiras deve respeitar os métodos de ensaio especificados no anexo B da NBR 7190/1997. Os valores devem ser referidos à condição-padrão de umidade $(\mathrm{U}=12 \%)$.

Na impossibilidade da realização do ensaio de compressão simples, permite-se avaliar o módulo de elasticidade $E_{c, m}$ por meio de ensaio de flexão, de acordo com o método especificado no anexo B (NBR 7190). Por este ensaio, determina-se o módulo aparente de elasticidade na flexão $E_{M}$, admitindo as seguintes relações das Equações (9) e (10): 
Coníferas: $\mathrm{E}_{\mathrm{M}}=0,85 \cdot \mathrm{E}_{\mathrm{c} 0}$

Dicotiledôneas: $\mathrm{E}_{\mathrm{M}}=0,90 \cdot \mathrm{E}_{\mathrm{c} 0}$
(9)

\subsubsection{Módulo de Elasticidade Transversal}

O módulo de elasticidade transversal $(G)$ é a relação entre as tensões de cisalhamento e a distorção. No caso de vigas a distorção pode ter efeito significativo nas deformações transversais (flechas). Os três módulos de elasticidade transversais denominados $G_{L R}, G_{L T}$ e $G_{R T}$, são as constantes elásticas nos planos $L R, L T$ e $R T$ respectivamente. (KRETSCHMANN, 2010a).

\subsubsection{Influência da umidade nas propriedades da madeira}

O teor de umidade da madeira (peso da água em relação ao peso da madeira à $0 \%$ de umidade) pode atingir $100 \%$ ou mais. Parte da água contida na madeira é denominada livre, que é armazenada nas cavidades das células da madeira, vasos e canais, enquanto aquela ligada no interior das paredes celulares é denominada água de adesão ou higroscópica. Quando a madeira é submetida à secagem, inicialmente é perdida a água livre. O valor correspondente ao teor de umidade quando se perdeu toda a água livre é denominado ponto de saturação das fibras (PSF). O PSF varia entre $25 \%$ e 32\%, dependendo da espécie analisada, com uma média de 28\%, para todas as espécies. (JANKOWSKY, 1990). Até atingir o PSF, a perda de umidade não interfere nas propriedades mecânicas da madeira.

Abaixo do PSF, as propriedades mecânicas da madeira variam de acordo com a variação do teor de umidade, o módulo de elasticidade e a resistência aumentam com a diminuição do teor de umidade (THELANDERSON, 2003).

A madeira é higroscópica e interage com a umidade do ar do ambiente. O teor de umidade em uma peça de madeira varia de acordo com a umidade e a temperatura do ambiente, de forma lenta, o que sugere que ocorre um gradiente de umidade na madeira (THELANDERSON, 2003).

A norma NBR7190 define que a condição padrão de referência para o teor de umidade na madeira é de $12 \%$ e que os resultados de ensaios realizados com teores de umidade da madeira, entre $10 \%$ e $20 \%$ (ASSOCIAÇÃO BRASILEIRA DE NORMAS 
TÉCNICAS, 1997), devem ser corrigidos de acordo com a equação (11), no caso da resistência, e com a equação 12 no caso do módulo de elasticidade.

$$
\begin{aligned}
& f_{12}=f_{u \%} \cdot\left[1+\frac{3 \cdot(U \%-12)}{100}\right] \\
& E_{12}=E_{u \% \cdot} \cdot\left[1+\frac{2 \cdot(U \%-12)}{100}\right]
\end{aligned}
$$

\subsubsection{Classes de resistência da NBR 7190/1997}

As classes de resistência das madeiras têm por objetivo o emprego de propriedades padronizadas, orientando a escolha do material para elaboração de projetos estruturais, sendo as peças de madeira enquadradas nas classes de resistência especificadas nas Tabelas 1 e 2 . O lote de madeiras ensaiado devem atender os requisitos mínimos das propriedades para ser enquadrado na classe determinada.

Tabela 1 - Classes de resistência das coníferas. (NBR 7190/1997)

\begin{tabular}{cccccc}
\hline \multicolumn{5}{c}{ Coníferas (Valores na condição-padrão de referência U=12\%) } \\
\hline Classes & $\mathrm{f}_{\mathrm{c} 0 \mathrm{k}} \mathrm{MPa}$ & $\mathrm{f}_{\mathrm{v} 0 \mathrm{k}} \mathrm{MPa}$ & $\mathrm{E}_{\mathrm{c} 0, \mathrm{~m}} \mathrm{MPa}$ & $\rho_{\text {bas.m }} \mathrm{kg} / \mathrm{m}^{3}$ & $\rho_{\text {aparente }} \mathrm{kg} / \mathrm{m}^{3}$ \\
\hline C 20 & 20 & 4 & 3500 & 400 & 500 \\
C 25 & 25 & 5 & 8500 & 450 & 550 \\
C 30 & 30 & 6 & 14500 & 500 & 600 \\
\hline
\end{tabular}

Tabela 2 - Classes de resistência das dicotiledôneas. (NBR7190/1997)

\begin{tabular}{cccccc}
\hline \multicolumn{5}{c}{ Dicotiledôneas (Valores na condição-padrão de referência U=12\%) } \\
\hline Classes & $\mathrm{f}_{\mathrm{c} 0 \mathrm{k}} \mathrm{MPa}$ & $\mathrm{f}_{\mathrm{v} 0 \mathrm{k}} \mathrm{MPa}$ & $\mathrm{E}_{\mathrm{c} 0, \mathrm{~m}} \mathrm{MPa}$ & $\rho_{\text {bas.m }} \mathrm{kg} / \mathrm{m}^{3}$ & $\rho_{\text {aparente }} \mathrm{kg} / \mathrm{m}^{3}$ \\
\hline C 20 & 20 & 4 & 9500 & 500 & 650 \\
C 30 & 30 & 5 & 14500 & 650 & 800 \\
C 40 & 40 & 6 & 19500 & 750 & 950 \\
C 60 & 60 & 8 & 24500 & 800 & 1000 \\
\hline
\end{tabular}




\subsection{MADEIRA CLASSIFICADA VISUALMENTE}

As peças de madeira serrada, independente da espécie ou dimensões podem apresentar variações significativas nas propriedades mecânicas. As peças devem ser classificadas de acordo com as suas propriedades. (KRETSCHMANN, 2010b).

A classificação visual presume que as propriedades mecânicas de uma peça de madeira são diferentes das propriedades mecânicas de uma peça isenta de defeitos.

A classificação por resistência de uma peça de madeira é alcançada com a combinação entre a classificação visual e a classificação mecânica (WIEGAND, 2008).

\subsubsection{Classificação da madeira estrutural com relação às propriedades mecânicas}

Um pré-requisito para o uso da madeira estrutural é o conhecimento das propriedades de resistência e do módulo de elasticidade, que devem estar enquadrados entre limites estabelecidos (JOHANSSONN, 2003).

Segundo Carreira (2003) como a madeira é um material natural, não é possível controlar as suas propriedades, ao contrário de materiais fabricados pelo homem, como aço, concreto e plástico, nos quais a qualidade do material é obtida com mudanças na composição das matérias-primas ou com mudanças ambientais de temperatura, pressão, etc. Existem poucos exemplos em que as propriedades da madeira sólida podem ser influenciadas de maneira similar. É possível incrementar a durabilidade da madeira em diferentes níveis por tratamento químico ou térmico. Com modificações químicas, a estabilidade dimensional e a durabilidade podem ser modificadas. Contudo, na medida em que as propriedades mecânicas são os limitantes para o uso estrutural, a única maneira de obter a qualidade desejada é a classificação. Existem dois tipos de sistemas de classificação por resistência:

Classificação visual de resistência: É baseada na inspeção visual superficial das peças, com relação aos seus defeitos naturais ou de processamento, para assegurar que as peças não possuem defeitos que excedam os limites fixados em regras de classificação padronizadas (CARREIRA, 2003).

Segundo Carreira (2003) a classificação visual da madeira é dividida em duas etapas distintas:

a) Atribuição de uma classe para cada peça de madeira a partir da identificação visual de certas características de crescimento. 
b) Determinação das propriedades de resistência e rigidez para cada classe de uma determinada espécie;

Classificação de resistência mecânica: Quando as peças são avaliadas mecanicamente, por métodos ou equipamentos, que medem um ou vários parâmetros em ações não destrutivas. Baseado nestas medições, as resistências, densidade e o módulo de elasticidade são estimados (CARREIRA, 2003).

Desde que as madeiras começaram a ser utilizadas para construção, muitas formas de classificação visual de resistências foram utilizadas. No entanto, as padronizações somente foram estabelecidas no início do século 20.

Nos Estados Unidos, a Norma ASTM D245, originalmente publicada em 1927, contêm orientações para o desenvolvimento de regras de classificação (MADSEN, 1992). Dos anos 1930 em diante, as padronizações de classificação foram introduzidas em vários países da Europa. As regras de classificação desenvolvidas ao longo dos últimos 60 anos diferem muito à respeito dos critérios de classificação, número de classes e limites das classes. Isto é devido ao grande número de espécies de madeira, qualidade e tipos de sistemas construtivos. A norma PS 20-70 (American Softwood Lumber Standard), que entrou em vigor nos Estados Unidos em 1970, incorpora várias características, incluindo as dimensões úmida e seca para determinação da retração da madeira. Sob exigência da PS 20-70, uma regra nacional norteamericana de classificação (National Grading Rule) foi escrita, definindo características uniformes de classificação para todas as espécies de coníferas na dimensão de caibros e pranchas (CARREIRA, 2003).

Todas as classificações visuais têm em comum a deficiência de avaliar todas as características relevantes apenas de forma visual, e somente são possíveis combinações simples das regras (JOHANSSONN, 2003).

A classificação visual depende exclusivamente da estimativa da resistência mecânica a partir de características externas visíveis, como exemplo, os nós e quantidade dos anéis de crescimento. Por outro lado, na classificação de resistência mecânica é possível, em determinados métodos, medir o módulo de elasticidade, a densidade, o teor de umidade e a proporção dos nós. A precisão com que as propriedades podem ser estimadas permite atingir graus mais elevados de qualidade (WIEGAND, 2008).

A classificação visual leva em conta uma série de propriedades que também são relevantes para a aparência. Por exemplo, uma peça classificada visualmente em uma classe com poucos defeitos e melhor estética, normalmente tem nós menores que uma peça enquadrada em uma classe menos atraente e menos resistente. Contudo, este não é o caso da 
classificação mecânica. Uma peça classificada mecanicamente como de alta resistência pode conter defeitos visualmente maiores que uma peça esteticamente desejável, pois depende também da complexidade e localização destes defeitos no corpo de prova, e que, muitas vezes, não são perceptíveis visualmente. A escolha de uma classe maior ou mais resistente não significa automaticamente uma peça mais bonita esteticamente (WIEGAND, 2008).

A idéia de utilizar parâmetros obtidos com ensaios não destrutivos para estimar a resistência, e utilizá-los como base para a classificação da madeira estrutural foi proposta simultaneamente nos Estados Unidos e na Austrália no fim dos anos 1950 (MADSEN, 1992). O principal propósito foi incrementar a acurácia dos processos de classificação por resistência para alcançar uma melhor utilização das qualidades disponíveis na madeira estrutural (JOHANSSONN, 2003).

\subsubsection{Defeitos na madeira estrutural}

Johanssonn (2003) define que a madeira estrutural apresenta diversos tipos de defeitos, como nós, fendas de topo, rachaduras, inclinação das fibras, apodrecimento, esmoados, bolsas de resina, presença de medula. A amplitude destes defeitos não importa somente em quanto cada defeito individual reduz a resistência, mas também com que frequência eles ocorrem. Nós são considerados defeitos sérios e que podem reduzir drasticamente a resistência, estão quase sempre presentes em grande número nas peças estruturais nas espécies do gênero Pinus. Rachaduras ou Trincas de topo também podem afetar gravemente a resistência, mas elas ocorrem com menor frequência e normalmente são defeitos isolados em uma peça de madeira de Pinus.

Os Nós afetam a resistência da madeira estrutural devido à redução da seção transversal e por ocasionar inclinação das fibras próximas. Os Nós podem ocorrer em aglomerados e, quando isto ocorre, para efeito de classificação são considerados, como um nó com dimensão maior. Em ensaios mecânicos de tração as rupturas ocorrem nos Nós em 95\% dos casos (JOHANSSONN, 2003).

A consideração da inclinação das fibras como um parâmetro de redução da resistência não se refere aos desvios ocasionados pelos nós, mas pela inclinação geral que ocorre, em relação à direção paralela às fibras, ao longo da direção longitudinal da peça de madeira (PERSTOPER,1999). 


\subsubsection{Regras de classificação visual}

A classificação visual de peças estruturais de madeira é realizada por meio de regras de classificação. Na América do Norte, as regras de classificação são escritas por uma associação de indústrias que representam uma área onde as espécies específicas são recolhidas, a Southern Pine Inspection Bureau (SPIB). O Pinus elliottii recebe o nome comercial de Slash Pine e o Pinus taeda o nome de Loblolly Pine. Ambos fazem parte do grupo Southern Pine e são classificados segundo as regras do (SPIB) (CARREIRA; DIAS, 2006).

Os critérios para a limitação dos defeitos descritos em todas as regras de classificação visual em vigor na América do Norte, incluindeo a SPIB, são baseados na norma ASTM D245 (Standard Practice for Establishing Structural Grades and Related Allowable Properties for Visually Graded Lumber), por exigência da National Grading Rule. Esta norma não fornece as regras de classificação visual, porém estabelece os critérios de como medir os defeitos e fornece meios para limitar os defeitos em função de uma razão de resistência (CARREIRA; DIAS, 2006).

De acordo com Madsen (1992), a norma ASTM D245-93 trata somente da classificação estrutural e, além disso, é limitada à classificação visual.

De acordo com a norma ASTM D245, a razão de resistência é uma relação hipotética entre a resistência de uma peça de madeira com características visíveis de crescimento, que reduzem sua resistência, e a resistência de um corpo de prova isento de defeitos desta mesma madeira (CARREIRA; DIAS, 2006).

A Tabela 3 apresenta as classes visuais descritas na National Grading Rule, e as razões de resistência à flexão mínima de cada classe, fornecendo um índice comparativo de qualidade. A classe visual Select Structural (SS), é a de melhor qualidade e admite o menor índice de defeitos, permitindo uma redução de até $33 \%$ na resistência, em relação à uma peça isenta de defeitos da mesma espécie. A classe visual $S 1$ é permite uma redução de $45 \%$, a classe visual $S 2$ uma redução de $55 \%$ e a classe visual $S 3$ uma redução de até $74 \%$ na resistência.

Tabela 3 - Classes visuais descritas na National Grading Rule.

\begin{tabular}{ccc}
\hline Dimensões & Classe & Razão de resistência à flexão (\%) \\
\hline \multirow{3}{*}{ Caibros e Pranchas } & Select Structural (SS) & $67 \%$ \\
& Classe (S1) & $55 \%$ \\
& Classe (S2) & $45 \%$ \\
& Classe (S3) & $26 \%$ \\
\hline
\end{tabular}


Para especificação em projetos, as peças enquadradas na Classe Visual SS são indicadas para os usos principais da estrutura, onde sejam requeridas as maiores cargas. As peças das classes visuais $S 1$ e $S 2$ são indicadas para uso secundário nas estruturas e as peças da classe visual $S 3$ ou desclassificadas não são indicadas para uso na estrutura.

\subsubsection{Medição das características de crescimento}

A medição dos defeitos é realizada visualmente, ou seja, sem o auxílio de nenhuma ferramenta complexa. Carreira e Dias (2006) apresentam as regras de classificação visual adaptadas pelo $S P I B$ e as principais características que devem ser observadas na classificação visual.

\section{Nós}

Deve-se medir os nós de maior diâmetro posicionados no centro da face larga, na borda da face larga e na face estreita das peças, conforme a Figura 3.

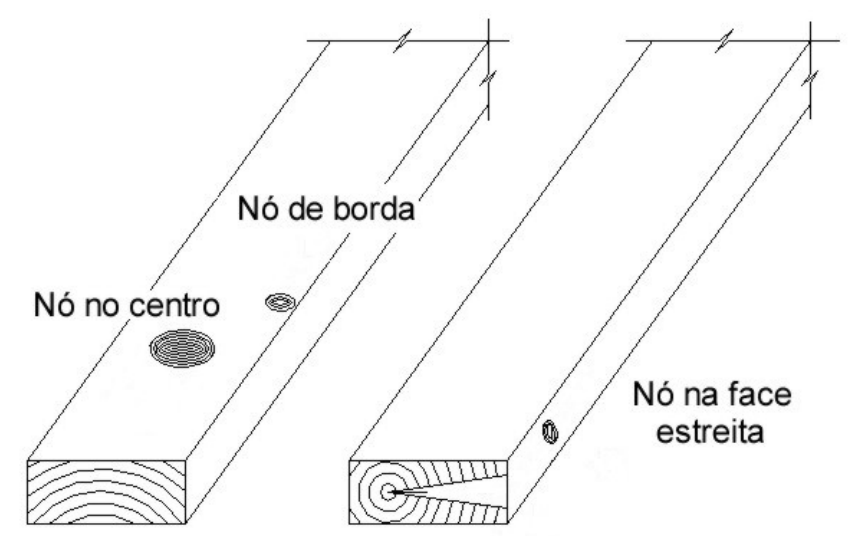

Figura 3 - Identificação dos nós em uma peça de madeira. (CARREIRA; DIAS, 2006)

\section{Inclinação das fibras}

A inclinação das fibras é medida nas quatro faces, e na zona que apresentar a maior inclinação geral, desconsiderando o desvio em torno dos nós, conforme a Figura 4. 


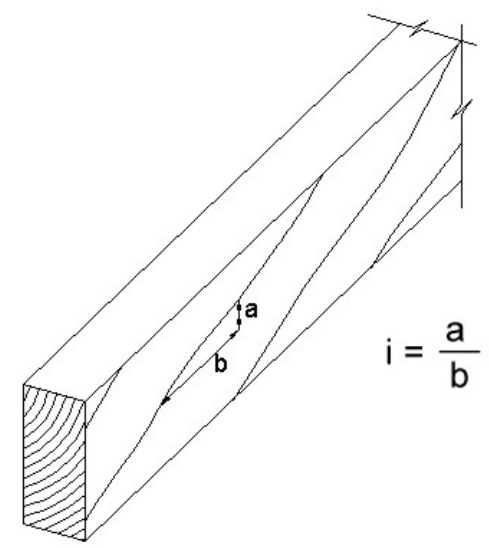

Figura 4 - Medida da inclinação das fibras de uma peça de madeira. (CARREIRA; DIAS, 2006)

A Tabela 4 apresenta os limites permitidos para os defeitos em cada classe visual. Segundo as regras do $S P I B$, para a flexão de vãos simples, rachas e fendas são restritas para as extremidades das vigas.

Tabela 4 - Dimensões admitidas dos defeitos em cada classe visual. (Carreira, 2003)

\begin{tabular}{|c|c|c|c|c|c|c|}
\hline \multirow{2}{*}{$\begin{array}{l}\text { Classe } \\
\text { Visual }\end{array}$} & \multicolumn{2}{|c|}{ Nós } & \multirow{2}{*}{$\begin{array}{l}\text { Inclinação } \\
\text { das Fibras }\end{array}$} & \multicolumn{2}{|c|}{ Rachas Anelares } & \multirow[b]{2}{*}{ Fendas } \\
\hline & $\begin{array}{c}\text { Face } \\
\text { Estreita }\end{array}$ & $\begin{array}{l}\text { Face } \\
\text { Larga }\end{array}$ & & Passante & Superficial & \\
\hline SS & $1 / 5$ & $1 / 3$ & $1: 12$ & 1 vez largura & Até 600 mm & 1 vez largura \\
\hline S1 & $1 / 4$ & $7 / 16$ & $1: 10$ & $1 \mathrm{vez}$ largura & Até $600 \mathrm{~mm}$ & $1 \mathrm{vez}$ largura \\
\hline $\mathrm{S} 2$ & $1 / 3$ & $1 / 2$ & $1: 8$ & 1,5 vez. largura & Até 1/4 comp. & 1,5 vez. largura \\
\hline S3 & $1 / 2$ & $3 / 4$ & $1: 4$ & 1/6 comp. peça & Sem limites & 1/6 comp. peça \\
\hline
\end{tabular}

\section{Densidade}

A norma ASTM D245-00 também define classes de densidade para a madeira, em função da taxa de crescimento da madeira serrada. A taxa de crescimento se refere à quantidade de anéis de crescimento presentes em $2,5 \mathrm{~cm}$ em uma linha radial da seção transversal. Assim, para ser considerada como densa, a peça de madeira deve ter seis ou mais anéis de crescimento e, mais de (1/3) um terço da seção transversal deve ser madeira de inverno. Peças com quatro ou mais anéis de crescimento, e com mais da metade da seção transversal com madeira de inverno podem ser consideradas como densa. Para ser considerada de média densidade a peça deve ter quatro ou mais anéis de crescimento. Peças com menos de 
quatro anéis de crescimento são classificadas como de baixa densidade (CARREIRA; DIAS, 2006).

As classes de densidade definidas pela ASTM D245-00 são apresentadas na Tabela 5 a seguir:

Tabela 5 - Classes de densidade definidas na ASTM D245-93

\begin{tabular}{ccc}
\hline Classe & Anéis / 2,5cm & $\begin{array}{c}\text { Quantidade de madeira de } \\
\text { inverno }\end{array}$ \\
\hline Densa & $\geq 6$ & $>1 / 3$ \\
& $\geq 4$ & $>1 / 2$ \\
Média & $\geq 4$ & \\
Baixa & $<4$ & \\
\hline
\end{tabular}

\subsection{ENSAIOS NÃO-DESTRUTIVOS}

A maior parte dos ensaios mecânicos é destrutivo e usando corpos de prova livres de defeitos. Peças estruturais de florestas plantadas são utilizadas com várias dimensões e contém irregularidades e defeitos que podem reduzir sua resistência. Em projetos de estruturas de madeira, as resistências devem ser conhecidas, para uma utilização mais econômica e segura. (KOLLMANN, 1968).

A madeira apresenta grande variabilidade de suas propriedades sendo, penalizada quando em competição com outros materiais estruturais que apresentam propriedades mecânicas mais uniformes. A classificação da madeira através do conhecimento das características de cada peça a ser usada, por ensaios não-destrutivos, é muito útil para equilibrar esta situação. Peças de qualidade superior poderiam ser escolhidas para uso crítico, enquanto as de baixa qualidade poderiam ser utilizadas em locais de menor requisição da resistência e rigidez. Avaliação não-destrutiva de materiais é, por definição, a ciência que identifica propriedades físicas ou mecânicas de uma peça de determinado material, sem alterar sua capacidade de uso (CALIL JUNIOR, MINÁ, 2003).

A avaliação não-destrutiva das estruturas (NDE) têm uma longa história de aplicação. Provas de carga em pontes datam de antes dos anos 1900. Provas de cargas em treliças, no entanto, são mais recentes. Ensaios não-destrutivos permitem avaliar cada peça individual, sem danos devido à sobrecarga (BODIG, JAYNE; 1993).

Algumas vantagens de ensaios não-destrutivos:

- Qualquer amostra pode ser examinada, incluindo elementos estruturais, partes de edificações, árvores em pé ou postes. 
- Um corpo de prova pode ser ensaiado diversas vezes sem sofrer danos, isso permite que em cada ensaio, as variáveis sejam alteradas, estudando assim as influências nas propriedades físicas e mecânicas da madeira.

- Diferentes propriedades ensaiadas em uma simples amostra podem ser correlacionadas.

Com a variedade de técnicas não-destrutivas para avaliação da madeira, algumas, têm sido mais utilizadas por parte dos institutos de pesquisa. Como exemplos:

- Técnica da Flexão estática - consiste na medição estática do MOE - Módulo de elasticidade na flexão de um exemplar de madeira, sendo o princípio de funcionamento da máquina de classificação da madeira serrada. MSR - Machine Stress Rating (TARGA; BALLARIN; BIAGGIONI, 2005);

- Técnica da vibração transversal (transverse vibration technique or ressonance technique) - É a análise da vibração de uma peça de madeira, com obtenção do módulo de elasticidade a partir da análise das frequências naturais de vibração (TARGA; BALLARIN; BIAGGIONI, 2005);

- Técnica da vibração longitudinal (longitudinal vibration technique) - É a análise da vibração de uma peça de madeira, com obtenção do módulo de elasticidade a partir da análise das frequências naturais de vibração no sentido longitudinal das fibras;

- Técnica das ondas de tensão (stress wave method) - consiste na aplicação de uma onda de tensão (impacto) no material e análise do fenômeno de propagação desse estímulo. A velocidade de propagação de uma onda de tensão induzida e sua atenuação no material são os principais parâmetros (TARGA; BALLARIN; BIAGGIONI, 2005);

- Técnica da propagação de ondas de ultra-som - Ondas acústicas (Acoustic emission - AE) e ultra-sônicas (Acousto-ultrasonic emission - $A U$ ), executada com as ondas acústicas de frequiência superior a $20.000 \mathrm{~Hz}$. Consiste na análise de propagação de uma onda e sua relação com as constantes elásticas da madeira. As ondas propagam-se com velocidades que dependem da direção de propagação e das constantes elásticas do material (NOGUEIRA, BALLARIN, 2003). 


\subsection{RELAÇÃO RESISTÊNCIA / MÓDULO DE ELASTICIDADE}

\subsubsection{Propriedades da madeira livre de defeitos}

Observando a microestrutura celular da madeira é razoável considerar que ela é constituída por pequenos tubos ligados (Figura 5). A largura do tubo, bem como sua espessura pode variar, mas as propriedades da parede celular são muito similares em todas as espécies de madeira. Isto em particular, se aplica à densidade da parede em torno de $1500 \mathrm{~kg} / \mathrm{m}^{3}$ (KOLLMANN, 1968). Isto significa que as propriedades do material madeira como o Módulo de Elasticidade (MOE), a resistência e a densidade ao longo da fibra estão fortemente relacionadas à espessura da parede celular. Isto explica porque a correlação entre propriedades das madeiras livres de defeitos são muito boas. Para pequenos corpos de prova de madeira, livres de defeitos da espécie Picea Abies, os coeficientes de determinação $\left(\mathrm{R}^{2}\right)$ determinados foram:

Resistência à flexão vs. MOE $\rightarrow \mathrm{R}^{2}=0,76$

Resistência à flexão vs. Densidade $\rightarrow \mathrm{R}^{2}=0,66$

MOE vs. Densidade $\rightarrow \mathrm{R}^{2}=0,64$

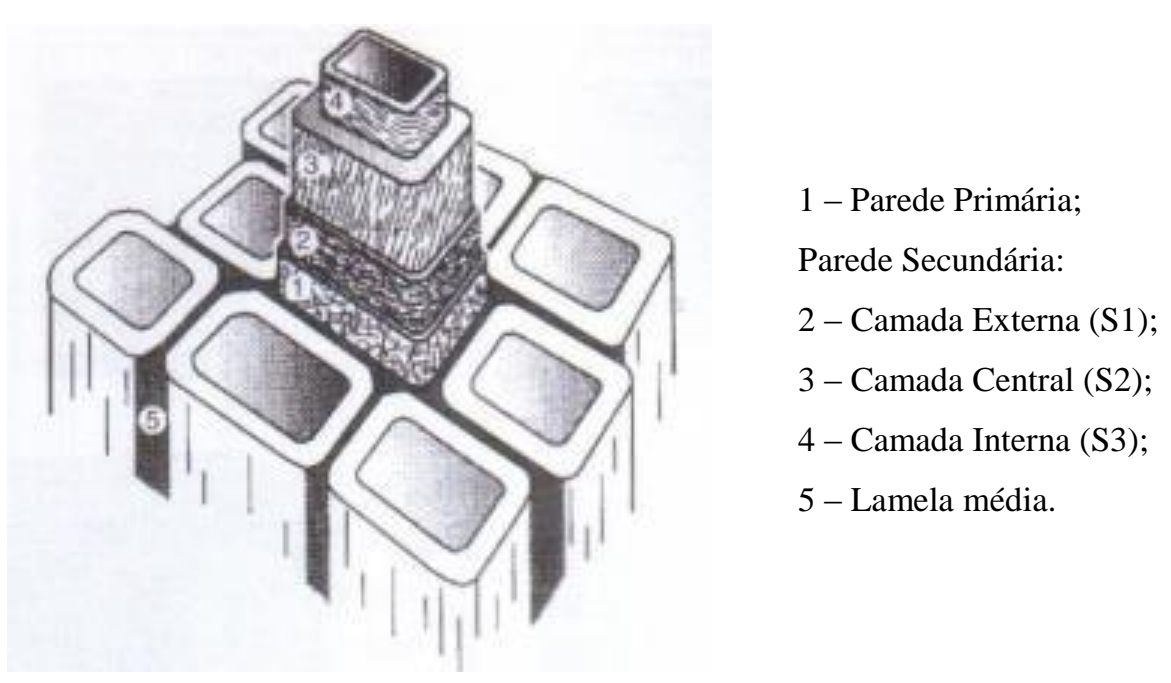

Figura 5 - Esquemático da estrutura microscópica da madeira.

\subsubsection{Módulo de elasticidade (MOE)}

Johanssonn (2003) estudou as relações entre diferentes propriedades da madeira e a resistência a tração para peças da espécie Abeto provenientes de oito diferentes localidades 
da Noruega (E, G, H, I, K, L, M, S), com seção 40 x 145 mm.. A correlação R² entre o módulo de elasticidade e a resistência da madeira variaram de 0,51 à 0,73 . Os melhores valores foram encontrados para ensaios de flexão com pequeno vão. Valores inferiores de correlação foram encontrados para a densidade e para a espessura dos anéis de crescimento, o coeficiente de correlação foi independente a origem da madeira, ver Tabela (6).

Tabela 6 - Relação entre resistência e o módulo de elasticidade da espécie Abeto da Noruega 40x145mm expresso em coeficiente de determinação ( $\left.\mathrm{R}^{2}\right)$ (Johanssonn et al., 2003)

\begin{tabular}{ccccc}
\hline Serraria & Tração & \multicolumn{3}{c}{ Flexão } \\
\hline \\
$\mathrm{N}$ & 149 & $\mathrm{R}^{2}$ & $\mathrm{~N}$ & $\mathrm{R}^{\mathbf{2}}$ \\
\hline $\mathrm{E}$ & 150 & 0,65 & 50 & 0,73 \\
\hline $\mathrm{G}$ & 150 & 0,70 & & \\
\hline $\mathrm{H}$ & 149 & 0,62 & & \\
\hline $\mathrm{I}$ & 152 & 0,51 & 50 & 0,60 \\
\hline $\mathrm{K}$ & 153 & 0,69 & 50 & 0,54 \\
\hline $\mathrm{L}$ & 139 & 0,68 & & 0,63 \\
\hline $\mathrm{M}$ & 154 & 0,66 & 56 & \\
\hline $\mathrm{S}$ & & 0,63 & & \\
\hline
\end{tabular}

No MOE para a madeira estrutural as deformações na flexão são devidas à contribuição de todo o comprimento da peça. Além disso, o posicionamento dos defeitos naturais na seção também tem importância fundamental. Os nós reduzem os valores do módulo de elasticidade, pois interferem na inclinação da grã da região próxima, reduzindo o módulo de elasticidade longitudinal (JOHANSSONN, 2003).

\subsubsection{Ensaios de peças em dimensões estruturais}

Os dados obtidos em ensaios em corpos de prova pequenos, livres de defeitos não representam exatamente os valores de resistência de peças com dimensões estruturais. São necessários ensaios em peças de dimensões similares as estruturais, pois fornecem dados de propriedades com a consideração de defeitos reais e usuais do material disponível no mercado. As normas norte americanas ASTM D198-76, e posteriormente a ASTM D4761, detalham os procedimentos de ensaio para madeira serrada na flexão com dimensões estruturais. Usualmente, cargas de três ou quatro pontos são aplicadas na maior ou menor inércia para medir a influência dos defeitos em vigas sujeitas à flexão. O carregamento em quatro pontos, com razão L/h entre 18 e 21, produz um momento constante, portanto não há tensão de cisalhamento na seção da viga entre as cargas (BODIG, 1993). 


\subsection{ENSAIO ESTÁTICO}

\subsubsection{Determinação das constantes elásticas por meio de ensaios estáticos}

Segundo Kollmann (1968) para a determinação do módulo de elasticidade (MOE) predominam os ensaios de flexão. Para o ensaio de flexão estática com uma carga central a razão do vão pela espessura da viga $(l / h)$ é de no mínimo 14:1 (este vão sofre influência do cisalhamento). O módulo de elasticidade pode ser calculado na região elástica linear da curva de força-deslocamento. A Equação (13) para calcular MOE é:

$$
M O E=\frac{P \cdot l^{3}}{4 \cdot f \cdot b \cdot h^{3}}
$$

Sendo:

$P=$ Força aplicada $(\mathrm{N})$

$f=$ Deslocamento $(\mathrm{mm})$;

$l=$ Vão livre $(\mathrm{mm})$;

$b=$ Largura da peça $(\mathrm{mm})$;

$h=$ Altura da peça $(\mathrm{mm})$;

O valor obtido de $M O E$ com este vão é menor que o real, uma vez que o deslocamento não é causado apenas pela deformação longitudinal, mas também pelo cisalhamento. A influência das tensões de cisalhamento pode ser negligenciada somente se $L / h \geq 18$. A razão entre o Módulo de Young $(E)$ e o Módulo de cisalhamento $(G)$ é um fator importante. Quando $E / G=17$, os valores do módulo de elasticidade, obtidos pela Equação (13) são mais baixos $(9.5 \%, 8.8 \%$ e $4.8 \%)$, comparado aos ensaios na flexão, e valores de $L / h$ entre 14,15 e 20 respectivamente.

A influência da tensão de cisalhamento pode ser considerada pela Equação (14):

$$
E=\frac{P \cdot l^{3}}{4 \cdot f \cdot b \cdot h^{3}} \cdot\left(1+1,2 \cdot \frac{E}{G} \cdot \frac{h^{2}}{l^{2}}\right)
$$

Enquanto as medidas das deformações longitudinais e laterais (constantes elásticas: $S_{11}, S_{22}$ e $S_{33}$ ) são facilmente obtidas, a determinação das deformações de 
cisalhamento (constantes elásticas: $\mathrm{S}_{44}, \mathrm{~S}_{55}$ e $\mathrm{S}_{66}$ ) é muito difícil para materiais anisotrópicos (KOLLMANN, 1968).

A norma americana ASTM D4761-02 estipula os valores da relação do vão entre os apoios e a altura da peça (L/h) entre 18 e 21. A força deve ser aplicada em dois pontos situados nos terças do vão entre os apoios, medindo-se a flecha no centro do vão. O MOE é determinado pela equação (15).

$$
M O E=\frac{23 \cdot \Delta F \cdot L^{3}}{1296 \cdot \Delta V \cdot I}
$$

Sendo:

MOE = Módulo de elasticidade estático (MPa);

$\Delta \mathrm{F}=$ Incremento da força $(\mathrm{N}) ;$

$\mathrm{L}=$ Vão entre os apoios da viga $(\mathrm{mm})$;

$\Delta \mathrm{V}=$ Incremento do deslocamento (mm);

$\mathrm{I}=$ Momento de inércia da seção transversal $\left(\mathrm{mm}^{4}\right)$;

Após as medições para determinar o MOE, as peças devem ser carregadas até a ruptura para a determinação da resistência à flexão (MOR), de acordo com a Equação (16):

$$
M O R=\frac{F_{m a ́ x} \cdot L}{b \cdot h^{2}}
$$

Sendo:

MOR = Módulo de ruptura à flexão $(\mathrm{MPa})$;

$\mathrm{F}_{\text {máx }}=$ Força máxima aplicada $(\mathrm{N})$;

$\mathrm{L}=$ Vão entre os apoios da viga $(\mathrm{mm})$;

$\mathrm{b}=$ Largura da seção transversal da peça $(\mathrm{mm})$;

$\mathrm{h}=$ Altura da seção transversal da peça $(\mathrm{mm})$;

\subsection{COMPORTAMENTO DINÂMICO DA MADEIRA}

Adicionalmente aos métodos estáticos para determinar as constantes elásticas da madeira, existem métodos dinâmicos baseados em medições das frequências naturais. 
Os ensaios de vibração possibilitam a determinação do módulo de elasticidade, da velocidade do som e das frequências naturais dos corpos de prova. Uma vantagem das medições dinâmicas é a curta duração do ensaio.

Tradicionalmente a parte da mecânica que estuda o movimento de corpos é subdividida em cinemática e dinâmica. A cinemática trata do movimento de partículas e corpos rígidos. A dinâmica, por outro lado, correlaciona movimento com fatores causais. Ambas são consideradas muito significantes para avaliar o comportamento mecânico da madeira. Bastões de baseball, coronhas de armas, dormentes de estradas de ferro, trilhos de segurança devem ser capazes de absorver e dissipar a energia de impacto. Materiais de embalagens absorvem energia, impedindo danos no seu conteúdo (BODIG, 1993).

Uma vibração mecânica ocorre quando um sistema é deslocado do equilíbrio estável. O sistema tende a retornar a posição inicial sob a ação de forças restauradoras, mas em geral atinge a posição original com certa velocidade, que o leva além desta posição. Em um sistema ideal, sem a presença de forças dissipativas, o sistema permaneceria em movimento oscilatório em torno da sua posição de equilíbrio (CALIL JUNIOR, MINÁ, 2003).

O período de vibração é o intervalo de tempo necessário para o sistema completar um ciclo inteiro de movimento. O número de ciclos por unidade de tempo é a freqüência e a amplitude é o máximo deslocamento do sistema em relação à posição de equilíbrio; quando o movimento é mantido somente por forças restauradoras, diz-se que a vibração é livre; Quando o efeito do atrito pode ser desprezado, diz-se que a vibração é não-amortecida. Embora toda vibração seja amortecida, na maioria das estruturas reais a frequência de vibração observada é essencialmente igual à frequência natural de um sistema não amortecido. Na maioria das estruturas o coeficiente de amortecimento está entre 2 e 20\%. (CALIL JUNIOR, MINÁ, 2003).

Vibrações em elementos de madeira são importantes em muitas aplicações. Estruturas de wood-frame estão em estado contínuo de movimento, em função da circulação de pessoas, cargas de vento, etc. Ondas sonoras de baixa energia podem definir as vibrações em seções inteiras de paredes e pisos. Dormentes de madeira são submetidos a uma vibração forçada à uma frequência devido ao tráfego ferroviário. A vibração também é utilizada em ensaios não-destrutivos (BODIG, 1993). 


\subsubsection{Tipos de vibração}

Em geral, as vibrações mecânicas podem ser classificadas em três tipos: flexional, axial e torcional (Figura 6). Embora os tipos de deslocamento sejam diferentes para as três vibrações, todas podem ser derivadas a partir de um conjunto similar de conceitos básicos (BODIG, 1993).

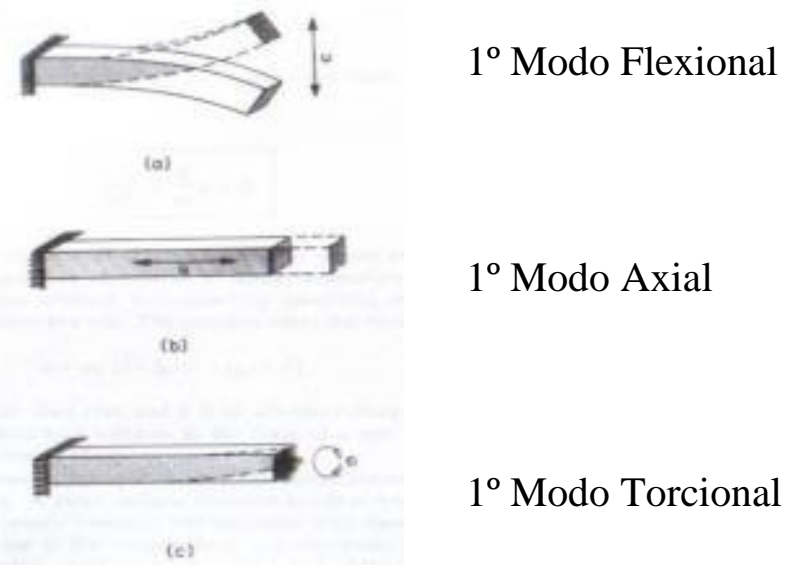

Figura 6 - Tipos de vibração mecânica: (a) flexional, (b) longitudinal, (c) torcional (BODIG, 1993).

Uma mola com a constante (k), um amortecedor com constante (r) e um corpo de massa (m), com o arranjo apresentado na Figura 7a, descreve a vibração de um sistema com um grau de liberdade. Um sistema com $n$ graus de liberdade, necessita de $n$ modelos semelhantes, como apresentado na Figura 7b. Independente do número de graus de liberdade, são chamados de modelos de parâmetros concentrados, pois se consideram todos elásticos, viscosos e as propriedades de massa agrupadas em um ponto simples. A matriz algébrica é extremamente útil descrevendo sistemas com dois ou mais graus de liberdade. (BODIG, 1993).

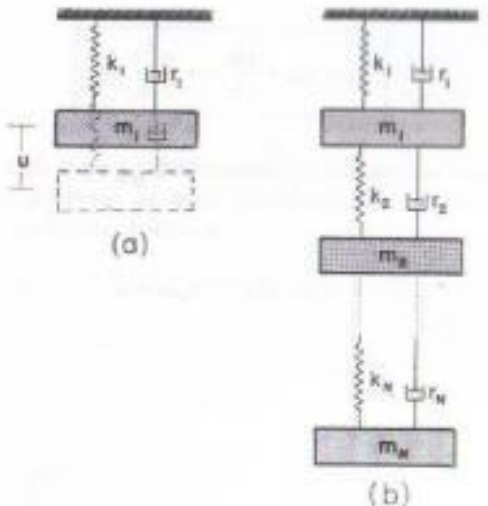

Figura 7 - Modos de vibração com vários graus de liberdade: (a) um grau, (b) $n$ graus (BODIG, 1993). 


\subsubsection{Velocidade do som na madeira}

$\mathrm{Na}$ madeira, a velocidade do som varia com a direção da fibra, pois o MOE transversal é muito menor que o MOE longitudinal (em torno de 1/20). A velocidade do som transversal às fibras é entre 1/5 e 1/3 do valor axial (KRETSCHMANN, 2010a).

Por exemplo, uma peça de madeira com módulo de elasticidade axial de 12400 MPa e densidade de $480 \mathrm{~kg} / \mathrm{m}^{3}$, possui uma velocidade de som na direção axial de cerca de $3800 \mathrm{~m} / \mathrm{s}$. Na direção transversal, o módulo de elasticidade transversal é de cerca de $690 \mathrm{MPa}$ e a velocidade do som é aproximadamente 890m/s (KRETSCHMANN, 2010a).

A velocidade do som diminui com o acréscimo da temperatura e do teor de umidade na proporção da influência destas variáveis no módulo de elasticidade e na densidade. A variabilidade na velocidade do som na madeira é diretamente relacionada ao módulo de elasticidade e da densidade (KRETSCHMANN, 2010a).

\subsubsection{Atrito interno na madeira}

Quando um material é deformado, uma energia mecânica é dissipada. O atrito interno é o termo usado para indicar o mecanismo que causa esta energia de dissipação.

O mecanismo de atrito interno na madeira é uma função complexa da temperatura e do teor de umidade. Existe um valor de umidade em que o atrito interno é mínimo, variando entre as espécies. Nos valores de umidade superiores ou inferiores a este mínimo, o atrito interno aumenta até o ponto de saturação das fibras. $\mathrm{O}$ valor do teor de umidade com atrito interno mínimo varia com a temperatura (KRETSCHMANN, 2010a).

Segundo estudado por Kretschmann (2010a), na temperatura ambiente de $23^{\circ} \mathrm{C}$ o atrito mínimo ocorre com teor de umidade em torno de $6 \%$. À temperatura de $-20^{\circ} \mathrm{C}$ isto ocorre no teor de umidade de $14 \%$ e na temperatura de $70^{\circ} \mathrm{C}$ o teor de umidade é de $4 \%$. Em $90^{\circ} \mathrm{C}$ o mínimo não é bem definido e ocorre próximo da umidade zero.

$\mathrm{O}$ valor de atrito interno varia de 0,1 para madeira com altos teores de umidade e temperatura, para menos de 0,02 para madeira com altas temperaturas e baixo teor de umidade. Madeiras com baixa temperatura, independente do teor de umidade, tem um valor intermediário (KRETSCHMANN, 2010a). 


\subsubsection{Módulo de elasticidade determinado por vibrações ressonantes}

A possibilidade de determinar o MOE da madeira estrutural utilizando ensaios dinâmicos já é discutida desde o início dos anos 1930 (HOFFMEYER, 1995). Os métodos tendem às aplicações práticas graças ao desenvolvimento das técnicas de medição associado aos ensaios dinâmicos e das transformadas rápidas de Fourier (FFT) (JOHANSSONN, 2003).

Para a madeira livre de defeitos o MOE dinâmico tem uma forte correlação com o valor do MOE estático e correlações mais fracas em relação à resistência à flexão (MOR). Wormuth (1993) obteve o coeficiente de correlação linear $\left(\mathrm{R}^{2}\right)$ de 0,85 entre o MOE dinâmico e o MOE estático para espécies de Abeto da Noruega de dimensões 10x10x200mm. Larsson (1997) ensaiou Abetos da Noruega com seções 38x89mm, 38x140mm e 38x184mm e obteve valores de $\mathrm{R}^{2}$ entre 0,68 e 0,91. Ele também estudou a correlação entre o MOE dinâmico e a resistência à flexão (MOR) na maior inércia e encontrou valores de $\mathrm{R}^{2}$ entre 0,39 e 0,61. Sauter (1992) estudou peças da Espécie Douglas fir (Pseudotsuga menziesii) e obteve o $\mathrm{R}^{2}=$ 0,71 para o MOE dinâmico na flexão em comparação com a resistência à flexão (MOR).

Uma desvantagem na utilização de vibrações ressonantes para estimar as propriedades de resistência e rigidez da madeira em relação à máquinas de classificação por flexão (MSR) é a obtenção apenas de um valor para o MOE da peça, enquanto que no outro caso, são avaliados valores de MOE em pequenos trechos (HOFFMEYER, 1995).

\subsection{ENSAIOS POR VIBRAÇÃO}

O módulo de elasticidade dinâmico $\left(E_{d}\right)$ pode ser medido utilizando métodos de vibração. A maioria dos ensaios é restrito às vibrações longitudinais ou transversais. A maioria dos dados reportados indica que o módulo de elasticidade dinâmico, $E d$, é maior que o módulo de elasticidade na flexão estática, MOE. É sugerido que essa diferença pode ser devida à velocidade de aplicação da carga. Entretanto, outros fenômenos podem ser responsáveis. $\mathrm{O}$ autor concluiu neste trabalho que os valores de módulo de elasticidade dinâmico, $E d$, para a madeira são entre $5 \%$ e $15 \%$ maiores que o MOE na flexão estática. (BODIG, 1993).

Devido à natureza da vibração para ensaios de flexão, o módulo de elasticidade obtido representa um valor médio da influência para a peça inteira. 
O módulo de elasticidade dinâmico $\left(E_{d}\right)$ pode ser determinado utilizando medidas das ondas de tensão longitudinal. A propagação das ondas de tensão longitudinal fornece os dados necessários para calcular $E_{d}$ (Equação (17)) ao longo do eixo do elemento.

$$
E_{d}=k \cdot c^{2} \cdot \rho
$$

Sendo:

$\mathrm{c}=$ Velocidade da onda de tensão; $(\mathrm{m} / \mathrm{s})$

$\rho=$ Massa específica $\left(\mathrm{kg} / \mathrm{m}^{3}\right)$

$\mathrm{k}=$ Constante, função das unidades de medida.

\subsection{VIBRAÇÃO LONGITUDINAL}

As equações de vibração de materiais contínuos se caracterizam por muitos graus de liberdade. Cada elemento de volume têm componentes de movimento ao longo de um ou dos três eixos de coordenadas ortogonais. Vibrações deste tipo requerem a derivação de equações de movimento para elementos de volume diferencial. Sequencialmente, a relação é integrada para o corpo inteiro. A abordagem destes parâmetros de distribuição contrasta com a análise anterior de parâmetros concentrados. As propriedades dos materiais são distribuídas através do corpo, seguindo uma análise mais realista, mas também mais complexa (BODIG, 1993).

Um exemplo simples de análise é do movimento em uma barra de qualquer seção transversal, mas de comprimento uniforme. A dimensão da seção transversal do elemento estrutural deve ser pequena em relação ao comprimento, de modo que o comprimento de onda de vibração longitudinal é grande em relação às dimensões da seção transversal. Esta restrição limita os níveis de vibração, e como consequência as equações são simplificadas. Além disso, assume-se que o material é homogêneo e contínuo, e que a seção plana antes da vibração, continua plana durante a vibração (BODIG, 1993).

Como mostrado na figura 8 , na seção transversal $C$ uma força $P$ é aplicada em uma barra de comprimento $l$. Em $D$ a força é $P+(\partial P / \partial x) d x$. Como resultado da força, a seção transversal $C$ será deslocada a uma distância $u$ para um novo local $C^{\prime}$ (BODIG, 1993). 


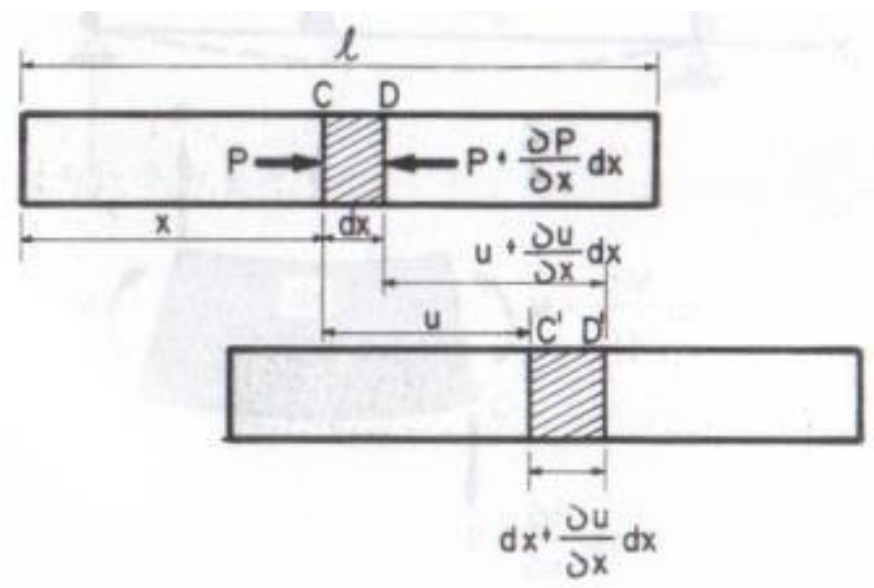

Figura 8 - Deslocamento e alongamento de uma barra na vibração longitudinal.

Similarmente, o deslocamento de $D$ para $D$ ' é dado por $u+(\partial u / \partial x) d x$. Mas pelas Leis de Hooke sabe-se que pela Equação (18):

$$
\frac{\partial P}{\partial x}=\gamma_{1}=\frac{P}{A \cdot E}
$$

A força $\mathrm{P}$ não é constante, com mudança de localização. Este fato pode ser expresso pela diferenciação da Equação (16), o que resulta na Equação (19):

$$
\text { A. } E \cdot \frac{\partial^{2} u}{\partial x^{2}}=\frac{\partial P}{\partial x}
$$

A ação da força no elemento diferencial da barra $(\partial P / \partial x) d x$ é a força resultante, e de acordo com as Leis de Newton, pela Equação (20), o movimento deve ser igual ao produto da massa e aceleração:

$$
\frac{\partial P}{\partial x} d x=m \cdot \frac{\partial^{2} u}{\partial t^{2}}=\rho \cdot A \cdot d x \cdot \frac{\partial^{2} u}{\partial t^{2}}
$$

Onde $\rho$ é a densidade de massa da barra $\left(\mathrm{g} / \mathrm{cm}^{3}\right.$ ou $\left.\mathrm{kg} / \mathrm{m}^{3}\right)$ e $A d x$ o volume diferencial do elemento. O produto $\rho \cdot A d x$ é a massa do volume diferencial do elemento. Substituindo $(\partial P / \partial x)$ da Equação (19) com a Equação (20), temos a Equação (21):

$$
A \cdot E \cdot \frac{\partial^{2} u}{\partial x^{2}} d x=\rho \cdot A \cdot \frac{\partial^{2} u}{\partial t^{2}} d x
$$

Que simplificada é apresentada na Equação (22): 


$$
\frac{\partial^{2} u}{\partial t^{2}}=\frac{E}{\rho} \cdot \frac{\partial^{2} u}{\partial x^{2}}
$$

Assumindo que as variáveis são separadas, a solução geral toma a forma da Equação (23):

$$
u=\left[C_{1} \cdot \operatorname{sen}\left(\frac{\varpi}{\varpi_{0}} \cdot x\right)+C_{2} \cdot \cos \left(\frac{\varpi}{\varpi_{0}} \cdot x\right)\right] \cdot\left[C_{3} \cdot \operatorname{sen} \varpi t+C_{4} \cdot \cos \varpi t\right]
$$

A fim de avaliar as quatro constantes $C_{i}$, são necessárias quatro equações auxiliares que representem várias condições de contorno. A forma da Equação (23) diferencial sugere a seguinte solução, mostrada na Equação (24):

$$
u=u_{0} \cdot \operatorname{sen}\left(\varpi_{0} \cdot t-\phi\right)
$$

Substituindo as duas derivadas de segunda ordem na Equação (24) e simplificando, tem-se a Equação (25):

$$
\varpi_{0}=c=\sqrt{E / \rho}
$$

Isto é, a velocidade de propagação da onda senoidal na direção longitudinal da barra $\left(\omega_{0}\right)$ é determinada pela razão do módulo de elasticidade $(E)$ pela massa específica $(\rho)$.

Independentemente do modo de vibração, a ressonância de um número finito de ondas, deve ocupar o comprimento da barra. Consequentemente, não ocorrem deslocamentos na extremidade da barra. Para o primeiro modo de vibração $(n=1)$, o comprimento de onda $\lambda$ é duas vezes o comprimento da barra. A Equação geral (26) relativa ao comprimento de onda para o comprimento da barra é:

$$
\lambda=\frac{2 . l}{n}
$$

O comprimento de onda é a razão da velocidade da onda $(c)$ pela frequência de vibração (f), substituindo nas Equações (25) e (26), como segue na Equação (27): 


$$
\lambda=\frac{c}{f}=\frac{1}{f} \cdot \sqrt{\frac{E}{\rho}}
$$

Combinando as Equações (26) e (27), leva a Equação (28) para a frequência de vibração, dada:

$$
f=\frac{n}{2 \cdot l} \cdot \sqrt{\frac{E}{\rho}}
$$

Rearranjando a expressão para o módulo de elasticidade, temos a Equação (29):

$$
E=E_{d}=4 \cdot l^{2} \cdot f^{2} \cdot \frac{\rho}{n^{2}}
$$

Assim, para a determinação do Módulo de Elasticidade dinâmico $\left(E_{d}\right)$ em $M P a$ ou $\mathrm{N} / \mathrm{mm}^{2}$, para uma barra submetida à vibração longitudinal, com as duas extremidades livres, no primeiro modo de vibração $(n=1)$, e substituindo na Equação (29) a densidade $(\rho)$ pela relação peso por volume $(m / V)$, a Equação (30):

$$
E_{d}=\frac{400 \cdot l^{2} \cdot f^{2} \cdot m}{V}
$$

$f=$ Frequência de ressonância fundamental $(\mathrm{kHz})$;

$m=\operatorname{massa}(\mathrm{g})$;

$l=\mathrm{V} \tilde{\mathrm{a}} \mathrm{(}(\mathrm{mm})$;

$V=$ Volume $\left(\mathrm{mm}^{3}\right)$.

\subsection{BROOKHUIS MICROELECTRONICS TIMBER GRADER - MTG}

A obtenção do módulo de elasticidade dinâmico a partir da frequência natural, conforme a Equação (30), é a base de formulação utilizada pelo aparelho portátil de classificação mecânica BrookHuis Microelectronics Timber Grader (MTG). Esse equipamento utiliza uma curva de correção para modificar o valor dinâmico obtido, em função da espécie ensaiada, para apresentar os valores estimados do Módulo de Elasticidade (MOE), utilizados para enquadramento de classes nas normas estruturais. 
O equipamento BrookHuis Microeletronics Timber Grader é um classificador mecânico para peças de madeira de uso estrutural com medição do módulo de elasticidade por meio de ondas de tensão longitudinal. O aparelho é portátil, com bateria recarregável e se comunica com o computador por Bluetooth. A face frontal do dispositivo portátil apresenta um ativador interno de impacto (Stress wave activator) e o sensor de leitura do sinal de retorno, conforme a Figura 9. (ROZEMA, 2013)
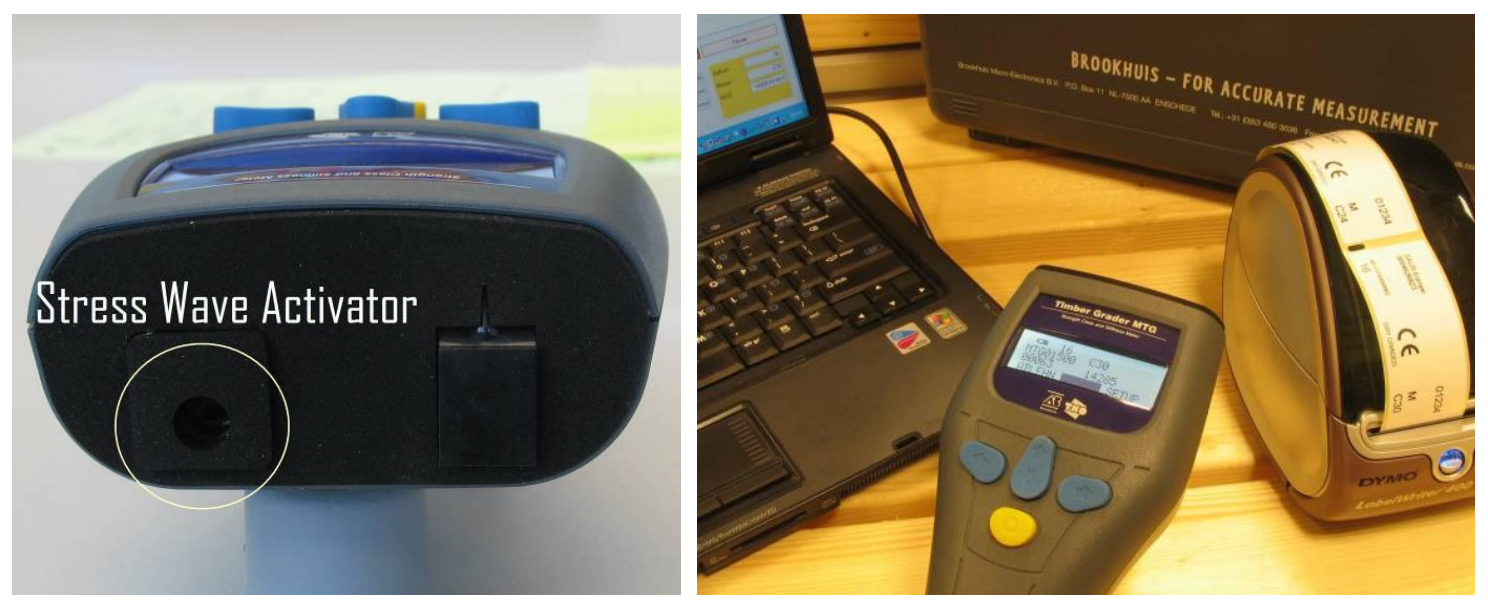

Figura 9 - MTG dispositivo portátil.

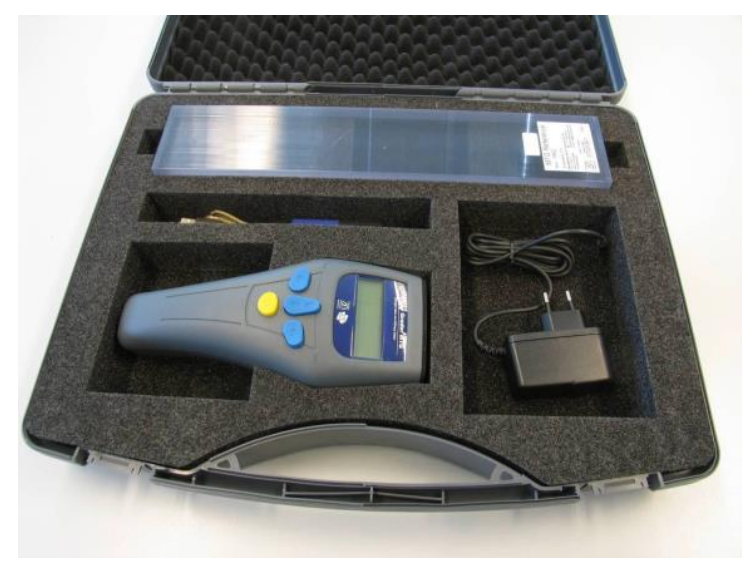

Figura 10 - Conjunto do Equipamento portátil MTG.

O conjunto do equipamento MTG (Figura 10) inclui:

- Medidor portátil com microprocessador e um software com menus;

- Software do programa “Timber Grader” para controlar o medidor MTG, e para a armazenagem e criação de relatórios no PC/laptop;

- Leitura do Módulo de Elasticidade (E) em N/mm²;

- Barra acrílica para calibração;

- Adaptador bluetooth para a comunicação com o PC/laptop; 
- Manual de instalação e uso;

- Aprovação CE e FCC do equipamento;

\subsubsection{Ensaio com o MTG}

No início do ensaio devem ser informados previamente ao software do MTG, características do corpo de prova como: dimensões, teor de umidade, temperatura e massa. $\mathrm{O}$ equipamento portátil deve ser levemente pressionado na extremidade da seção transversal da peça de madeira. Ao pressionar o botão central amarelo, o ativador mecânico interno impacta o corpo de prova, então o sensor de onda de tensão grava o sinal de retorno da vibração. $\mathrm{O}$ software converte esse sinal em resultados (Frequência natural, Módulo de Elasticidade, classe de resistência, etc.). Os resultados são transferidos a um PC / laptop por Bluetooth. Esses resultados podem ser "traduzidos" em um dos muitos padrões internacionais usados para classificação mecânica da madeira. Durante a ação o equipamento portátil não pode ser movimentado. (ROZEMA, 2013).

Pode ser medido o MOE de uma peça por vez. A viga deve estar livre de vibrações da fundação que não devem ser transmitidas à madeira. As peças podem estar gradeadas, separadas por tabiques ou livres no momento do ensaio. (ROZEMA, 2013).

\subsubsection{Especificações técnicas}

O propósito do MTG é estimar o Módulo de elasticidade da madeira:

- Com seção transversal retangular serrada ou aplainada;

- Com dimensões dentro das especificadas na tabela 7;

- Madeira tratada ou não contra organismos xilófagos.

O MTG não foi projetado para medir a madeira com as seguintes características:

- Madeira tratada com retardantes de fogo;

- Madeira laminada colada;

- Madeira com ligações "finger joint".

Rozema (2013) estimou a classe de resistência de acordo com as normas europeias, baseadas em 3000 ensaios não destrutivos para as seguintes espécies: 
Coníferas: Douglas fir, Larch, Pinus radiata, Spruce.

Dicotiledôneas: Angelim Vermelho, Azobe, Bangkirai, Basralocus, Beech, Bilinga, Chestnut, Cumaru, Cupiaba, Denya, Greenheart, Karri, Limbali, Louro Itauba, Massaranduba, Muiracatiara, Mukulungu, Niove, Oak, Piquia, Piquia Marfim, Robinia, Sapucaia, Sucupira Amarela, Sucupira Vermelha, Tali, Uchi Torrado, Vitex.

Os ensaios para enquadramento em classes de resistência foram adequados à norma EN 14081-4 (ROZEMA, 2013).

\section{MTG com impacto por ativador interno}

$\mathrm{O}$ ativador mecânico interno do equipamento aplica um impulso na direção axial da peça de madeira com uma quantidade fixa de energia (Figura 11). Devido à força limitada, as peças ensaiadas com o ativador interno estão limitadas as dimensões da Tabela 7. (ROZEMA, 2013).
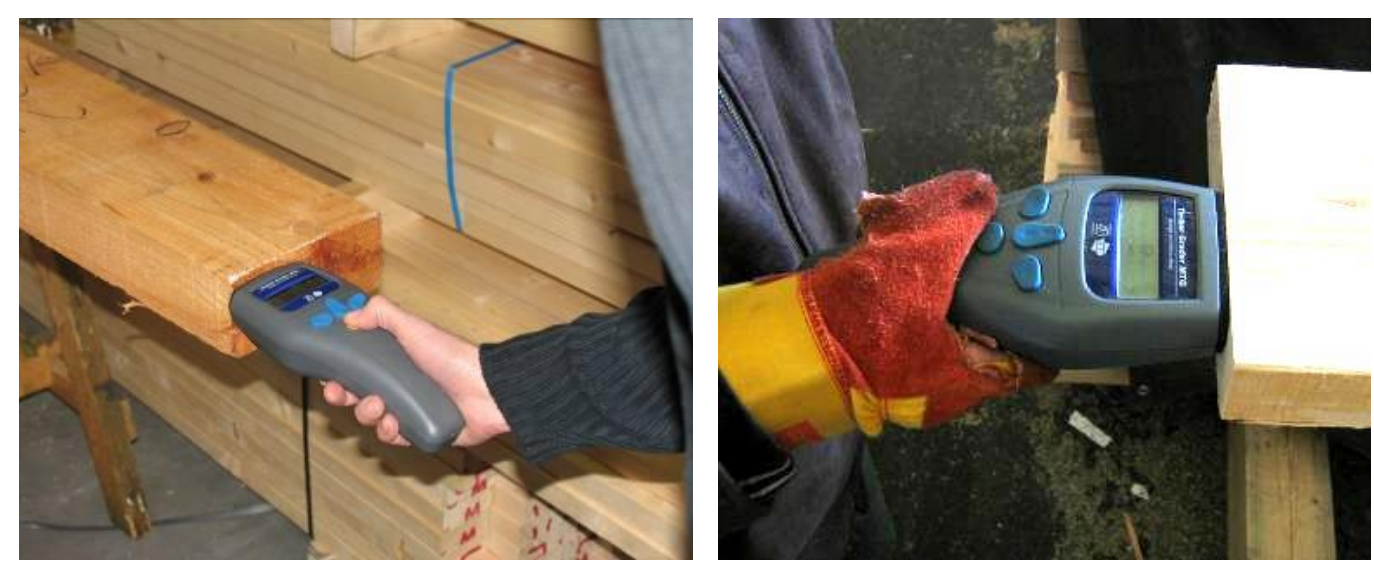

Figura 11 - Medições do módulo de elasticidade com o MTG utilizando ativador interno.

\section{MTG com impacto externo}

Os ativadores de onda externos ao equipamento são definidos como martelos com massa determinada de $100 \mathrm{~g}, 200 \mathrm{~g}$ ou $300 \mathrm{~g}$ que podem ser utilizados como ativador mecânico, dependendo da rugosidade de acabamento da extremidade do corpo de prova, bem como a seção transversal e o comprimento (Figura 12). A força do impacto com o martelo não interfere na medida do módulo de elasticidade. Os limites de dimensões dos corpos de prova para utilização de ativadores externos estão na Tabela 7. (ROZEMA, 2013). 

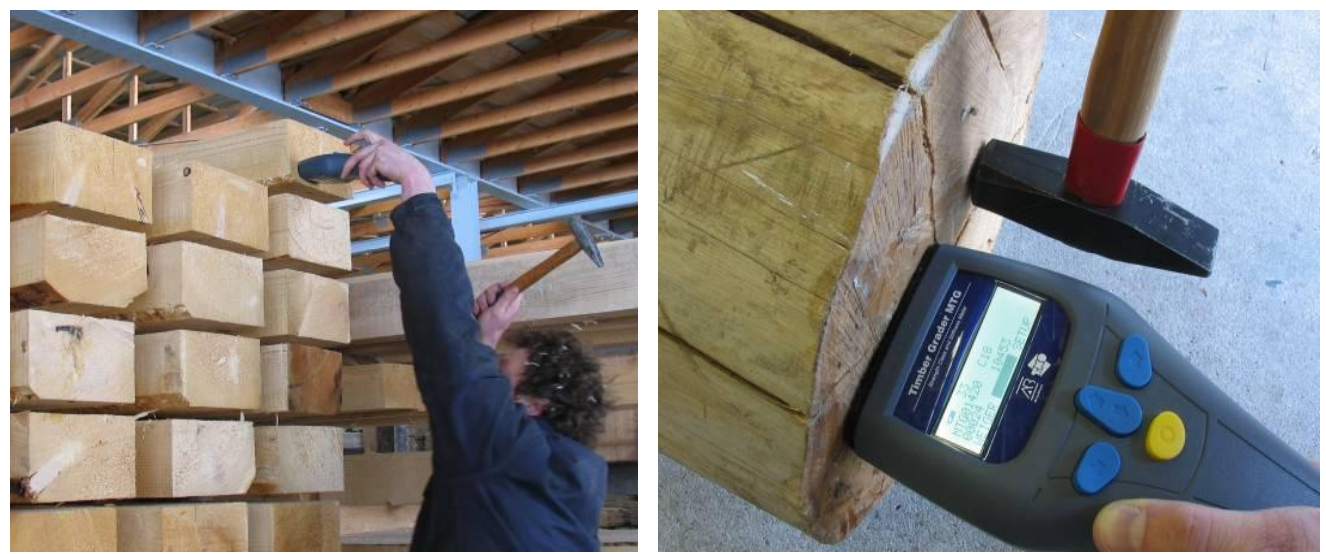

Figura 12 - Medições do MOE com o MTG utilizando ativador externo.

Tabela 7 - Limites das características das peças estruturais para ensaio com o MTG.

\begin{tabular}{lcc}
\hline \multicolumn{1}{c}{ Características das Madeiras } & Com Ativador Interno & Com ativador Externo \\
\hline Espessura da peça & Entre 15 e $115 \mathrm{~mm}$ & Entre 15 e $300 \mathrm{~mm}$ \\
Largura da peça & Entre 50 e $250 \mathrm{~mm}$ & Entre 50 e $400 \mathrm{~mm}$ \\
Comprimento da peça & Entre 1.500 e $8.000 \mathrm{~mm}$ & Entre 1.500 e $20.000 \mathrm{~mm}$ \\
Peso da peça & Entre 1 e $500 \mathrm{~kg}$ \\
Teor de umidade & Entre $2 \%$ e $50 \%$ \\
Temperatura da madeira & Entre 0 e $50^{\circ} \mathrm{C}$ \\
Massa específica Dicotiledôneas & Entre 400 e $1400 \mathrm{~kg} / \mathrm{m}^{3}$ \\
Massa específica Coníferas & Entre 300 e $800 \mathrm{~kg} / \mathrm{m}^{3}$ \\
\hline
\end{tabular}

A Tabela 8 apresenta as tolerâncias das informações de entrada no software para manter a precisão da leitura.

Tabela 8 - Tolerâncias dos dados de entrada para o Software MTG

\begin{tabular}{ll}
\hline Características & Tolerâncias \\
\hline Comprimento da madeira & $+/-1 \%$ \\
Espessura da madeira & $+/-1 \mathrm{~mm}$ \\
Largura da madeira & $+/-1,5 \mathrm{~mm}$ \\
Peso da madeira & $+/-1 \%$ \\
Teor de umidade da madeira até o PSF & $+/-5 \%$ Teor de Umidade \\
\hline
\end{tabular}




\subsection{TRABALHOS TÉCNICO-CIENTÍFICOS SOBRE OBTENÇÃO DE MÓDULO DE ELASTICIDADE PARA MADEIRA}

Carreira (2003) classificou visualmente 600 peças de Pinus sp, com densidade média de $520 \mathrm{kgf} / \mathrm{m}^{3}$, em apenas dois dias empregando duas pessoas. As peças foram separadas em quatro grupos: Classe de Seleção Estrutural com alta densidade (SS-D), com baixa densidade (SS-ND), Classe secundária densa ( $\left.\mathrm{N}^{\circ} 2-\mathrm{D}\right)$ e não-densa ( $\left.\mathrm{N}^{\circ} 2-\mathrm{ND}\right)$. As madeiras foram ensaiadas na flexão estática, na vibração transversal e na máquina MSR. Para espécies de Pinus elliottii e Pinus taeda com seção transversal de 3,5cm x 12,5cm, a Tabela 9 apresenta os valores característicos de resistência à flexão $(M O R k)$ e valores médios do Módulo de Elasticidade (MOEm) encontrados para o lote ensaiado e também os valores destas características estabelecidos pelo SPIB (Southern Pine Inspection Bureau):

Tabela 9 - Propriedades mecânicas de peças estruturais de Pinus sp. (CARREIRA, 2003)

\begin{tabular}{ccccc}
\hline & \multicolumn{2}{c}{ Amostra estudada } & \multicolumn{2}{c}{ Southern Pine Norte Americano } \\
\cline { 2 - 5 } Classe & MORk $(\mathrm{MPa})$ & MOEm $(\mathrm{MPa})$ & MORk $(\mathrm{MPa})$ & MOEm $(\mathrm{MPa})$ \\
\hline $\mathrm{N}^{\circ}$ 2-ND & 21,9 & 7608 & 19,9 & 9520 \\
$\mathrm{~N}^{\circ} 2-\mathrm{D}$ & 28,7 & 9182 & 25,0 & 11560 \\
SS-ND & 79,5 & 9899 & 40,6 & 11560 \\
SS-D & 107,6 & 14303 & 46,6 & 12920 \\
\hline
\end{tabular}

Carreira (2003) concluiu que para o MOR a presença de defeitos é muito mais significativa na redução da resistência do que a diferença de densidade, com correlação entre o MOR e o MOE na flexão estática de $\mathrm{R}^{2}=0,65$. A estimativa do $E$ por vibração transversal apresentou correlação com o MOE na flexão estática de $\mathrm{R}^{2}=0,98$. O E obtido pela máquina MSR apresentou correlação de $\mathrm{R}=0,92$ para o MOE na flexão estática, porém ocorreu aumento da dispersão com o aumento da densidade. A correlação entre a densidade aparente à $12 \%$ e o módulo de elasticidade na compressão foi de $\mathrm{R}^{2}=0,47$.

Freitas (2004) classificou peças estruturais de Pinus spp pela MSR (Machine Stress rate) e constatou que a velocidade da peça não é um parâmetro que influencia nos valores do MOE dinâmico. Porém a intensidade da carga aplicada influencia no MOE dinâmico, observando bons valores de coeficiente de regressão $\left(\mathrm{r}^{2}\right)$ com o MOE na flexão. $\mathrm{O}$ autor verificou que é indispensável a classificação visual juntamente com a classificação mecânica. 
Segundinho (2012) avaliou a eficácia de métodos de ensaio baseados nas frequências naturais de vibração, com utilização do aparelho Sonelastic ${ }^{\circledR}$ Stand Alone, em vigas de Pinus oocarpa, sendo 14 peças de dimensões $(45 \times 90 \times 2300 \mathrm{~mm}), 30$ peças de dimensões (40x240x2010 mm) e 30 peças de dimensões $(40 \times 240 \times 3050 \mathrm{~mm})$, com os resultados apresentados na Tabela 10. O método da frequência natural por vibração longitudinal apresentou resultados confiáveis e um método prático, pois não há necessidade de suportes específicos ou calibrações prévias para a obtenção do módulo de elasticidade de peças estruturais de madeira, reduzindo o tempo de execução e favorecendo o ensaio de grande quantidade de peças. A Tabela 10 apresenta os resultados obtidos pelo autor, de MOE na flexão estática e suas correlações com o E na vibração longitudinal para as diferentes dimensões para a espécie de Pinus oocarpa.

Tabela 10 - Propriedades mecânicas de peças estruturais de Pinus oocarpa. (SEGUNDINHO, 2012)

\begin{tabular}{ccccc}
\hline $\begin{array}{c}\text { Pinus oocarpa } \\
\text { Dimensões }\end{array}$ & $\begin{array}{c}\text { MOE vibração } \\
\text { longitudinal (MPa) }\end{array}$ & $\begin{array}{c}\text { MOE estático } \\
(\mathrm{MPa})\end{array}$ & $\begin{array}{c}\text { Correlação entre } \\
\text { MOE v.l. e est. }\end{array}$ & $\begin{array}{c}\text { Dendidade } \\
\text { Aparente }\left(\mathrm{g} / \mathrm{cm}^{3}\right)\end{array}$ \\
\hline $45 \times 90 \times 2300 \mathrm{~mm}$ & 10455 & 9443 & 0,98 & 0,531 \\
$40 \times 240 \times 2010 \mathrm{~mm}$ & 14809 & 13118 & 0,88 & 0,612 \\
$40 \times 240 \times 3050 \mathrm{~mm}$ & 14142 & 13185 & 0,89 & 0,602 \\
\hline
\end{tabular}

O método de vibração longitudinal apresentou valores fortemente correlacionados. Comparando os resultados entre os métodos, utilizando a porcentagem média de variação em relação ao módulo de elasticidade estático, o módulo de elasticidade na vibração longitudinal apresentou valores sempre superiores na ordem de 11,08\%, 13,73\%, 10,62\% respectivamente as seções ensaiadas (SEGUNDINHO, 2012).

Foram também comparadas a velocidade da onda de tensão longitudinal de árvores em pé e de madeira serrada. Os resultados apresentados em valores médios das velocidades de onda de tensão aplicados longitudinalmente através do tronco da árvore foram $3771.5 \mathrm{~m} / \mathrm{s}$ e para as tábuas foram $4362.8 \mathrm{~m} / \mathrm{s}$. Os resultados do teste-T indicaram que os valores médios da amostragem foram significantemente diferentes entre si em um nível de confiança de $95 \%$, e velocidade de onda de tensão ao quadrado teve uma correlação com o MOE estático de $\left(\mathrm{R}^{2}=0,72\right)$ e com o MOR de $\left(\mathrm{R}^{2}=0,60\right)$. A razão principal para estas diferenças é o teor de umidade, sendo a umidade das tábuas menor que o ponto de saturação das fibras, enquanto nas árvores o teor de umidade é maior. Os valores de velocidade em condições com baixo teor de umidade são altamente comparáveis com as madeiras em condição saturada (BUCUR, 2006). A velocidade em condições de umidade abaixo do ponto 
de saturação das fibras é sempre maior que a velocidade em madeira com umidade acima do PSF (HORACEK, TIPPNER; 2012).

Horacek e Tippner (2012) avaliaram as propriedades da madeira da espécie Pinus sylvestris $L$. correlacionando o módulo de elasticidade dinâmico $(E d)$ estimado pela técnica de onda de tensão longitudinal e propriedades de flexão estática, módulo de elasticidade na flexão estática (MOE) e resistência à flexão (MOR). Os resultados obtidos para corpos de prova de massa específica entre $370 \mathrm{kgf} / \mathrm{m}^{3}$ e $543 \mathrm{kgf} / \mathrm{m}^{3}$, correlacionaram a densidade com as propriedades de flexão estática (MOE e MOR), O coeficiente de correlação foi 0,73 para o MOE e 0,50 para o MOR. A estimativa do $E d$ com a técnica de ondas de tensão apresentou valores maiores que o do MOE estático na flexão, mas ambos foram altamente correlacionados, o coeficiente de correlação entre o $E d$ e o MOE estático foi $\left(\mathrm{R}^{2}=0,96\right)$ e com o MOR foi $\left(\mathrm{R}^{2}=0,74\right)$.

Segundo Oliveira, Campos e Sales (2002) os valores de MOE dinâmico são mais altos que os valores para MOE estático, com resultados obtidos dos testes dinâmicos 17\% maiores que os estáticos. Halabe et al. (1997) explica a razão das diferenças entre o $E d$ e o MOE na flexão estática para a madeira como um material de alto amortecimento e viscoelástico. Para uma amostra de madeira vibrando, a força de restauração elástica é proporcional ao deslocamento e a força dissipativa (amortecimento) é proporcional à velocidade. Portanto, quando uma força é aplicada por um tempo muito curto, como nos ensaios dinâmicos, o material se comporta como um sólido elástico, enquanto para cargas de maior duração, como no ensaio estático, o comportamento é como um líquido viscoso.

Os produtores de madeira serrada da costa da Columbia Britânica investigaram os sistemas mais adequados de classificação mecânica de madeiras com obtenção dos resultados do módulo de elasticidade (MOE) e sua correlação com métodos alternativos. Para a vibração longitudinal foram utilizados o MTG e o MiCROTEC Viscan, para a vibração transversal a Metriguard Modelo E340 e para os métodos estáticos biapoiados de acordo com a ASTM D198 e ASTM D4761 (BARRETT, 2008).

O módulo de elasticidade $\left(\mathrm{E}_{340}\right)$ obtido pelo ensaio de vibração transversal com o equipamento Metriguard E340 foi comparado com o módulo de elasticidade pelo ensaio estático para longos vãos de acordo com a ASTM D4761 ( $\left.\mathrm{E}_{4761}\right)$ em peças da espécie SprucePine-Fir com dimensões 38x89mm, vão de 4,28m e carga aplicada no centro do vão. Houve uma forte relação $\left(E_{4761}=0,991 . E_{340}\right)$ e alto coeficiente de correlação $\left(R^{2}=0,981\right)$ entre $E_{4761}$ e $E_{340}$. Baseado nestes ensaios, os resultados de vibração transversal da Metriguard E340 
foram utilizados como referência nos estudos dos módulos de elasticidade citados no artigo deste autor (BARRETT, 2008).

Os módulos de elasticidade medidos com a Metriguard E120 E-Computer foram confirmados como essencialmente os mesmos do MOE determinado nos ensaios de flexão estática biapoiada. Esses MOEs são livres da contribuição do cisalhamento. O MOE também foi medido utilizando dois sistemas de onda de tensão longitudinal, o MiCROTEC Viscan Stress Grader e o Brookhuis Timber Grader (MTG), com os valores de MOE medido com esses instrumentos em média $2 \%$ maiores que o E-Computer e da flexão estática. Pode-se concluir que os valores de MOE obtidos pelos ensaios não-destrutivos do E-Computer, Microtec e MTG são similares (BARRETT, 2008).

Os valores de MOE, $\mathrm{E}_{340}, \mathrm{E}_{\mathrm{ViSCAN}}, \mathrm{E}_{198}$ e $\mathrm{MOR}$ foram medidos em corpos de prova com 3 diferentes seções transversais $(45 \times 90$, 90x90 e 105x105mm) de Cicuta canadense classificada visualmente. As linhas de regressão traçadas pelos dados indicam em média que $\mathrm{E}_{\mathrm{ViSCAN}}$ é aproximadamente 2,2\% maior que $\mathrm{E}_{340}$ (BARRETT, 2008).

Nas relações entre $E_{\mathrm{MTG}}$ e $\mathrm{E}_{340}$, medidas para as amostras de Cicuta com 90x90mm, as linhas de regressão traçadas pelos dados indicam que o $E_{\text {MTG }}$ e $E_{340}$ são essencialmente equivalentes. Os valores estáticos do $\mathrm{E}_{198}$ foram de $6 \%$ à $9 \%$ menores que o $\mathrm{E}_{340}, \mathrm{E}_{\mathrm{ViSCAN}}$ e $\mathrm{E}_{\mathrm{MTG}}$. Em função do $\mathrm{E}_{198}$ ser ensaiado em vãos pequenos, inclui-se nestes resultados a interferência da flexão por cisalhamento, enquanto os demais testes têm valores essencialmente livres de cisalhamento no MOE. (BARRETT, 2008)

As correlações para as regressões, relacionando a resistência à flexão (MOR) com os Módulos de Elasticidade $E_{340}, E_{\text {ViSCAN }}$ e $E_{M T G}$ são aproximados $\left(R^{2}=0,50\right.$ à 0,54). A correlação entre os valores de MOR e o $\mathrm{E}_{198}$ foi de $\mathrm{R}^{2}=0,67$. (BARRETT, 2008).

O valores de MOE obtidos nos ensaios destrutivos, pela ASTM D198, no estado limite último, foram menores que o MOE em ensaios dinâmicos não-destrutivos. Estes valores de MOE incluem deformação por cisalhamento e consequentemente diminuem o valor do MOE o que é consistente com as predições para a viga teórica e outros estudos experimentais (BARRETT, 2008).

Ensaios desenvolvidos por Halabe et al. (1997), com técnicas de ensaio nãodestrutivo de vibração transversal e de ondas de tensão longitudinal testaram sua acurácia na avaliação da qualidade da madeira estrutural. O artigo apresenta os resultados de um programa experimental, projetado para examinar as correlações entre as características das ondas de tensão e vibração transversal de madeira com teor de umidade acima do PSF (entre $25 \%$ e $30 \%$ ) e madeira com teor de umidade de $12 \%$ da espécie Southern Pine (Pinus sp.) e o 
Módulo de Elasticidade (MOE) e resistência (MOR) na flexão estática em dimensões estruturais.

Halabe et al. (1997) reporta o coeficiente de determinação $\left(\mathrm{R}^{2}\right)$ entre o MOE na flexão estática na flexão e a velocidade de onda de tensão foi $\mathrm{R}^{2}=0,61$ para madeira acima do PSF e R $\mathrm{R}^{2}=0,45$ para madeira $12 \%$ de teor de umidade para Southern Pine.

Os resultados de regressão do MOE na flexão estática longitudinal ( $E e$ ) versus o MOE por onda de tensão longitudinal $(E t)$ apresentaram coeficientes de determinação $\mathrm{R}^{2}=0,73$ para a madeira acima do PSF e $\mathrm{R}^{2}=0,74$ para madeira com teor de umidade de $12 \%$. Isso indica que $74 \%$ do comportamento observado foi explicado pelo modelo de regressão (HALABE, 1997).

\subsection{CONCLUSÕES DA REVISÃO BIBLIOGRÁFICA}

As técnicas padronizadas de ensaio estático para obtenção do módulo de elasticidade são apresentadas pela norma brasileira NBR 7190/1997 e por normas internacionais como a ASTM D4761 (2002) e ASTM D198 (1976), com enfoque no ensaio de peças com dimensões estruturais, as quais podem ser correlacionadas com as dimensões e localizações dos defeitos naturais ou de processamento na madeira serrada. Este mapeamento de defeitos pode seguir os valores especificados pelo SPIB.

Os trabalhos apresentados na literatura reforçam a viabilidade dos ensaios para obtenção do módulo de elasticidade por meios dinâmicos como vibração transversal e ondas de tensão longitudinal com correlações altas nas estimativas do módulo de elasticidade estático da madeira. Os valores do MOE dinâmico são superiores aos valores do MOE estático. Também destaca-se a importância da verificação dos valores de teor de umidade, densidade e também da realização de classificação visual dos defeitos na madeira para complementar a acurácia dos resultados dos ensaios dinâmicos em comparação com os ensaios estáticos normatizados.

A validação dos aparelhos que utilizam métodos dinâmicos de ensaio para o módulo de elasticidade são regulados pela norma européia EN14081 (2010), sendo que o equipamento de ensaio BrookHuis Microeletronics Timber Grader (MTG) utilizado neste trabalho recebeu esta certificação.

O aparelho de ensaio MTG calcula o valor do módulo de elasticidade dinâmico, $E_{D I N}$, através da frequência natural na vibração longitudinal e ajusta o valor, para cada 
espécie, em um banco de dados interno do software para estimar o Módulo de Elasticidade, $\mathrm{E}_{\mathrm{MTG}}$, das peças de madeira. Existe a necessidade de efetuar ensaios complementares com a utilização do equipamento de vibração longitudinal MTG em espécies brasileiras para calibração das curvas de correção da regressão, que determinam o módulo de elasticidade. Em função da origem e das condições ambientais diferentes entre o Brasil e a Europa ocorrem variações nas propriedades físicas e mecânicas.

\section{MATERIAIS E MÉTODOS}

A primeira etapa do trabalho foi a realização de uma classificação visual no lote de madeira da espécie Pinus elliottii, provenientes da região sudoeste do Estado de São Paulo.

Após a classificação visual, foram realizados os ensaios de vibração longitudinal por ondas de tensão, com determinação da frequência natural da madeira, no primeiro modo longitudinal e o módulo de elasticidade ( $\left.\mathrm{E}_{\mathrm{MTG}}\right)$ estimado pelo equipamento portátil, e também para a obtenção da frequência natural da peça para cálculo do módulo de elasticidade dinâmico $\left(E_{D I N}\right)$. Em seguida foram realizados os ensaios de flexão estática em relação ao eixo de maior inércia, sendo determinados os valores de MOE e MOR.

Todos os ensaios e procedimentos foram realizados no Laboratório de Madeiras e Estruturas de Madeira (LaMEM), do Departamento de Engenharia de Estruturas (SET) da Escola de Engenharia de São Carlos (EESC), da Universidade de São Paulo (USP).

\subsection{MATERIAIS}

Foi utilizado nesta pesquisa um lote de 260 peças de madeira da espécie Pinus elliottii, adquirido na empresa Sguário Madeiras, sendo proveniente da região Sudoeste do Estado de São Paulo, com dimensões nominais de 45mm x 105mm x 2500mm. A Figura (13) mostra o referido lote. As peças foram previamente secas em estufa. 


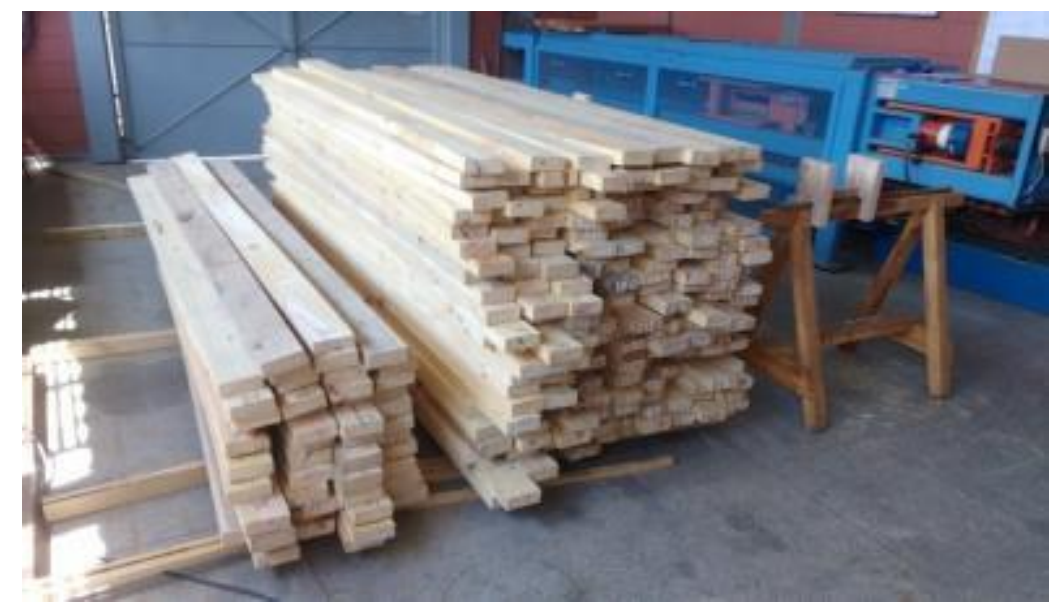

Figura 13 - Lote de 260 peças de 45x105x2500mm de Pinus elliottii.

\subsection{MÉTODOS}

A seguir está apresentado um detalhamento dos procedimentos utilizados na obtenção das propriedades das peças de madeira.

\subsubsection{Determinação do teor de umidade}

Para realização dos ensaios de foram determinados os teores de umidade de cada peça ensaiada, com o valor médio entre três medidas ao longo da peça, a fim de realizar as correções dos valores dos resultados para a condição padrão de referência de umidade à $12 \%$. As peças foram previamente secas em estufa na indústria e o valor de umidade médio foi de $9,4 \%$. Para a determinação do teor de umidade de cada peça foi utilizado medidor de umidade da madeira por contato que funciona com geração de campo elétrico de alta frequência, modelo M52 da marca Marrari (Figura 14).

Os valores da densidade aparente e das propriedades de MOE das peças foram corrigidos para a condição padrão de referência, a $12 \%$ de umidade de acordo com a NBR7190. 


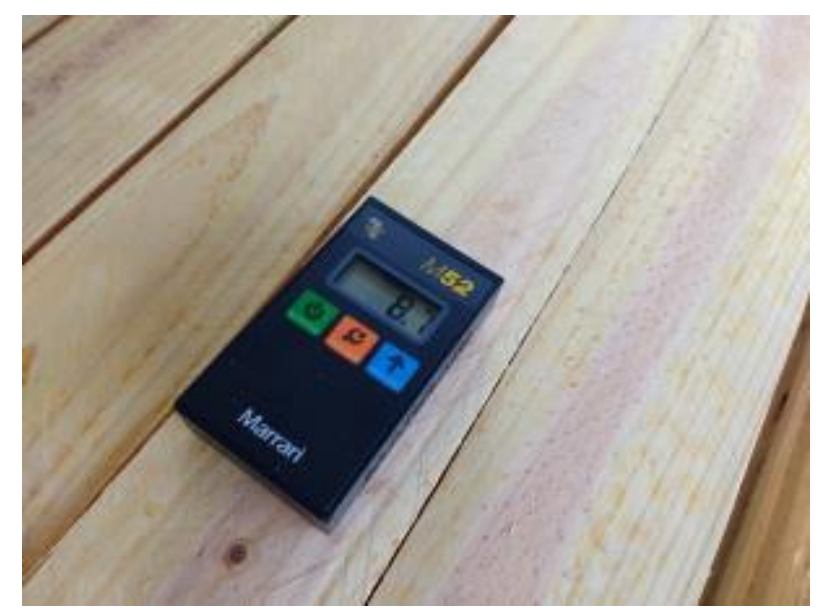

Figura 14 - Medidor de umidade por contato M52 Marrari.

\subsubsection{Classificação Visual}

As peças foram previamente classificadas visualmente de acordo com o as regras do SPIB (Southern Pine Inspection Bureau), para determinar o efeito dos defeitos naturais e de processamento que possam afetar suas propriedades mecânicas. As peças com deformações excessivas, esmoados e bolsas de resina, foram eliminadas, restando 213 peças.

Foram limitados os diâmetros dos nós no centro da face larga, nós na borda da face larga, nós na face estreita, inclinação das fibras, presença de fendas, rachas, esmoados e bolsas de resina.

As peças foram distribuídas em 4 classes, SS (Select Structural), S1, S2 e S3, em função do tamanho dos defeitos.

Para as peças de Pinus elliottii de seção transversal 45x105mm e comprimento $2500 \mathrm{~mm}$ foram adotados os limites conforme a Tabela 11.

Tabela 11 - Limitações dos defeitos em cada classe para peças com seção transversal de 45x105mm.

\begin{tabular}{ccccccc}
\hline \multirow{2}{*}{ Classe } & \multicolumn{2}{c}{ Nós } & \multirow{2}{*}{ Inclinação } & \multicolumn{2}{c}{ Rachas Anelares } & \\
\cline { 2 - 3 } & Face & Face & das Fibras & Passante & Superficial & \multirow{2}{*}{ Fendas } \\
& estreita & Larga & & & & \\
\hline SS & $9 \mathrm{~mm}$ & $37 \mathrm{~mm}$ & $8 \%$ & $105 \mathrm{~mm}$ & $600 \mathrm{~mm}$ & $105 \mathrm{~mm}$ \\
S1 & $11 \mathrm{~mm}$ & $47 \mathrm{~mm}$ & $10 \%$ & $105 \mathrm{~mm}$ & $600 \mathrm{~mm}$ & $105 \mathrm{~mm}$ \\
S2 & $15 \mathrm{~mm}$ & $53 \mathrm{~mm}$ & $12,5 \%$ & $157 \mathrm{~mm}$ & $625 \mathrm{~mm}$ & $157 \mathrm{~mm}$ \\
S3 & $23 \mathrm{~mm}$ & $79 \mathrm{~mm}$ & $25 \%$ & $416 \mathrm{~mm}$ & - & $416 \mathrm{~mm}$ \\
\hline
\end{tabular}


Para auxílio na medição dos defeitos foi elaborada uma régua com as marcações das dimensões limite para a seção estudada, conforme as Figuras 15 e 16.

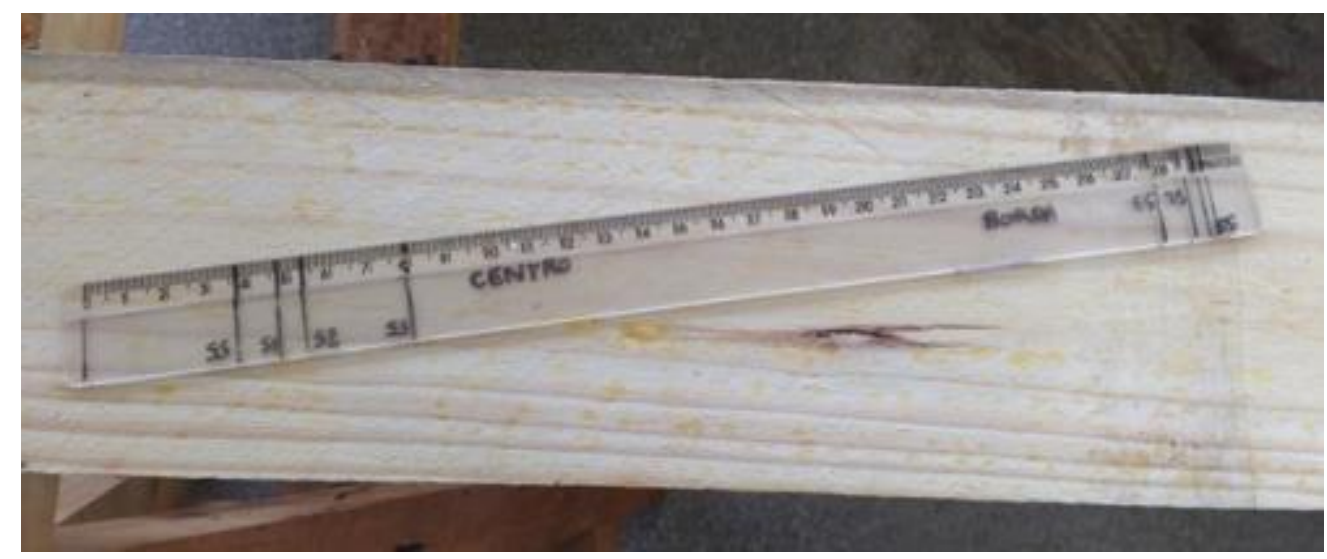

Figura 15 - Modelo da régua com os limites de dimensões dos nós.

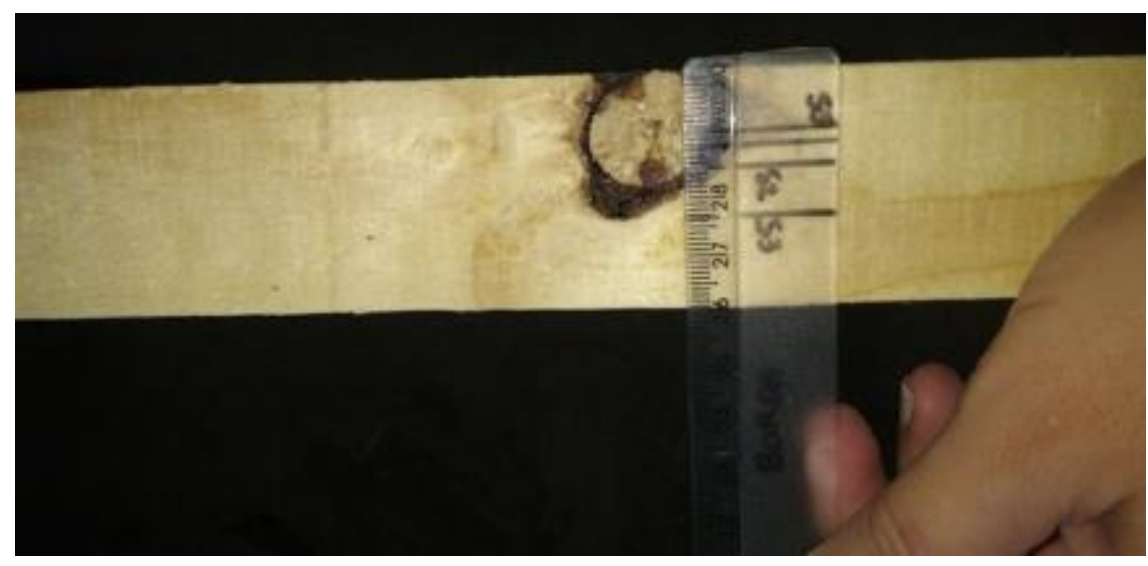

Figura 16 - Medição de um nó de borda com a régua adaptada.

\subsubsection{Módulo de elasticidade dinâmico obtido pelo MTG ( $\left.\mathbf{E}_{\mathrm{MTG}}\right)$}

O módulo de elasticidade dinâmico foi obtido pelo equipamento BrookHuis Micro-Eletronics Timber Grader (MTG) seguindo os procedimentos apontados no item 2.9. (Figuras 17 e 18). 


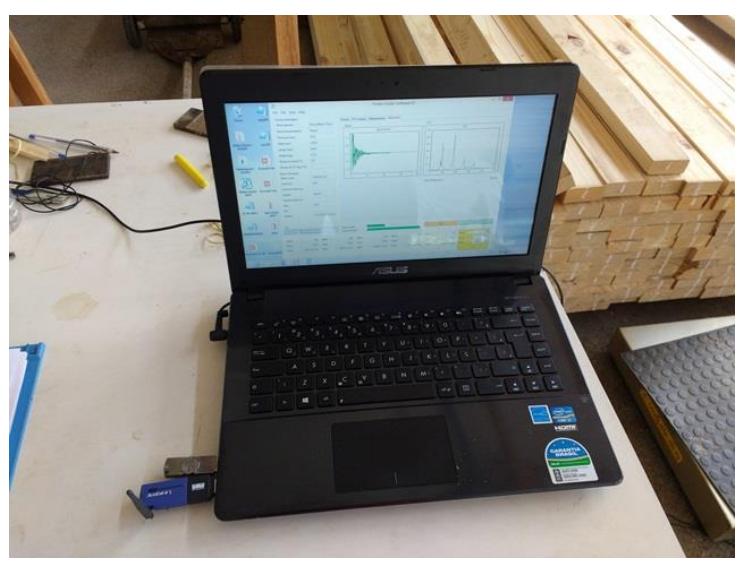

Figura 17 - Computador com bluetooth e software de aquisição de dados.
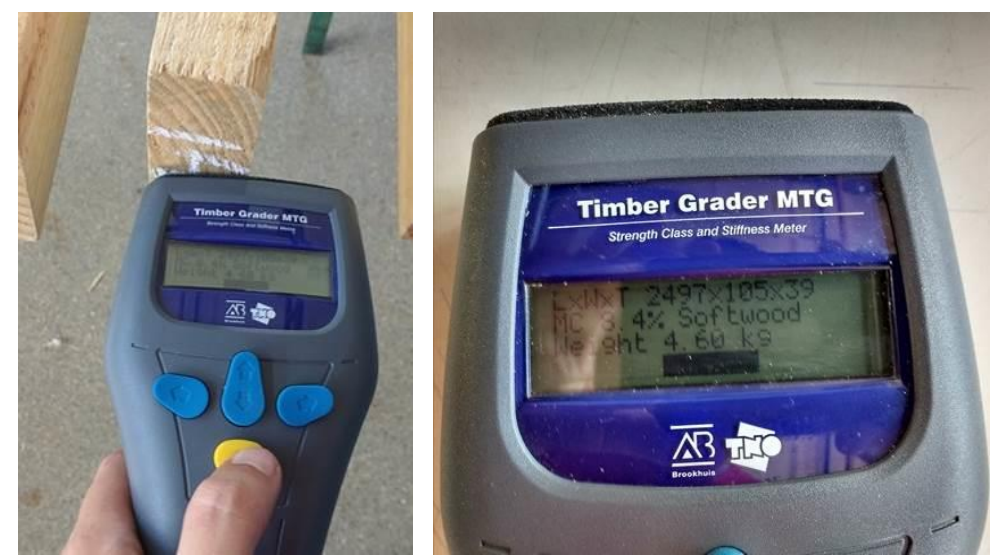

Figura 18 - Posicionamento do MTG para obtenção do MOE estimado e display do aparelho.

O aparelho é calibrado por uma barra de acrílico, que acompanha o kit, independente da espécie estudada, os dados são armazenados no computador e podem ser exportados para análises externas ao software. Estes arquivos armazenam todos os dados inseridos e os resultados dos ensaios.

\subsubsection{Módulo de elasticidade dinâmico calculado pela frequência natural ( $\left.\mathrm{E}_{\mathrm{DIN}}\right)$}

Os valores da frequência natural do primeiro modo longitudinal, também foram utilizados para calcular o valor do Módulo de Elasticidade dinâmico das peças, para serem comparados com os valores de módulo de elasticidade $\left(\mathrm{E}_{\mathrm{MTG}}\right)$ corrigidos pelo software do MTG, verificando as correções do software para estimativa do MOE estático. O módulo de elasticidade dinâmico ( $\left.\mathrm{E}_{\mathrm{DIN}}\right)$ foi determinado de acordo com a Equação (30), conforme apresentado na revisão bibliográfica, no item 2.8: 


\subsubsection{Flexão estática}

Para os testes de flexão estática em relação ao eixo de maior inércia. Foram realizados os procedimentos de ensaio de acordo com a ASTM D4761-02, sendo determinado o Módulo de Elasticidade (MOE) e a resistência (MOR) na flexão estática, com as peças na pior posição dos defeitos naturais, em função da classificação visual anterior.
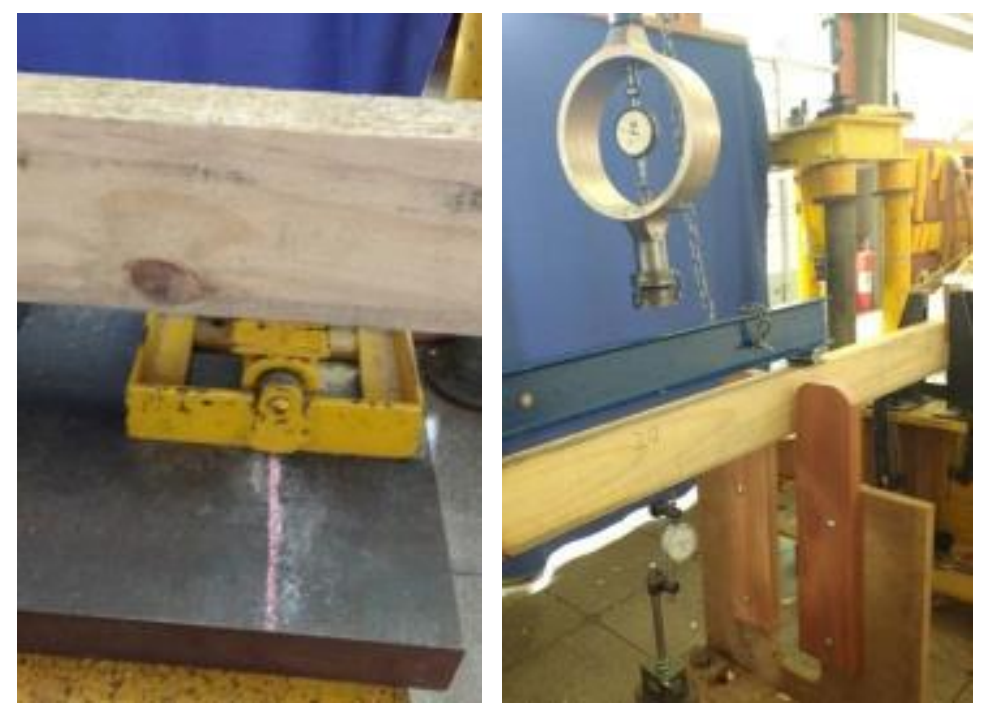

Figura 19 - Detalhe do apoio rotulado e do sistema de aplicação da carga.

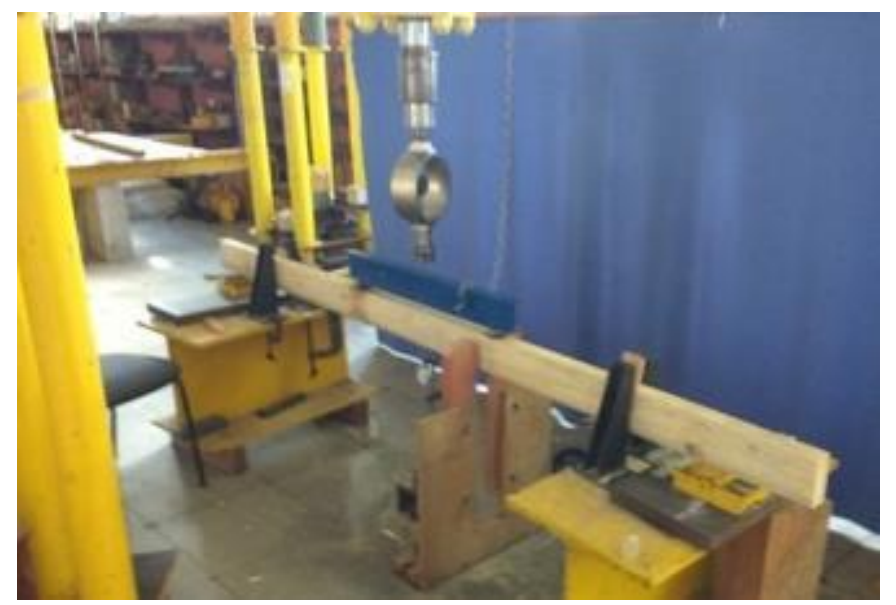

Figura 20 - Montagem do ensaio estático para obtenção do MOE e MOR

Conforme apresentado no item 2.5, neste ensaio as peças foram apoiadas em suportes rotulados com uma relação $(\mathrm{L} / \mathrm{h})$ de 18 , com vão (L) de $1890 \mathrm{~mm}$. A força foi aplicada por pistão hidráulico e uma bomba, acoplado a um anel dinamométrico com capacidade total de 46,59 kN (Figuras 19 e 20). A força é aplicada sobre uma viga metálica 
que divide a carga em dois pontos equidistantes do vão entre os apoios (630mm) (Figura 21). As peças foram contraventadas para evitar a perda de estabilidade. A deformação foi medida com um relógio comparador, com precisão de $0,1 \mathrm{~mm}$, posicionado no ponto central do vão, e as leituras feitas até a deformação limite de 9,45mm (L/200), com medições a cada incremento de $230 \mathrm{~N}$. Após essas medições, as peças foram carregadas até a ruptura para a determinação da resistência MOR.

O MOE estático foi determinado de acordo com a Equação (15)

O MOR foi determinado de acordo com a Equação (16):

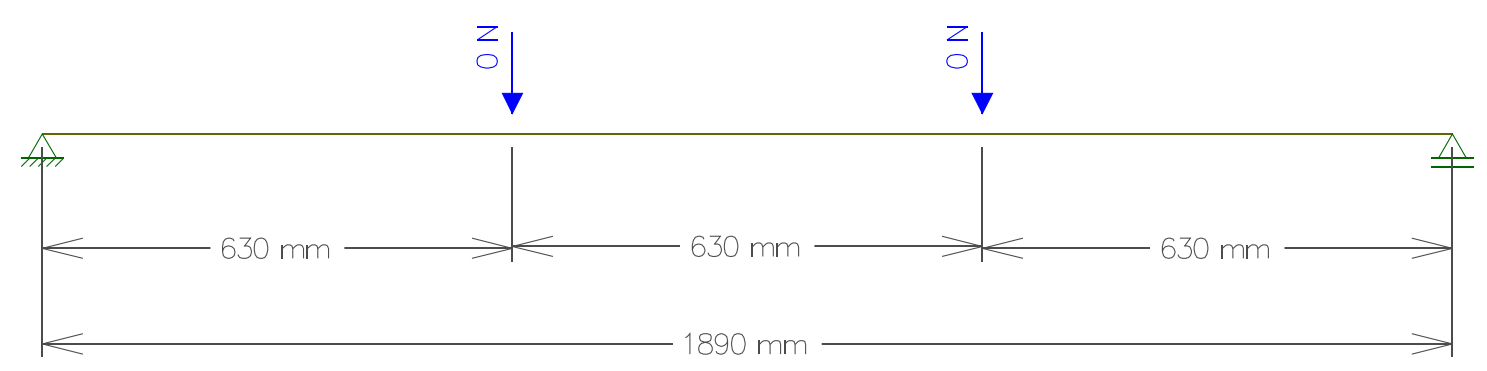

Figura 21 - Esquemático dos espaçamentos para ensaio da peça de 45x105mm. 


\section{RESULTADOS OBTIDOS}

\subsection{CLASSIFICAÇÃO VISUAL}

Após a classificação visual do lote, das 260 peças iniciais, foram excluídas 47 peças que não atenderam os limites mínimos de defeitos, em função de nós, empenamentos e esmoados, reduzindo a quantidade de amostras do lote em 18\%, para 213 peças. A Tabela 12 apresenta a quantidade de peças enquadradas em cada classe visual.

Tabela 12 - Quantidade de peças por classe visual.

\begin{tabular}{cccccc}
\hline & SS & S1 & S2 & S3 & Lote \\
\hline Quantidades & 72 & 43 & 42 & 56 & 213 \\
\hline$\%$ & 33,8 & 20,2 & 19,7 & 26,3 & 100
\end{tabular}

\subsection{DADOS DAS AMOSTRAS}

A Tabela 13 apresenta os seguintes valores obtidos para as peças classificadas como SS, teor de umidade, densidade aparente à 12\%, Módulo de Elasticidade Estático (MOE), Módulo de Elasticidade Dinâmico ( $\left.\mathrm{E}_{\mathrm{DIN}}\right)$, Módulo de Elasticidade obtido pelo MTG $\left(\mathrm{E}_{\mathrm{MTG}}\right)$ e a resistência à flexão $(\mathrm{MOR})$. As Tabelas 14 à 16 apresentam os valores para as peças das demais classes.

Tabela 13 - Propriedades das peças da Classe SS.

\begin{tabular}{ccccccc}
\hline $\mathbf{C P}$ & $\begin{array}{c}\text { Umidade } \\
(\boldsymbol{\%})\end{array}$ & $\begin{array}{c}\text { Densidade } \\
\text { Aparente } \\
\left(\mathbf{K g} / \mathbf{m}^{\mathbf{3}}\right)\end{array}$ & $\begin{array}{c}\text { MOE } \\
(\mathbf{M P a})\end{array}$ & $\begin{array}{c}\mathbf{E}_{\mathbf{M T G}} \\
(\mathbf{M P a})\end{array}$ & $\mathbf{E}_{\text {DIN }}(\mathbf{M P a})$ & MOR (MPa) \\
\hline 3 & 9,5 & 500 & 10437 & 11663 & 12719 & 28,3 \\
\hline 6 & 12,2 & 650 & 13480 & 14472 & 15460 & 88,8 \\
\hline 11 & 10,8 & 558 & 9641 & 9721 & 10499 & 40,1 \\
\hline 17 & 10,2 & 496 & 9473 & 9898 & 10739 & 61,9 \\
\hline 18 & 8,9 & 442 & 6645 & 8049 & 8816 & 29,6 \\
\hline 19 & 12 & 526 & 11410 & 12868 & 13769 & 39,3 \\
\hline 22 & 8,9 & 427 & 6574 & 6619 & 7249 & 35,8 \\
\hline 26 & 8,2 & 432 & 8020 & 7636 & 8405 & 23,8 \\
\hline 32 & 8,3 & 457 & 8356 & 8000 & 8801 & 28,0 \\
\hline
\end{tabular}




\begin{tabular}{ccccccc}
\hline & Umidade & Densidade & MOE & $\mathbf{E}_{\text {MTG }}$ & & \\
CP & Aparente & $(\mathrm{MPa})$ & $(\mathrm{MPa})$ & & \\
& $(\%)$ & $\left(\mathrm{Kg} / \mathrm{m}^{3}\right)$ & & & & \\
& & & & & & \\
\hline
\end{tabular}

Continuação da tabela $13 .$.

\begin{tabular}{|c|c|c|c|c|c|c|}
\hline 40 & 8,8 & 408 & 7298 & 7006 & 7679 & 34,0 \\
\hline 44 & 8,8 & 489 & 7296 & 7844 & 8598 & 38,1 \\
\hline 50 & 10,1 & 506 & 6209 & 6410 & 6960 & 34,6 \\
\hline 60 & 11,4 & 584 & 9426 & 11759 & 12641 & 30,9 \\
\hline 63 & 8,4 & 483 & 7888 & 7910 & 8696 & 37,2 \\
\hline 65 & 9 & 467 & 6226 & 6421 & 7028 & 25,1 \\
\hline 66 & 9,4 & 470 & 5752 & 5786 & 6315 & 23,6 \\
\hline 69 & 8,6 & 467 & 7891 & 8179 & 8979 & 29,0 \\
\hline 79 & 10 & 510 & 8537 & 8429 & 9158 & 31,3 \\
\hline 83 & 11,1 & 576 & 9729 & 11230 & 12100 & 62,7 \\
\hline 88 & 8,4 & 453 & 8140 & 7291 & 8015 & 22,9 \\
\hline 89 & 10,2 & 543 & 9757 & 10701 & 11610 & 34,8 \\
\hline 90 & 10,3 & 438 & 7532 & 8014 & 8688 & 28,6 \\
\hline 92 & 8,2 & 435 & 5206 & 5622 & 6190 & 24,0 \\
\hline 94 & 10 & 471 & 9171 & 8936 & 9708 & 53,4 \\
\hline 95 & 9,7 & 518 & 11292 & 11116 & 12105 & 69,0 \\
\hline 97 & 8,7 & 340 & 4076 & 3769 & 4135 & 19,3 \\
\hline 110 & 11,5 & 593 & 10516 & 13291 & 14277 & 68,5 \\
\hline 113 & 10,1 & 540 & 7631 & 7076 & 7682 & 35,8 \\
\hline 115 & 9,4 & 398 & 6773 & 6201 & 6768 & 30,2 \\
\hline 121 & 8,4 & 487 & 6982 & 6815 & 7491 & 31,9 \\
\hline 122 & 9,5 & 503 & 7884 & 7262 & 7920 & 38,8 \\
\hline 123 & 8,3 & 484 & 7199 & 6136 & 6750 & 33,0 \\
\hline 127 & 9 & 577 & 10388 & 10704 & 11716 & 59,2 \\
\hline 129 & 8,9 & 512 & 8659 & 7923 & 8679 & 50,6 \\
\hline 134 & 8,9 & 505 & 6464 & 7262 & 7954 & 35,7 \\
\hline 137 & 9,3 & 509 & 7055 & 7433 & 8118 & 38,3 \\
\hline 141 & 9,3 & 495 & 7392 & 7843 & 8566 & 38,8 \\
\hline 142 & 8,8 & 420 & 5450 & 5543 & 6076 & 36,1 \\
\hline 147 & 11,2 & 514 & 9074 & 10360 & 11154 & 52,8 \\
\hline 148 & 8,7 & 465 & 8583 & 8547 & 9375 & 23,9 \\
\hline 152 & 11,2 & 594 & 11410 & 11416 & 12292 & 53,1 \\
\hline 155 & 10 & 571 & 9468 & 9297 & 10102 & 50,3 \\
\hline 157 & 10,2 & 570 & 10758 & 11521 & 12499 & 81,8 \\
\hline 161 & 12,4 & 443 & 6702 & 7046 & 7515 & 18,8 \\
\hline
\end{tabular}

Continua... 
\begin{tabular}{ccccccc}
\hline & Umidade & Densidade & MOE & $\mathbf{E}_{\text {MTG }}$ & & \\
CP & $(\%)$ & Aparente & $(\mathrm{MPa})$ & $(\mathrm{MPa})$ & & \\
& & $\left(\mathrm{Kg} / \mathrm{m}^{3}\right)$ & & & & \\
& & & & &
\end{tabular}

\begin{tabular}{|c|c|c|c|c|c|c|}
\hline & & & & & \multicolumn{2}{|c|}{ Continuação da tabela $13 .}$. \\
\hline 166 & 10 & 535 & 9111 & 10301 & 11192 & 40,5 \\
\hline 167 & 9,3 & 493 & 8954 & 9860 & 10769 & 30,9 \\
\hline 170 & 8,3 & 480 & 7709 & 6743 & 7418 & 47,4 \\
\hline 173 & 10 & 522 & 10031 & 10015 & 10881 & 60,9 \\
\hline 174 & 9,1 & 498 & 6688 & 6347 & 6941 & 37,9 \\
\hline 177 & 9,6 & 461 & 4929 & 5189 & 5654 & 14,8 \\
\hline 179 & 9,8 & 412 & 6488 & 7193 & 7827 & 39,1 \\
\hline 184 & 7,9 & 425 & 5626 & 5716 & 6306 & 23,4 \\
\hline 185 & 8,8 & 492 & 6665 & 6478 & 7100 & 49,4 \\
\hline 187 & 11 & 559 & 8569 & 9621 & 10375 & 62,5 \\
\hline 191 & 10,1 & 504 & 7948 & 9218 & 10008 & 16,3 \\
\hline 193 & 8,3 & 412 & 5668 & 5676 & 6243 & 20,0 \\
\hline 194 & 9,1 & 471 & 5798 & 6113 & 6686 & 20,2 \\
\hline 203 & 10,4 & 555 & 10239 & 11807 & 12791 & 51,3 \\
\hline 204 & 10 & 472 & 7564 & 7719 & 8387 & 43,5 \\
\hline 206 & 8,4 & 497 & 8040 & 7234 & 7952 & 38,5 \\
\hline 209 & 13,3 & 646 & 10368 & 12368 & 13096 & 68,0 \\
\hline 210 & 9,4 & 513 & 10050 & 10408 & 11359 & 52,1 \\
\hline 212 & 12,9 & 727 & 12652 & 13155 & 13975 & 61,4 \\
\hline 213 & 7,9 & 390 & 7178 & 7487 & 8259 & 37,3 \\
\hline 214 & 9,4 & 448 & 5118 & 6124 & 6684 & 13,6 \\
\hline 220 & 9,1 & 564 & 9850 & 9211 & 10075 & 61,5 \\
\hline 221 & 9,4 & 450 & 7864 & 7925 & 8650 & 23,2 \\
\hline 224 & 8,9 & 498 & 6723 & 6825 & 7476 & 33,2 \\
\hline 228 & 11 & 428 & 4692 & 5111 & 5512 & 19,9 \\
\hline 230 & 11,2 & 629 & 11170 & 11307 & 12069 & 76,3 \\
\hline 248 & 11,1 & 655 & 14728 & 15999 & 17239 & 76,4 \\
\hline 256 & 12,5 & 616 & 9728 & 11789 & 12564 & 65,3 \\
\hline
\end{tabular}


Tabela 14 - Propriedades das peças da Classe S1.

\begin{tabular}{|c|c|c|c|c|c|c|}
\hline $\mathbf{C P}$ & $\begin{array}{c}\text { Umidade } \\
(\%)\end{array}$ & $\begin{array}{c}\text { Densidade } \\
\text { Aparente } \\
\left(\mathbf{K g} / \mathbf{m}^{3}\right)\end{array}$ & $\begin{array}{l}\text { MOE } \\
\text { (MPa) }\end{array}$ & $\begin{array}{c}\mathbf{E}_{\mathrm{MTG}} \\
(\mathrm{MPa})\end{array}$ & $\mathbf{E}_{\text {DIN }}(\mathbf{M P a})$ & MOR (MPa) \\
\hline 23 & 10,2 & 387 & 6994 & 6260 & 6792 & 30,3 \\
\hline 28 & 9,6 & 460 & 8382 & 7940 & 8653 & 34,5 \\
\hline 36 & 9,6 & 497 & 6910 & 6028 & 6569 & 35,3 \\
\hline 38 & 9,1 & 436 & 7053 & 6752 & 7386 & 21,8 \\
\hline 45 & 10,6 & 529 & 7096 & 8016 & 8671 & 16,6 \\
\hline 51 & 9,1 & 424 & 4233 & 3994 & 4369 & 27,4 \\
\hline 52 & 9,1 & 446 & 6822 & 6303 & 6894 & 41,3 \\
\hline 64 & 8,3 & 496 & 9175 & 8403 & 9244 & 22,2 \\
\hline 74 & 9,3 & 455 & 5564 & 5960 & 6509 & 20,0 \\
\hline 78 & 9,7 & 522 & 5250 & 5357 & 5834 & 19,7 \\
\hline 98 & 10,1 & 555 & 9874 & 10198 & 11072 & 31,7 \\
\hline 101 & 8,6 & 516 & 8763 & 7804 & 8567 & 24,9 \\
\hline 111 & 9,7 & 469 & 4787 & 6320 & 6882 & 35,9 \\
\hline 116 & 8,9 & 496 & 6295 & 5982 & 6553 & 25,6 \\
\hline 118 & 8,9 & 481 & 8937 & 9195 & 10073 & 44,0 \\
\hline 126 & 9,2 & 511 & 6637 & 7314 & 7994 & 32,8 \\
\hline 130 & 10,1 & 502 & 5385 & 5231 & 5679 & 22,2 \\
\hline 133 & 10 & 510 & 8426 & 8160 & 8866 & 41,9 \\
\hline 135 & 7,8 & 422 & 5594 & 6108 & 6744 & 22,7 \\
\hline 143 & 8,1 & 400 & 6445 & 6063 & 6722 & 30,5 \\
\hline 144 & 7,1 & 525 & 7717 & 8036 & 8914 & 17,0 \\
\hline 151 & 9,5 & 509 & 7391 & 8766 & 9560 & 34,2 \\
\hline 156 & 9 & 456 & 6839 & 6897 & 7549 & 26,8 \\
\hline 160 & 9,1 & 402 & 4481 & 4433 & 4848 & 25,3 \\
\hline 162 & 9,1 & 416 & 4298 & 4357 & 4765 & 34,2 \\
\hline 163 & 10 & 555 & 9784 & 12545 & 13630 & 46,7 \\
\hline 168 & 9,1 & 460 & 6988 & 7894 & 8635 & 13,8 \\
\hline 186 & 10,2 & 465 & 7994 & 8675 & 9412 & 25,0 \\
\hline 189 & 11,7 & 496 & 6460 & 7181 & 7702 & 31,6 \\
\hline 192 & 8 & 427 & 7553 & 7623 & 8404 & 20,5 \\
\hline 195 & 8,3 & 478 & 8369 & 7901 & 8692 & 21,4 \\
\hline 196 & 10 & 488 & 6368 & 6561 & 7129 & 28,0 \\
\hline 200 & 13,2 & 534 & 10033 & 11726 & 12427 & 29,2 \\
\hline 207 & 10,5 & 572 & 10715 & 10420 & 11278 & 31,2 \\
\hline 216 & 10,3 & 455 & 6922 & 6705 & 7269 & 45,1 \\
\hline
\end{tabular}




\begin{tabular}{ccccccc}
\hline & Umidade & Densidade & MOE & $\mathbf{E}_{\text {MTG }}$ & & \\
CP & Aparente & E & MPa) & MOR (MPa) \\
& $(\%)$ & $\left(\mathrm{Kg} / \mathrm{m}^{3}\right)$ & & $(\mathrm{MPa})$ & & \\
& & & & & \\
\hline
\end{tabular}

\begin{tabular}{lcccccc}
\hline & & & & \multicolumn{2}{c}{ Continuação da Tabela 14... } \\
\hline 217 & 9,1 & 462 & 7832 & 7478 & 8179 & 44,1 \\
\hline 225 & 8,7 & 429 & 8091 & 8283 & 9087 & 22,2 \\
\hline 229 & 9,3 & 521 & 5586 & 5249 & 5732 & 18,9 \\
\hline 234 & 9,8 & 542 & 6886 & 6553 & 7131 & 32,0 \\
\hline 245 & 8,9 & 515 & 7214 & 7322 & 8021 & 26,9 \\
\hline 246 & 9 & 451 & 3183 & 3541 & 3876 & 19,8 \\
\hline 250 & 8,4 & 428 & 7356 & 7162 & 7873 & 45,1 \\
\hline 254 & 9,4 & 483 & 7374 & 7520 & 8207 & 39,8 \\
\hline
\end{tabular}

Tabela 15 - Propriedades das peças da Classe S2.

\begin{tabular}{ccccccc}
\hline & Umidade & Densidade & MOE & $\mathbf{E}_{\text {MTG }}$ & & \\
CP & Aparente & DIN & MPa) & MOR (MPa) \\
& $(\%)$ & $\left(\mathrm{Kg} / \mathrm{m}^{3}\right)$ & $(\mathrm{MPa})$ & $(\mathrm{MPa})$ & & \\
& & & & &
\end{tabular}

\begin{tabular}{ccccccc}
\hline 5 & 10,9 & 579 & 14366 & 16006 & 17273 & 57,4 \\
\hline 7 & 8,8 & 430 & 6178 & 6192 & 6787 & 21,1 \\
\hline 8 & 9,4 & 548 & 10640 & 11362 & 12400 & 53,9 \\
\hline 21 & 9,5 & 496 & 9378 & 9131 & 9958 & 22,3 \\
\hline 27 & 10,2 & 448 & 7692 & 7709 & 8364 & 43,9 \\
\hline 29 & 9,7 & 492 & 6466 & 7824 & 8520 & 20,3 \\
\hline 30 & 9,2 & 378 & 6627 & 6602 & 7216 & 18,5 \\
\hline 31 & 9,5 & 529 & 6679 & 8414 & 9176 & 16,3 \\
\hline 33 & 9,7 & 519 & 6401 & 7361 & 8016 & 23,6 \\
\hline 41 & 8,9 & 465 & 5875 & 6282 & 6881 & 32,3 \\
\hline 48 & 10 & 481 & 6956 & 6666 & 7243 & 32,3 \\
\hline 53 & 9,1 & 425 & 3325 & 3432 & 3754 & 17,8 \\
\hline 56 & 8,6 & 455 & 7379 & 6712 & 7368 & 15,9 \\
\hline 68 & 9 & 466 & 9259 & 7937 & 8688 & 42,4 \\
\hline 70 & 10,5 & 472 & 8517 & 8664 & 9379 & 37,9 \\
\hline 71 & 8,3 & 424 & 5972 & 5701 & 6272 & 20,5 \\
\hline 73 & 8,2 & 415 & 5314 & 5043 & 5551 & 23,9 \\
\hline 75 & 8,4 & 452 & 7773 & 6761 & 7388 & 35,4 \\
\hline 76 & 10,2 & 432 & 5192 & 5482 & 5948 & 32,4 \\
\hline & & & & & & Continua... \\
\hline
\end{tabular}




\begin{tabular}{|c|c|c|c|c|c|c|}
\hline $\mathbf{C P}$ & $\begin{array}{c}\text { Umidade } \\
(\%)\end{array}$ & $\begin{array}{c}\text { Densidade } \\
\text { Aparente } \\
\left(\mathrm{Kg} / \mathbf{m}^{3}\right)\end{array}$ & $\begin{array}{l}\text { MOE } \\
\text { (MPa) }\end{array}$ & $\begin{array}{l}\mathbf{E}_{\mathrm{MTG}} \\
(\mathrm{MPa})\end{array}$ & $\mathbf{E}_{\text {DIN }}(\mathbf{M P a})$ & MOR (MPa) \\
\hline & & & & & \multicolumn{2}{|c|}{ Continuação da tabela $15 .}$. \\
\hline 77 & 10,3 & 511 & 7245 & 7060 & 7654 & 36,7 \\
\hline 82 & 9,5 & 514 & 8241 & 9061 & 9881 & 4,1 \\
\hline 102 & 9,3 & 499 & 10163 & 9836 & 10743 & 45,8 \\
\hline 154 & 9 & 432 & 7160 & 6817 & 7462 & 19,3 \\
\hline 158 & 9,2 & 446 & 5972 & 5576 & 6095 & 23,8 \\
\hline 164 & 9,1 & 460 & 7122 & 8147 & 8910 & 26,9 \\
\hline 169 & 8,4 & 423 & 4986 & 5434 & 5974 & 18,1 \\
\hline 175 & 9,3 & 427 & 4479 & 4691 & 5123 & 25,1 \\
\hline 176 & 7,5 & 431 & 6623 & 6779 & 7499 & 32,7 \\
\hline 178 & 10,9 & 552 & 6479 & 6093 & 6575 & 27,0 \\
\hline 180 & 10,1 & 469 & 3439 & 4689 & 5091 & 9,6 \\
\hline 188 & 9 & 454 & 6656 & 6104 & 6681 & 24,6 \\
\hline 198 & 8,6 & 430 & 6227 & 6507 & 7143 & 27,0 \\
\hline 199 & 9 & 453 & 8545 & 7723 & 8453 & 26,0 \\
\hline 201 & 8 & 442 & 6304 & 6968 & 7682 & 19,9 \\
\hline 202 & 8 & 469 & 5960 & 6411 & 6746 & 11,8 \\
\hline 218 & 9,4 & 455 & 5327 & 5632 & 6146 & 15,1 \\
\hline 219 & 9,8 & 477 & 6557 & 5944 & 6468 & 25,1 \\
\hline 222 & 7,8 & 459 & 7853 & 7727 & 8531 & 31,7 \\
\hline 223 & 9,5 & 478 & 6568 & 6194 & 6756 & 19,8 \\
\hline 231 & 8 & 470 & 7920 & 7225 & 7966 & 30,9 \\
\hline 240 & 10,1 & 558 & 8645 & 10096 & 10962 & 37,1 \\
\hline 249 & 8,8 & 431 & 6340 & 6821 & 7476 & 29,5 \\
\hline
\end{tabular}

Tabela 16 - Propriedades das peças da Classe S3.

\begin{tabular}{ccccccc}
\hline $\mathbf{C P}$ & $\begin{array}{c}\text { Umidade } \\
(\boldsymbol{\%})\end{array}$ & $\begin{array}{c}\text { Densidade } \\
\text { Aparente } \\
\left(\mathbf{K g} / \mathbf{m}^{3}\right)\end{array}$ & $\begin{array}{c}\text { MOE } \\
(\mathbf{M P a})\end{array}$ & $\begin{array}{c}\mathbf{E}_{\mathbf{M T G}} \\
(\mathbf{M P a})\end{array}$ & $\mathbf{E}_{\text {DIN }}(\mathbf{M P a})$ & MOR (MPa) \\
\hline 1 & 10 & 502 & 6483 & 7117 & 7732 & 15,6 \\
\hline 2 & 9,2 & 417 & 5417 & 5726 & 6258 & 29,9 \\
\hline 4 & 9,5 & 502 & 9215 & 11395 & 12428 & 25,4 \\
\hline 10 & 12 & 566 & 9837 & 11356 & 12151 & 28,6 \\
\hline 13 & 11,7 & 484 & 10999 & 12831 & 13825 & 50,6 \\
\hline
\end{tabular}

Continua... 
\begin{tabular}{ccccccc}
\hline & Umidade & Densidade & MOE & $\mathbf{E}_{\text {MTG }}$ & & \\
CP & Aparente & E & & \\
& $(\%)$ & $(\mathrm{MPa})$ & $(\mathrm{MPa})$ & & MOR (MPa) \\
& $\left(\mathrm{Kg} / \mathrm{m}^{3}\right)$ & & & & \\
\hline
\end{tabular}

\begin{tabular}{|c|c|c|c|c|c|c|}
\hline & & & & & \multicolumn{2}{|c|}{ Continuação da tabela 16.} \\
\hline 14 & 8,8 & 415 & 6392 & 6576 & 7208 & 32,6 \\
\hline 15 & 10,7 & 479 & 5885 & 6724 & 7268 & 12,3 \\
\hline 24 & 8,6 & 530 & 8501 & 9602 & 10540 & 21,9 \\
\hline 35 & 8,8 & 396 & 7654 & 7099 & 7782 & 26,8 \\
\hline 37 & 9 & 421 & 8826 & 7418 & 8119 & 23,3 \\
\hline 42 & 12,1 & 515 & 6317 & 8204 & 8771 & 23,6 \\
\hline 43 & 10,9 & 532 & 7686 & 8864 & 9566 & 46,7 \\
\hline 46 & 8,6 & 442 & 6870 & 8112 & 8905 & 19,9 \\
\hline 47 & 8,9 & 425 & 6349 & 6829 & 7481 & 22,4 \\
\hline 57 & 8,9 & 532 & 8235 & 7031 & 7702 & 29,5 \\
\hline 59 & 8,4 & 394 & 6246 & 5250 & 5771 & 27,0 \\
\hline 61 & 9,3 & 459 & 5559 & 5631 & 6150 & 17,7 \\
\hline 72 & 9,6 & 440 & 5338 & 5087 & 5544 & 29,0 \\
\hline 80 & 8,1 & 419 & 6065 & 5814 & 6405 & 21,7 \\
\hline 81 & 9 & 476 & 6102 & 6935 & 7591 & 19,8 \\
\hline 84 & 9,4 & 463 & 7408 & 8828 & 9635 & 23,6 \\
\hline 87 & 7,5 & 493 & 6779 & 6033 & 6674 & 37,3 \\
\hline 96 & 11,6 & 542 & 8482 & 9575 & 10277 & 30,5 \\
\hline 99 & 9,4 & 519 & 9405 & 10957 & 11958 & 41,2 \\
\hline 100 & 8 & 442 & 6097 & 6163 & 6794 & 38,3 \\
\hline 103 & 9,5 & 494 & 4574 & 5057 & 5515 & 37,9 \\
\hline 107 & 7,7 & 408 & 4451 & 4804 & 5307 & 14,5 \\
\hline 108 & 9,6 & 527 & 7025 & 7393 & 8057 & 39,4 \\
\hline 109 & 8,3 & 439 & 4668 & 4911 & 5402 & 21,9 \\
\hline 112 & 8,2 & 456 & 7043 & 7951 & 8754 & 27,8 \\
\hline 114 & 9,3 & 453 & 6222 & 5529 & 6039 & 22,7 \\
\hline 117 & 9,2 & 460 & 7017 & 8679 & 9486 & 15,2 \\
\hline 120 & 9,5 & 484 & 4374 & 4529 & 4939 & 18,8 \\
\hline 125 & 9,5 & 610 & 12341 & 11395 & 12427 & 39,5 \\
\hline 132 & 8,8 & 472 & 3349 & 3845 & 4214 & 10,6 \\
\hline 136 & 8,6 & 580 & 7396 & 6664 & 7316 & 35,3 \\
\hline 139 & 9,5 & 541 & 5605 & 5607 & 6114 & 28,7 \\
\hline 140 & 8,4 & 448 & 5808 & 6418 & 7055 & 13,3 \\
\hline 145 & 8,8 & 286 & 3913 & 4248 & 4656 & 23,9 \\
\hline
\end{tabular}




\begin{tabular}{ccccccc}
\hline $\mathbf{C P}$ & $\begin{array}{c}\text { Umidade } \\
(\boldsymbol{\%})\end{array}$ & $\begin{array}{c}\text { Densidade } \\
\text { Aparente } \\
\left(\mathbf{K g} / \mathbf{m}^{\mathbf{3}}\right)\end{array}$ & $\begin{array}{c}\text { MOE } \\
(\mathbf{M P a})\end{array}$ & $\begin{array}{c}\mathbf{E}_{\mathbf{M T G}} \\
\mathbf{( M P a})\end{array}$ & $\mathbf{E}_{\mathbf{D I N}}(\mathbf{M P a})$ & MOR (MPa) \\
\hline & & & & & & \\
\hline 146 & 9,4 & 439 & 7828 & 6595 & 7198 & 23,3 \\
\hline 149 & 11,6 & 504 & 6439 & 6982 & 7495 & 24,9 \\
\hline 153 & 8 & 474 & 7794 & 6872 & 7576 & 29,9 \\
\hline 159 & 11 & 499 & 8225 & 8107 & 8742 & 29,7 \\
\hline 165 & 10,4 & 599 & 7941 & 8430 & 9132 & 32,6 \\
\hline 171 & 9 & 504 & 6644 & 6405 & 7010 & 30,6 \\
\hline 181 & 10,4 & 456 & 6133 & 5986 & 6485 & 27,7 \\
\hline 190 & 8,9 & 415 & 5518 & 6120 & 6704 & 19,8 \\
\hline 205 & 10,5 & 429 & 5741 & 6014 & 6510 & 26,1 \\
\hline 211 & 8,1 & 434 & 5673 & 5335 & 5877 & 32,6 \\
\hline 215 & 7,9 & 477 & 6179 & 7178 & 7919 & 12,4 \\
\hline 226 & 8,7 & 474 & 8158 & 8188 & 8982 & 35,3 \\
\hline 239 & 11,2 & 551 & 5486 & 8686 & 9352 & 30,0 \\
\hline 251 & 10,6 & 526 & 7126 & 9690 & 10481 & 25,5 \\
\hline 252 & 9,5 & 521 & 9857 & 8479 & 9248 & 36,8 \\
\hline 253 & 8,1 & 462 & 6981 & 7787 & 8579 & 29,4 \\
\hline 255 & 9,5 & 466 & 7325 & 7161 & 7809 & 23,5 \\
\hline & & & & & & \\
\hline
\end{tabular}




\section{ANÁLISE DOS RESULTADOS}

Neste item estão apresentadas as análises estatísticas nos resultados obtidos e as suas relações entre as diferentes propriedades estudadas para este lote de madeira. Para as análises foi utilizado o software R.

\subsection{ESTATÍSTICA DESCRITIVA}

As Tabelas 17 a 22 apresentam as estatísticas descritivas dos resultados obtidos para cada propriedade considerando o lote completo e cada uma das classes separadamente.

Tabela 17 - Estatística descritiva dos resultados de teor de umidade.

\begin{tabular}{lccccc}
\hline \multicolumn{1}{c}{ Umidade } & $\begin{array}{c}\text { Lote } \\
\text { Completo }\end{array}$ & SS & S1 & S2 & S3 \\
\hline Média (\%) & 9,5 & 9,7 & 9,4 & 9,2 & 9,4 \\
Erro padrão (\%) & 0,1 & 0,1 & 0,2 & 0,1 & 0,2 \\
Mediana (\%) & 9,3 & 9,4 & 9,2 & 9,2 & 9,3 \\
Desvio padrão (\%) & 1,1 & 1,3 & 1,0 & 0,8 & 1,1 \\
Mínimo (\%) & 7,1 & 7,9 & 7,1 & 7,5 & 7,5 \\
Máximo (\%) & 13,3 & 13,3 & 13,2 & 10,9 & 12,1 \\
\hline Coeficiente de Variação & $12 \%$ & $13 \%$ & $11 \%$ & $9 \%$ & $12 \%$ \\
Quantidade de peças & 213 & 72 & 43 & 42 & 56 \\
\hline
\end{tabular}

Tabela 18 - Estatística descritiva dos resultados de Densidade aparente à $12 \%$.

\begin{tabular}{lccccc}
\hline \multicolumn{1}{c}{ Densidade Aparente } & $\begin{array}{c}\text { Lote } \\
\text { Completo }\end{array}$ & SS & S1 & S2 & S3 \\
\hline Média $\left(\mathbf{k g f} / \mathbf{m}^{3}\right)$ & 484 & 502 & 479 & 468 & 477 \\
Erro padrão $\left(\mathbf{k g f} / \mathbf{m}^{3}\right)$ & 4 & 8 & 7 & 7 & 8 \\
Mediana $\left(\mathbf{k g f} / \mathbf{m}^{3}\right)$ & 477 & 496 & 481 & 460 & 474 \\
Desvio padrão $\left(\mathbf{k g f} / \mathbf{m}^{3}\right)$ & 59 & 70 & 46 & 43 & 57 \\
Mínimo $\left(\mathbf{k g f} / \mathbf{m}^{3}\right)$ & 286 & 340 & 387 & 378 & 286 \\
Máximo $\left(\mathbf{k g f} / \mathbf{m}^{\mathbf{3}}\right)$ & 727 & 727 & 572 & 579 & 610 \\
\hline Coeficiente de Variação & $12 \%$ & $14 \%$ & $10 \%$ & $9 \%$ & $12 \%$ \\
Quantidade de peças & 213 & 72 & 43 & 42 & 56 \\
\hline
\end{tabular}


Tabela 19 - Estatística descritiva dos resultados de Módulo de Elasticidade na flexão estática.

\begin{tabular}{lccccc}
\hline \multicolumn{1}{c}{ MOE } & $\begin{array}{c}\text { Lote } \\
\text { Completo }\end{array}$ & SS & S1 & S2 & S3 \\
\hline Média (MPa) & 7270 & 8250 & 7071 & 7019 & 6875 \\
Erro padrão (MPa) & 128 & 249 & 252 & 299 & 228 \\
Mediana (MPa) & 6985 & 7920 & 6994 & 6625 & 6564 \\
Desvio padrão (MPa) & 1960 & 2112 & 1652 & 1938 & 1709 \\
Mínimo (MPa) & 3183 & 4076 & 3183 & 3325 & 3349 \\
Máximo (MPa) & 14728 & 14728 & 10715 & 14366 & 12341 \\
\hline Coeficiente de Variação & $27 \%$ & $26 \%$ & $23 \%$ & $28 \%$ & $25 \%$ \\
Quantidade de peças & 213 & 72 & 43 & 42 & 56 \\
\hline
\end{tabular}

Tabela 20 - Estatística descritiva dos resultados de Módulo de Elasticidade obtido pelo MTG.

\begin{tabular}{lccccc}
\hline \multicolumn{1}{c}{ E } & Lote Completo & SS & S1 & S2 & S3 \\
\hline Média (MPa) & 7558 & 8611 & 7214 & 7162 & 7254 \\
Erro padrão (MPa) & 143 & 293 & 284 & 322 & 261 \\
Mediana (MPa) & 7137 & 7924 & 7181 & 6770 & 6959 \\
Desvio padrão (MPa) & 2203 & 2489 & 1861 & 2084 & 1950 \\
Mínimo (MPa) & 3432 & 3769 & 3541 & 3432 & 3845 \\
Máximo (MPa) & 16006 & 15999 & 12545 & 16006 & 12831 \\
\hline Coeficiente de Variação & $29 \%$ & $29 \%$ & $26 \%$ & $29 \%$ & $27 \%$ \\
Quantidade de peças & 213 & 72 & 43 & 42 & 56 \\
\hline
\end{tabular}

Tabela 21 - Estatística descritiva dos resultados de MOE Dinâmico.

\begin{tabular}{lccccc}
\hline \multicolumn{1}{c}{ E $_{\text {DIN }}$} & Lote completo & SS & S1 & S2 & S3 \\
\hline Média (MPa) & 8235 & 9354 & 7870 & 7814 & 7909 \\
Erro padrão (MPa) & 153 & 310 & 305 & 347 & 280 \\
Mediana (MPa) & 7757 & 8684 & 7873 & 7425 & 7583 \\
Desvio padrão (MPa) & 2353 & 2633 & 2001 & 2252 & 2093 \\
Mínimo (MPa) & 3754 & 4135 & 3876 & 3754 & 4214 \\
Máximo (MPa) & 17273 & 17239 & 13630 & 17273 & 13825 \\
\hline Coeficiente de Variação & $29 \%$ & $28 \%$ & $25 \%$ & $29 \%$ & $26 \%$ \\
Quantidade de peças & 213 & 72 & 43 & 42 & 56 \\
\hline
\end{tabular}

Tabela 22 - Estatística descritiva dos resultados de MOR.

\begin{tabular}{lccccc}
\hline \multicolumn{1}{c}{ MOR } & Lote Completo & SS & S1 & S2 & S3 \\
\hline Média (MPa) & 30,9 & 40,8 & 29,3 & 27,0 & 27,1 \\
Erro padrão (MPa) & 0,9 & 2,1 & 1,3 & 1,7 & 1,1 \\
Mediana (MPa) & 28,6 & 37,2 & 28,0 & 25,1 & 26,9 \\
Desvio padrão (MPa) & 14,1 & 17,4 & 8,8 & 11,1 & 8,6 \\
Mínimo (MPa) & 4,1 & 13,6 & 13,8 & 4,1 & 10,6 \\
Máximo (MPa) & 88,8 & 88,8 & 46,7 & 57,4 & 50,6 \\
\hline Coeficiente de Variação & $46 \%$ & $43 \%$ & $30 \%$ & $41 \%$ & $32 \%$ \\
Quantidade de peças & 213 & 72 & 43 & 42 & 56 \\
\hline
\end{tabular}




\subsection{FATOR DE CORREÇÃO ENTRE O E EIN E O E ETG}

O aparelho MTG calcula por meio da frequência natural o módulo de elasticidade dinâmico, $\mathrm{E}_{\mathrm{DIN}}$, e o software interno reduz os valores dinâmicos, em função da espécie, resultando no valor do $\mathrm{E}_{\mathrm{MTG}}$.

Tabela 23 - Correção do MTG em relação ao MOE estático.

\begin{tabular}{cccccc}
\hline \multirow{2}{*}{ Classe Visual } & $\mathbf{E}_{\text {DIN }}(\mathbf{M P a})$ & $\begin{array}{c}\text { Relação ao } \\
\text { MOE }\end{array}$ & $\mathbf{E}_{\text {MTG }}(\mathbf{M P a})$ & Relação ao & $\begin{array}{c}\text { Fator de } \\
\text { correção }\end{array}$ \\
\hline Lote completo & $\mathbf{8 2 3 5}$ & $\mathbf{+ 1 3 , 2 7 \%}$ & $\mathbf{7 5 5 8}$ & $\mathbf{+ 3 , 9 6 \%}$ & $\mathbf{0 , 9 1 7 8}$ \\
SS & 9354 & $+13,38 \%$ & 8611 & $+4,38 \%$ & 0,9206 \\
S1 & 7870 & $+11,30 \%$ & 7214 & $+2,02 \%$ & 0,9166 \\
S2 & 7814 & $+11,33 \%$ & 7162 & $+2,04 \%$ & 0,9166 \\
S3 & 7909 & $+15,04 \%$ & 6875 & $+5,51 \%$ & 0,9172 \\
\hline
\end{tabular}

A Tabela 23 apresenta os valores de $\mathrm{E}_{\mathrm{DIN}}$, que foram superiores aos valores do MOE na flexão estática. O software do MTG multiplica $E_{D I N}$ por um fator de correção, que variou de 0,9166 à 0,9206, determinando os valores do $\mathrm{E}_{\mathrm{MTG}}$, para a espécie Pinus elliottii, os valores do $\mathrm{E}_{\mathrm{MTG}}$ são mais próximos aos valores do MOE.

\subsection{VALORES CARACTERÍSTICOS DO MOE E DO MOR}

Foram determinados os valores característicos do Módulo de Elasticidade (MOE) e da resistência (MOR) na flexão estática, de acordo com a formulação da norma NBR 7190/1997, para o lote completo e para cada classe visual.

A Figura 22 apresenta os valores característicos obtidos para o MOE na flexão estática. 


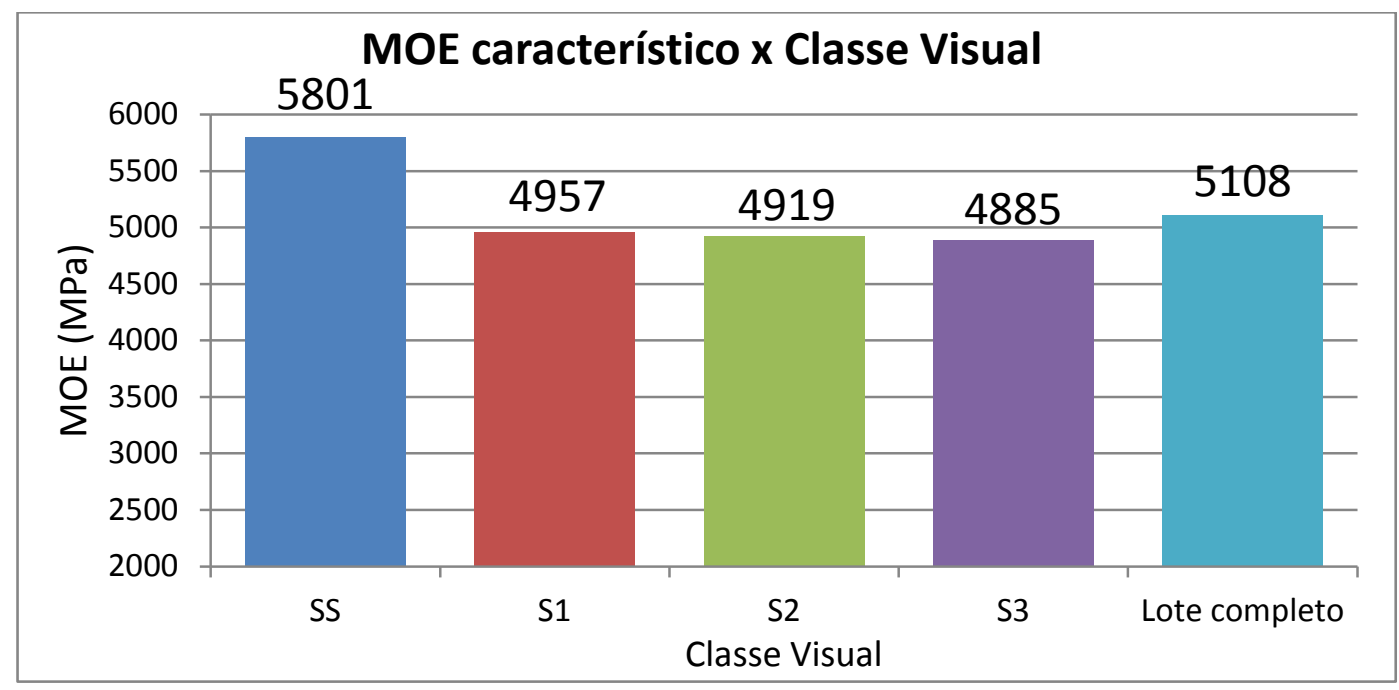

Figura 22 - Valores Característicos de MOE de acordo com a NBR7190.

O Módulo de Elasticidade (MOE) característico na flexão estática à $12 \%$ de umidade, apresentou valor para o lote completo foi de $5108 \mathrm{MPa}$. A classe SS apresentou o maior valor, com $5801 \mathrm{MPa}, 13,6 \%$ acima do valor do lote completo. As classes S1, S2 e S3 apresentaram valores iguais a $4957 \mathrm{MPa}(-3,0 \%), 4919 \mathrm{MPa}(-3,7 \%)$ e $4885 \mathrm{MPa}(-4,4 \%)$ respectivamente. Os valores de MOE entre as classes S1, S2 e S3 foram próximos. Os valores médios do MOE na flexão estática, estão abaixo do valor para classe de resistência para coníferas C25 (8500 MPa) da NBR7190, com as peças sendo enquadradas na classe C20 $(3500 \mathrm{MPa})$.

A Figura 23 apresenta os valores característicos da resistência à flexão (MOR) para cada uma das diferentes classes visuais e para o lote completo.

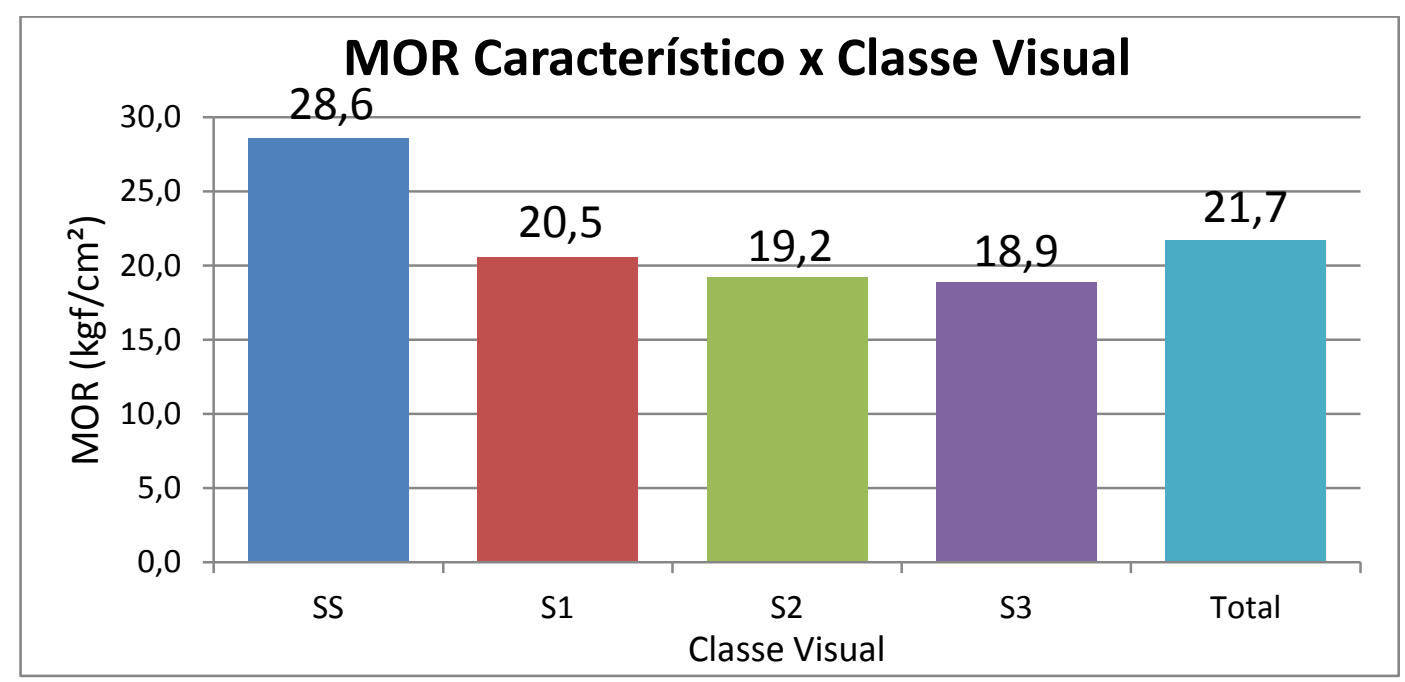

Figura 23 - Valores Característicos de MOR de acordo com a NBR7190. 
A resistência à flexão (MOR) para o lote completo foi $21,7 \mathrm{MPa}$. A classe SS apresentou o maior valor $28,6 \mathrm{MPa}, 31,8 \%$ acima do valor do lote completo. As classes S1, S2 e S3 apresentaram valores de 20,5 MPa (-5,5\%), 19,2 MPa (-11,5\%) e 18,9 MPa (-12,9\%) respectivamente.

Todas as classes apresentaram valores próximos de densidade. Para os valores característicos de MOE e MOR, a classe SS apresentou melhores resultados. A variação dos valores característicos das propriedades entre as classes S1, S2 e S3 foi pequena, indicando que a junção dessas classes não teria influência significativa, para o lote avaliado.

\subsection{CORRELAÇÃO ENTRE O E}

Para a análise comparativa entre os dados do módulo de elasticidade obtido com o MTG, $\mathrm{E}_{\mathrm{MTG}}$, e o módulo de elasticidade obtido pelo ensaio estático, MOE, foi utilizado o modelo de regressão linear simples, sendo o MOE a variável independente $(x)$, como variável dependente $(y)$ foi adotado o $\mathrm{E}_{\mathrm{MTG}}$.

Para a utilização do modelo de regressão linear simples, é necessário que sejam satisfeitas as seguintes condições:

1) A média dos erros $\left(\varepsilon_{i}\right)$ é igual a zero e a variância $\sigma^{2}$ é desconhecida e constante, para $1 \leq i \leq n$.

2) Para, $i \neq j$, $\varepsilon_{\mathrm{i}}$ e $\varepsilon_{\mathrm{j}}$ não devem ser correlacionados, ou seja, $\operatorname{COV}\left(\varepsilon_{\mathrm{i}} ; \varepsilon_{\mathrm{j}}\right)=0$, para $i \neq j, i \leq 1$ e $j \leq \mathrm{n}$.

3) A distribuição dos $\varepsilon_{\mathrm{i}}$ é normal, para $1 \leq i \leq n$.

A relação entre as variáveis $x$ e $y$ é representada por uma reta de tipo:

$$
y\left(x_{i}\right)=\propto+\beta\left(x_{i}\right)+\varepsilon_{i}
$$

Onde:

$y=$ Variável resposta dependente;

$x_{i}=$ Variável independente da observação $i$;

$\alpha=$ constante;

$\beta=$ Coeficiente angular;

$\varepsilon_{i}=$ Resíduo das variações de $y$ não explicadas pela variação de $x$. 
A análise foi feita determinando a equação da regressão linear, o coeficiente de correlação e analisando os resíduos, para verificar o atendimento dos requisitos. Após, foi feita a análise da variância para verificar a condição do modelo ajustado.

\subsubsection{Lote completo}

A Figura 24 apresenta o diagrama de dispersão e a regressão entre o $E_{\text {MTG }} \mathrm{e} o$ MOE, para os dados do lote completo.

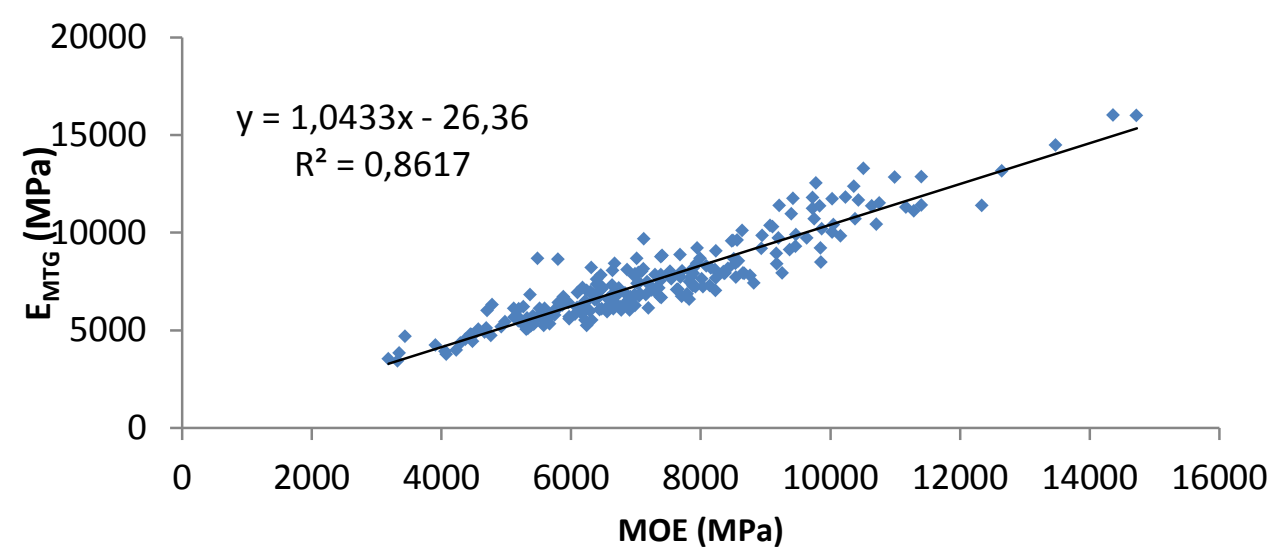

Figura 24 - Diagrama de dispersão e reta de regressão entre o MOE e o $\mathrm{E}_{\mathrm{MTG}}$ do lote completo.

A Figura 25 apresenta o gráfico dos resíduos em função dos valores estimados para o $\mathrm{E}_{\mathrm{MTG}}$, podendo ser observada a homogeneidade da variância.

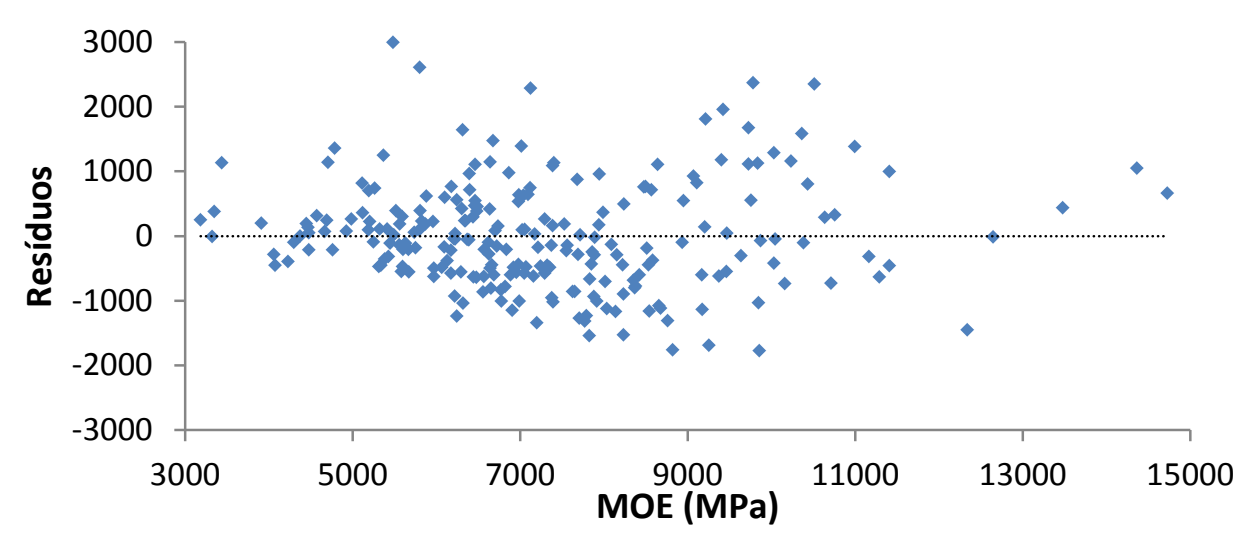

Figura 25 - Gráfico dos resíduos contra valores estimados para o MOE do lote completo.

A Figura 26 apresenta o gráfico dos resíduos padronizados contra os escores normais, observando-se, aproximadamente uma distribuição normal. 


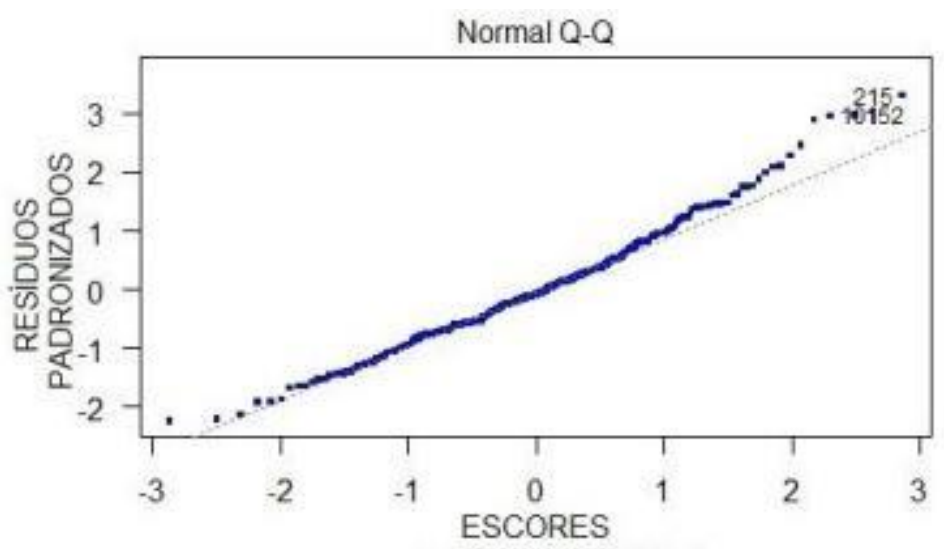

Figura 26 - Gráfico de probabilidade normal dos resíduos para o $\mathrm{E}_{\mathrm{MTG}}$ do lote completo.

Atendidas as suposições da regressão, a Tabela 24 apresenta os resultados da análise de variância.

Tabela 24 - Quadro de ANOVA ( $\left.\mathrm{E}_{\mathrm{MTG}} \mathrm{x} \mathrm{MOE}\right)$ - lote completo.

\begin{tabular}{lccccc}
\hline & gl & SQ & MQ & F & Valor-P \\
\hline Regressão & 1 & $9,829 \mathrm{E}+08$ & $9,829 \mathrm{E}+08$ & 1457,6 & 0,0000 \\
Resíduo & 211 & $1,578 \mathrm{E}+08$ & 674331 & & \\
Total & 212 & $1,141 \mathrm{E}+09$ & & & \\
\hline
\end{tabular}

Para os graus de liberdade $(1,211)$, o valor de F, a um nível de significância de $\alpha=0,05$ é 3,86. Como o valor calculado de $\mathrm{F}$ é igual a 1457,6 , pode-se concluir que existe evidência estatística de que a proporção da variância total explicada pela regressão é altamente significativa. Assim, o modelo de regressão linear dado por $\left\{E_{M T G}(M P a)=\right.$ $\left.1,0433 \cdot M O E_{E}(M P a)-26,36\right\}$ é adequado.

\subsubsection{Classe Visual SS}

A Figura 27 apresenta o diagrama de dispersão e a regressão entre o $E_{\text {MTG }}$ e o MOE obtido pela flexão estática, para os dados da Classe Visual SS. 


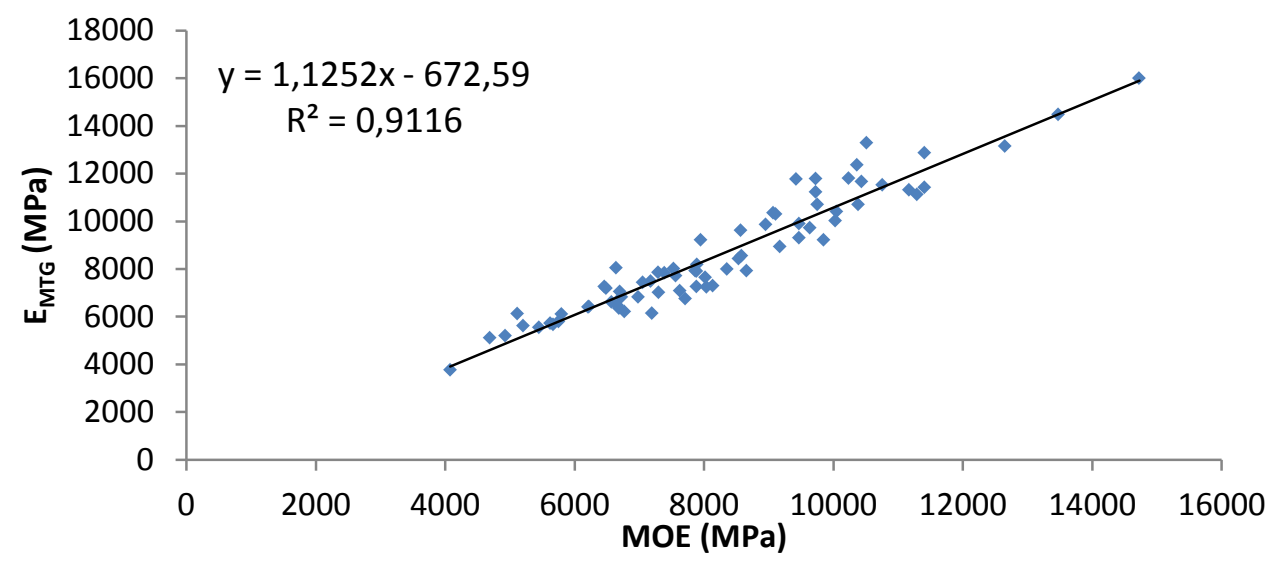

Figura 27 - Diagrama dispersão e reta de regressão entre o MOE e o $\mathrm{E}_{\mathrm{MTG}}$ da Classe SS.

A Figura 28 apresenta o gráfico dos resíduos contra os valores estimados para o MOE MTG, onde pode ser observada a homogeneidade da variância.

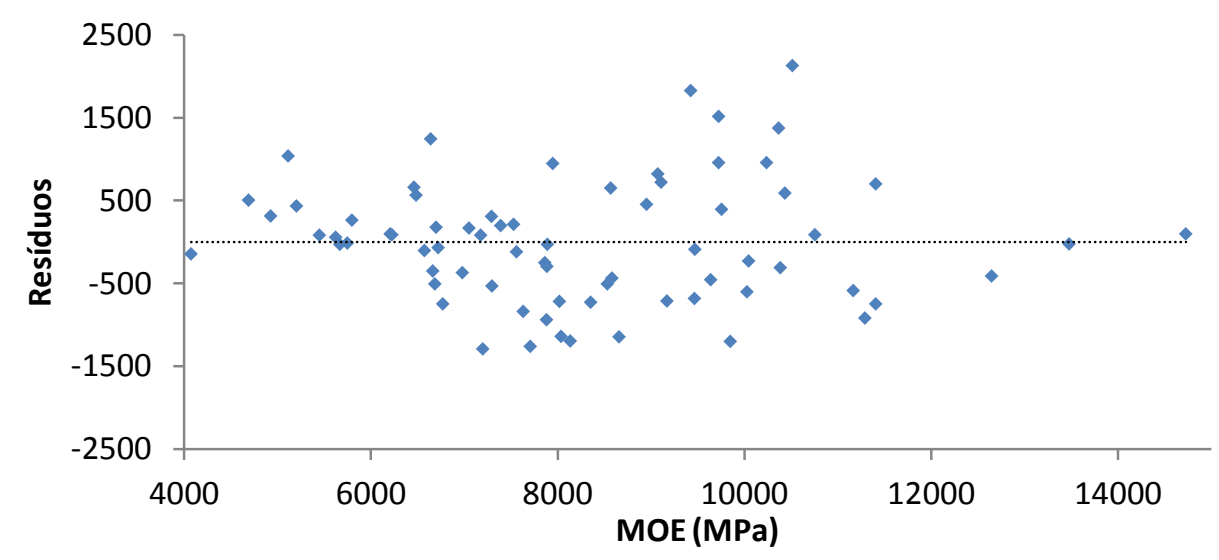

Figura 28 - Gráfico dos resíduos contra valores estimados para o $\mathrm{E}_{\mathrm{MTG}}$ - Classe SS

A Figura 29 apresenta o gráfico dos resíduos padronizados contra os escores normais, observando-se, aproximadamente, uma distribuição normal.

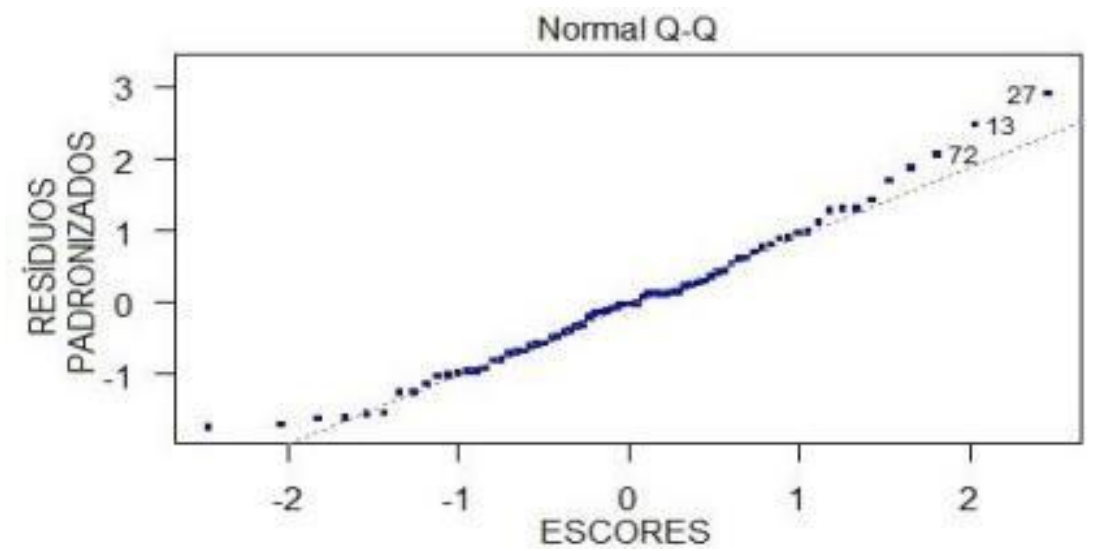

Figura 29 - Gráfico de probabilidade normal dos resíduos para o $\mathrm{E}_{\mathrm{MTG}}$ da Classe SS. 
Atendidas as suposições da regressão, a Tabela 25 apresenta os resultados da análise de variância.

Tabela 25- Quadro de ANOVA (E $\left.\mathrm{E}_{\mathrm{MTG}} \mathrm{x} \mathrm{MOE}\right)$ - classe SS.

\begin{tabular}{lccccc}
\hline & gl & SQ & MQ & F & Valor-P \\
\hline Regressão & 1 & $4,010 \mathrm{E}+08$ & $4,010 \mathrm{E}+08$ & 721,9 & 0,0000 \\
Resíduo & 70 & $3,888 \mathrm{E}+07$ & 555436 & & \\
Total & 71 & $4,399 \mathrm{E}+08$ & & & \\
\hline
\end{tabular}

Para os graus de liberdade (1,70), o valor de F, a um nível de significância de $\alpha=0,05$ é 3,90. Como o valor calculado de $\mathrm{F}$ é igual a 721,9 , pode-se concluir que existe evidência estatística de que a proporção da variância total explicada pela regressão é altamente significativa. Assim, o modelo de regressão linear dado por $\left\{E_{M T G}(M P a)=1,1252\right.$ - $M O E(M P a)-672,59\}$ é adequado.

\subsubsection{Classe Visual S1}

A Figura 30 apresenta o diagrama de dispersão e a regressão entre o $E_{\text {MTG }}$ e $o$ MOE, para os dados da Classe Visual S1.

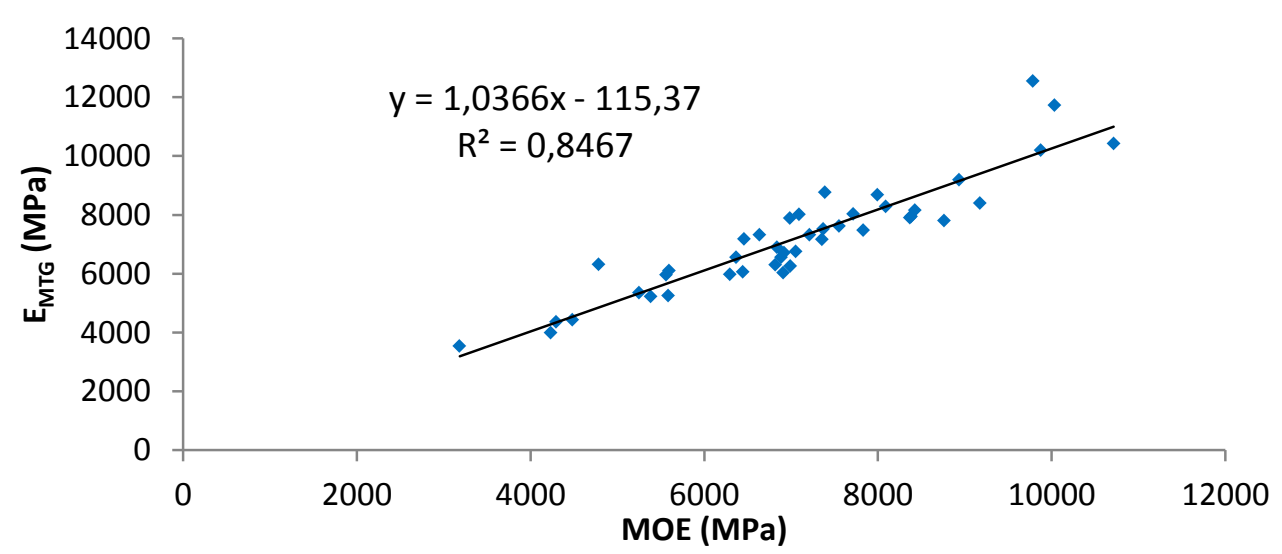

Figura 30 - Diagrama dispersão e reta de regressão entre o MOE estático e o $\mathrm{E}_{\mathrm{MTG}}$ da Classe S1.

A Figura 31 apresenta o gráfico dos resíduos em função dos valores estimados para o $\mathrm{E}_{\mathrm{MTG}}$, podendo ser observada a homogeneidade da variância. 


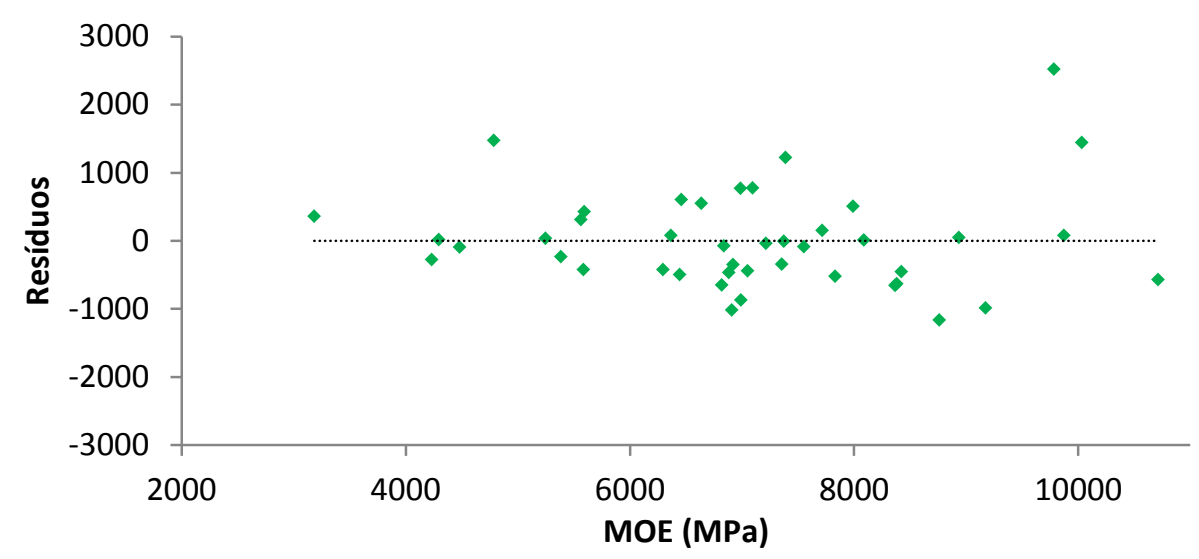

Figura 31 - Gráfico dos resíduos contra valores estimados para o $\mathrm{E}_{\mathrm{MTG}}$ - Classe S1

A Figura 32 apresenta o gráfico dos resíduos padronizados contra os escores normais, observando-se, aproximadamente uma distribuição normal.

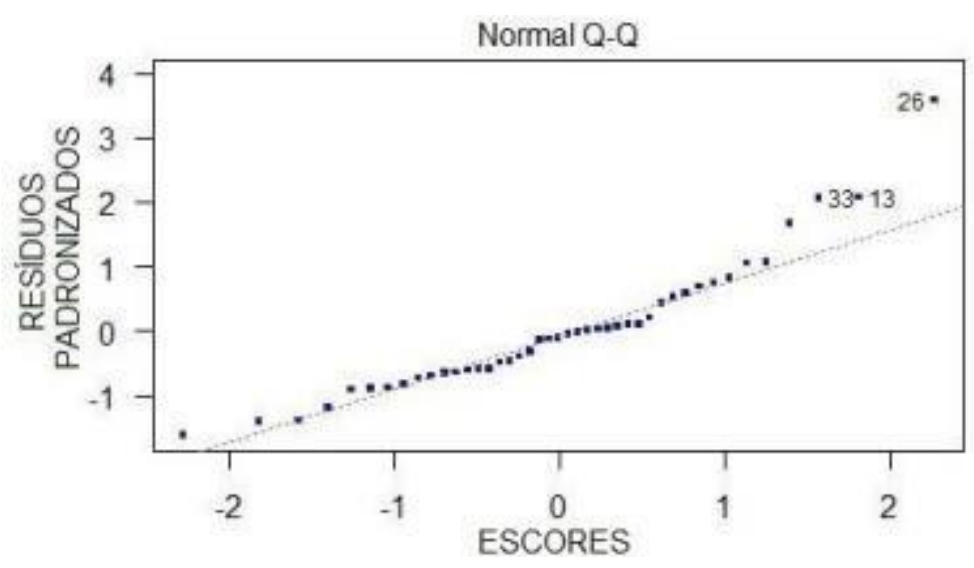

Figura 32 - Gráfico de probabilidade normal dos resíduos para o $\mathrm{E}_{\mathrm{MTG}}$ da Classe S1.

Atendidas as suposições da regressão, a Tabela 26 apresenta os resultados da análise de variância.

Tabela 26- Quadro de ANOVA ( $\mathrm{E}_{\mathrm{MTG}} \mathrm{x}$ MOE) - classe S1.

\begin{tabular}{lccccc}
\hline & gl & SQ & MQ & F & Valor-P \\
\hline Regressão & 1 & $1,231 \mathrm{E}+08$ & $4,010 \mathrm{E}+08$ & 226,5 & 0,0000 \\
Resíduo & 41 & $2,228 \mathrm{E}+07$ & 543500 & & \\
Total & 42 & $1,454 \mathrm{E}+08$ & & & \\
\hline
\end{tabular}

Para os graus de liberdade $(1,41)$, o valor de F, a um nível de significância de $\alpha=0,05$ é 3,95. Como o valor calculado de $\mathrm{F}$ é igual a 226,5, pode-se concluir que existe evidência estatística de que a proporção da variância total explicada pela regressão é altamente significativa. Assim, o modelo de regressão linear dado por $\left\{E_{M T G}(M P a)=1,0366\right.$ - $M O E(M P a)-115,37\}$ é adequado. 


\subsubsection{Classe Visual S2}

A Figura 33 apresenta o diagrama de dispersão e a regressão entre o $E_{M T G}$ e o MOE, para os dados da Classe Visual S2.

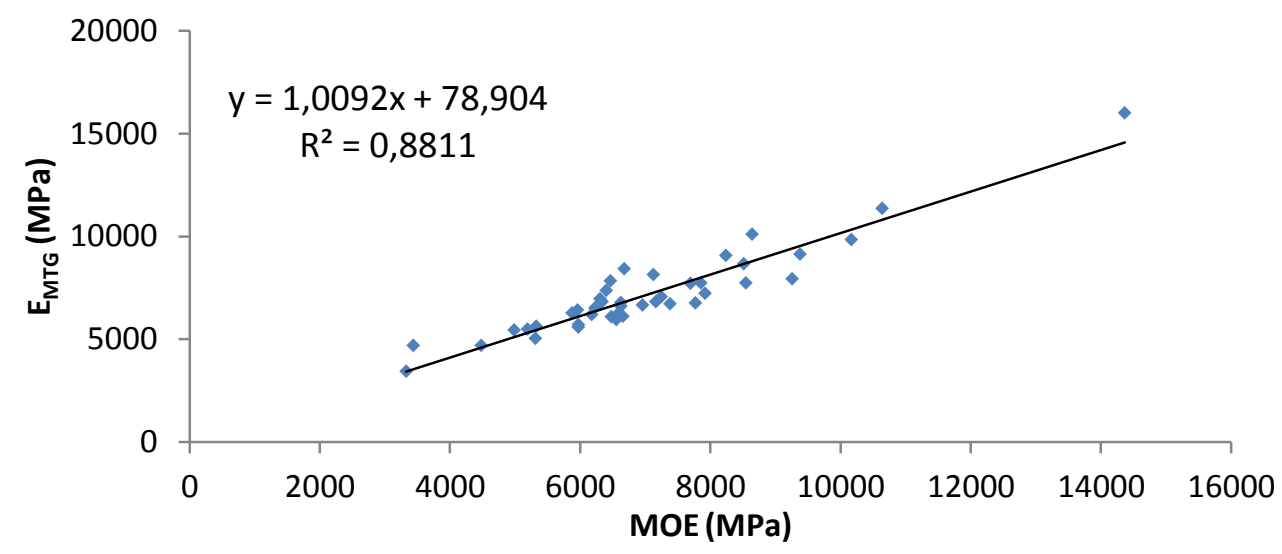

Figura 33 - Diagrama dispersão e reta de regressão entre o MOE e o $\mathrm{E}_{\mathrm{MTG}}$ da Classe $\mathrm{S} 2$.

A Figura 34 apresenta o gráfico dos resíduos em função dos valores estimados para o $\mathrm{E}_{\mathrm{MTG}}$, podendo ser observada a homogeneidade da variância.

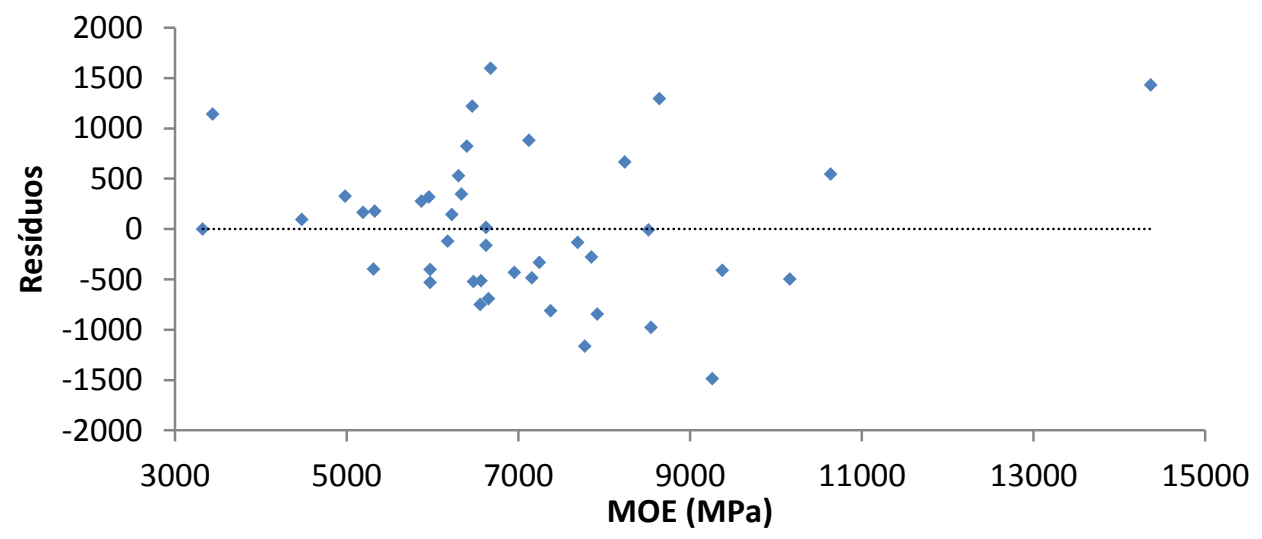

Figura 34 - Gráfico dos resíduos contra valores estimados para o $\mathrm{E}_{\mathrm{MTG}}$ - Classe S2.

A Figura 35 apresenta o gráfico dos resíduos padronizados contra os escores normais, observando-se, aproximadamente, uma distribuição normal. 


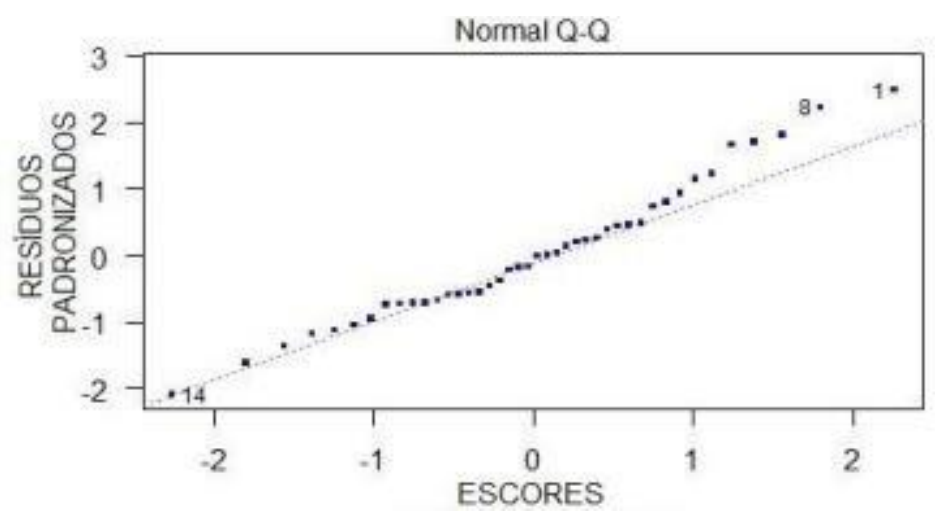

Figura 35 - Gráfico de probabilidade normal dos resíduos para o $\mathrm{E}_{\mathrm{MTG}}$ da Classe S2.

Atendidas as suposições da regressão, a Tabela 27 apresenta os resultados da análise de variância.

Tabela 27 - Quadro de ANOVA (E $\mathrm{E}_{\mathrm{MTG}}$ x MOE) - classe S2.

\begin{tabular}{lccccc}
\hline & gl & SQ & MQ & F & Valor-P \\
\hline Regressão & 1 & $1,569 \mathrm{E}+08$ & $1,569 \mathrm{E}+08$ & 296,4 & 0,0000 \\
Resíduo & 40 & $2,117 \mathrm{E}+07$ & 529354 & & \\
Total & 41 & $1,781 \mathrm{E}+08$ & & & \\
\hline
\end{tabular}

Para os graus de liberdade $(1,40)$, o valor de F, a um nível de significância de $\alpha=0,05$ é 3,96. Como o valor calculado de F é igual a 296,4 , pode-se concluir que existe evidência estatística de que a proporção da variância total explicada pela regressão é altamente significativa. Assim, o modelo de regressão linear dado por $\left\{E_{M T G}(M P a)=1,0092\right.$ $\cdot \operatorname{MOE}(\mathrm{MPa})+78,904\}$ é adequado.

\subsubsection{Classe Visual S3}

A Figura 36 apresenta o diagrama de dispersão e a regressão entre o $E_{\text {MTG }}$ e o MOE, para os dados da Classe Visual S3.

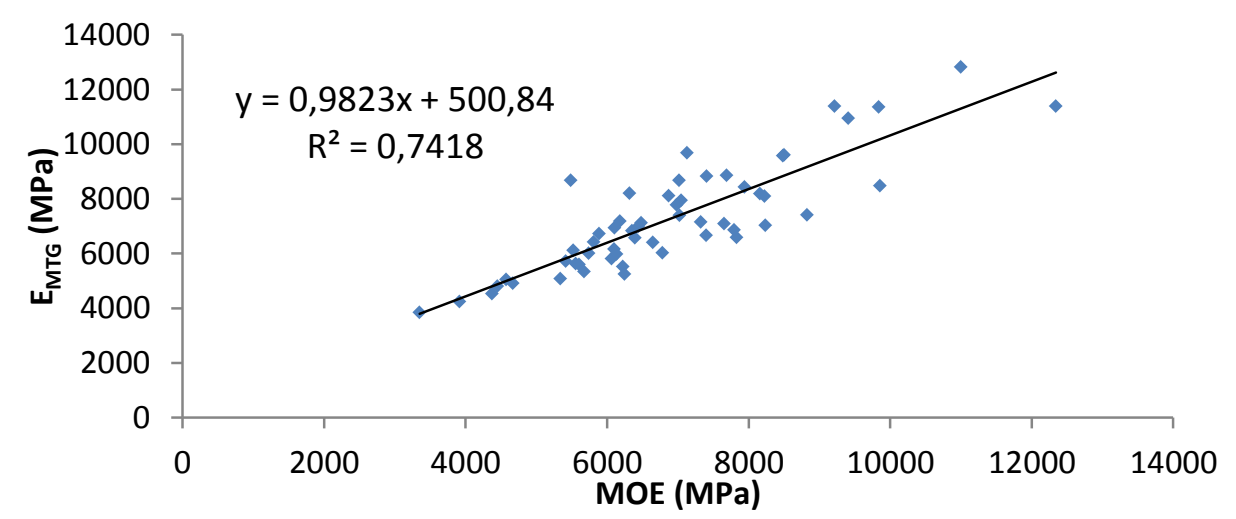

Figura 36 - Diagrama dispersão e reta de regressão entre o MOE e o $\mathrm{E}_{\mathrm{MTG}}$ da Classe S3. 
A Figura 37 apresenta o gráfico dos resíduos em função dos valores estimados para o $\mathrm{E}_{\mathrm{MTG}}$, podendo ser observada a homogeneidade da variância.

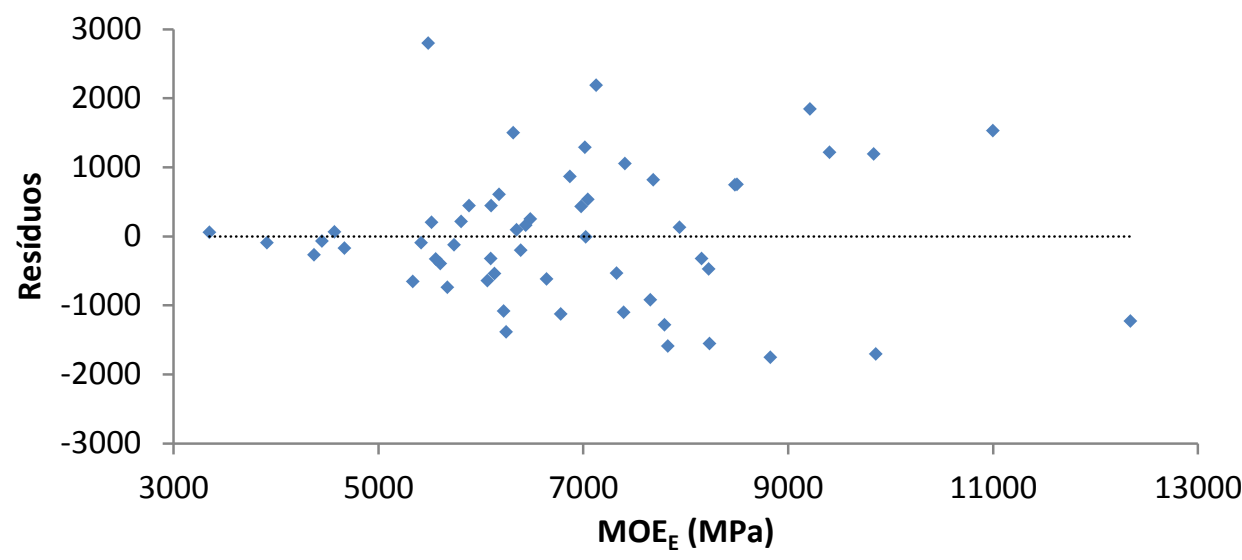

Figura 37 - Gráfico dos resíduos contra valores estimados para o $\mathrm{E}_{\mathrm{MTG}}$ - Classe S3

A Figura 38 apresenta o gráfico dos resíduos padronizados contra os escores normais, observando-se, aproximadamente, uma distribuição normal.

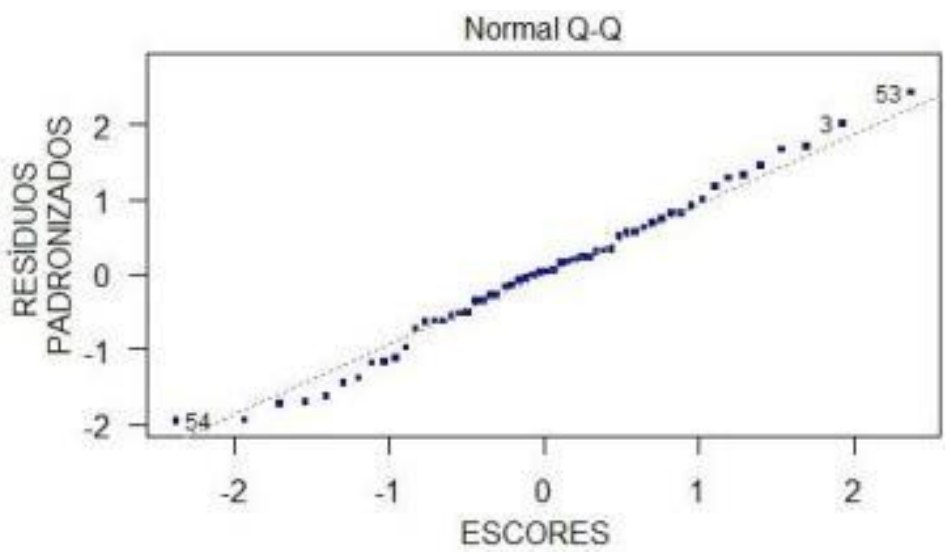

Figura 38 - Gráfico de probabilidade normal dos resíduos para o $\mathrm{E}_{\mathrm{MTG}}$ da Classe S3.

Atendidas as suposições da regressão, a Tabela 28 apresenta os resultados da análise de variância.

Tabela 28 - Quadro de ANOVA ( $\mathrm{E}_{\mathrm{MTG}} \mathrm{x}$ MOE) - classe S3.

\begin{tabular}{lccccc}
\hline & gl & SQ & MQ & F & Valor-P \\
\hline Regressão & 1 & $1,551 \mathrm{E}+08$ & $1,551 \mathrm{E}+08$ & 155,1 & 0,0000 \\
Resíduo & 54 & $5,398 \mathrm{E}+07$ & 543500 & & \\
Total & 55 & $2,091 \mathrm{E}+08$ & & & \\
\hline
\end{tabular}

Para os graus de liberdade $(1,54)$, o valor de F, a um nível de significância de $\alpha=0,05$ é 3,93. Como o valor calculado de $\mathrm{F}$ é igual a 155,1 , pode-se concluir que existe evidência estatística de que a proporção da variância total explicada pela regressão é 
altamente significativa. Assim, o modelo de regressão linear dado por $\left\{E_{M T G}(M P a)=0,9823\right.$ $\cdot \operatorname{MOE}(M P a)+500,84\}$ é adequado.

\subsubsection{Resumo das Correlações $\mathrm{E}_{\mathrm{MTG}} \mathrm{x} \mathrm{MOE}$}

A Tabela 29 apresenta o resumo dos valores das correlações da regressão linear entre o $\mathrm{E}_{\mathrm{MTG}}$ e o MOE na flexão estática para as diferentes classes de madeira.

Tabela 29 - Correlação da regressão linear entre o $\mathrm{E}_{\mathrm{MTG}}$ e o MOE.

\begin{tabular}{ccc}
\hline & Correlação do E $\mathbf{M}_{\mathbf{M T G}}$ com o MOE & \\
\hline Classe & Coeficiente de Correlação & Equação \\
Lote Completo & 0,86 & $1,0433$. MOE-26,36 \\
SS & 0,91 & $1,1252$. MOE-672,59 \\
S1 & 0,85 & $1,0366$. MOE-115,37 \\
S2 & 0,88 & $1,0092$. MOE+78,904 \\
S3 & 0,74 & $0,9823$. MOE+500,84 \\
\hline
\end{tabular}

Os valores de $\mathrm{E}_{\mathrm{MTG}}$, após a aproximação definida pelo software do aparelho MTG, em função da espécie estudada, apresentaram boas correlações com o MOE na flexão estática. Foi observada uma maior correlação da regressão linear nas peças com menor incidência de defeitos, classe visual SS. A presença dos defeitos naturais nas classes S1, S2 e S3, afetaram negativamente a correlação entre as propriedades.

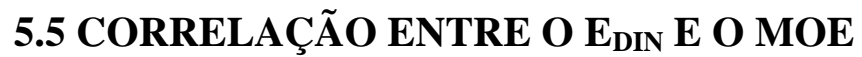

Para a análise comparativa entre os dados do módulo de elasticidade dinâmico, $\mathrm{E}_{\mathrm{DIN}}$, obtido pela frequência natural da vibração longitudinal e o módulo de elasticidade obtido pelo ensaio de flexão estática, MOE, foi utilizado o modelo de regressão linear simples, sendo o MOE a variável independente $(x)$, como variável dependente $(y)$ foi adotado o $\mathrm{E}_{\mathrm{DIN}}$.

A análise foi feita determinando a equação da regressão linear, o coeficiente de correlação analisando os resíduos, para verificar o atendimento dos requisitos. Após, foi feita análise da variância para verificar a condição do modelo ajustado. 


\subsubsection{Lote completo}

A Figura 39 apresenta o diagrama de dispersão e a regressão entre o $E_{\text {DIN }}$ e o MOE, para os dados do lote completo.

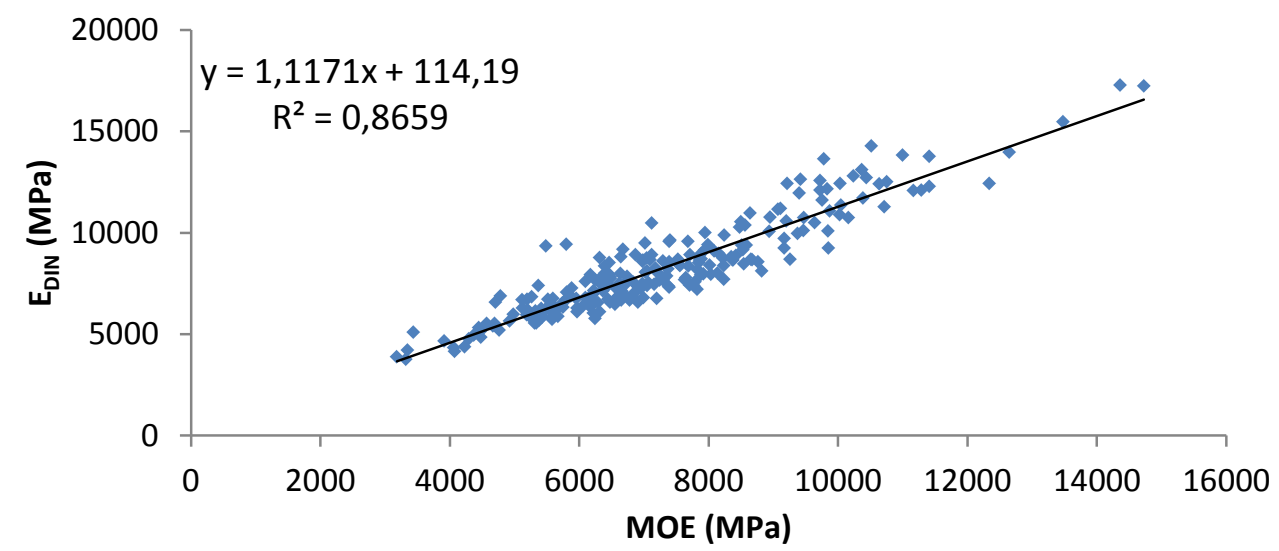

Figura 39 - Diagrama de dispersão e reta de regressão entre o MOE e o $\mathrm{E}_{\mathrm{DIN}}$ do lote completo.

A Figura 40 apresenta o gráfico dos resíduos em função dos valores estimados para o $\mathrm{E}_{\mathrm{DIN}}$, podendo ser observada a homogeneidade da variância.

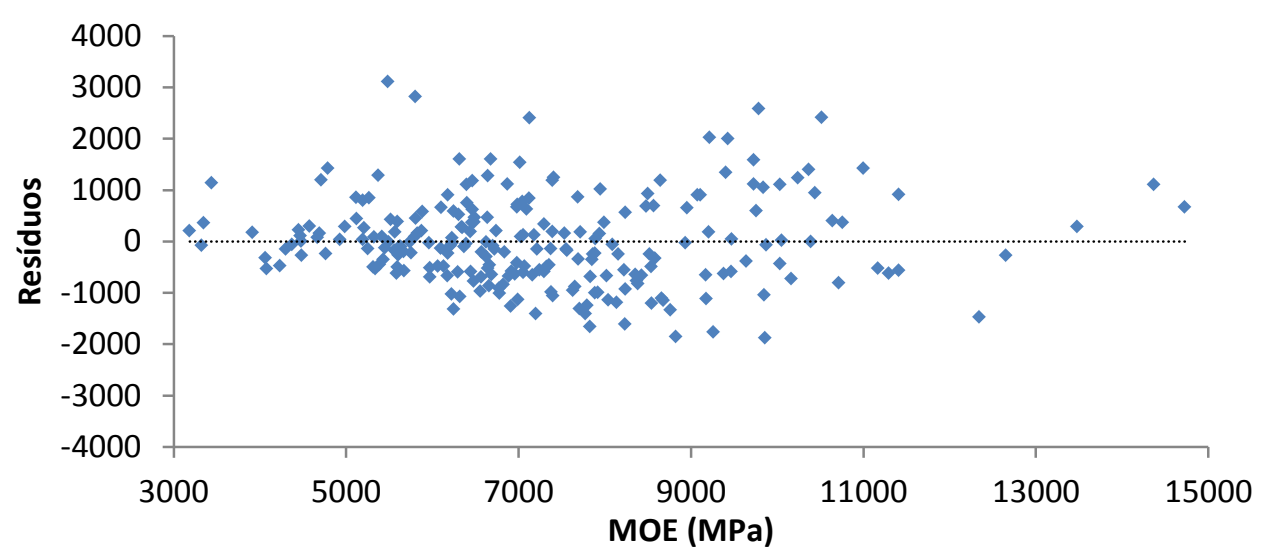

Figura 40 - Gráfico dos resíduos contra valores estimados para o $\mathrm{E}_{\mathrm{DIN}}$ para o lote completo.

A Figura 41 apresenta o gráfico dos resíduos padronizados contra os escores normais, observando-se, aproximadamente, uma distribuição normal. 


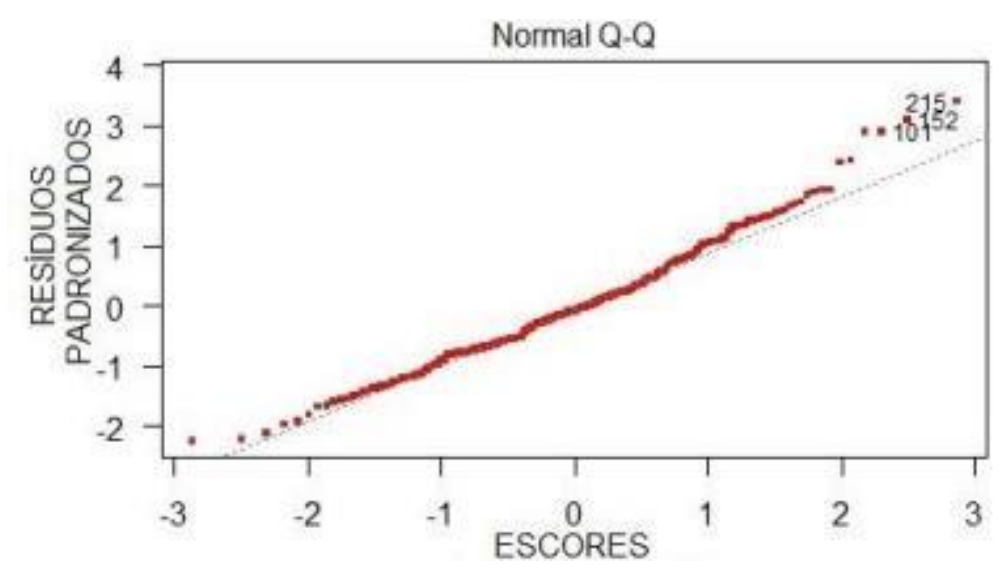

Figura 41 - Gráfico de probabilidade normal dos resíduos para o $\mathrm{E}_{\mathrm{DIN}}$ do lote completo.

Atendidas as suposições da regressão, a Tabela 30 apresenta os resultados da análise de variância.

Tabela 30 - Quadro de ANOVA ( $\left.\mathrm{E}_{\mathrm{DIN}} \mathrm{x} \mathrm{MOE}\right)$ - lote completo.

\begin{tabular}{lccccc}
\hline & gl & SQ & MQ & F & Valor-P \\
\hline Regressão & 1 & $1,127 \mathrm{E}+09$ & $9,829 \mathrm{E}+08$ & 1511,5 & 0,0000 \\
Resíduo & 211 & $1,744 \mathrm{E}+08$ & 674331 & & \\
Total & 212 & $1,301 \mathrm{E}+09$ & & & \\
\hline
\end{tabular}

Para os graus de liberdade $(1,211)$, o valor de F, a um nível de significância de $\alpha=0,05$ é 3,86. Como o valor calculado de F é igual a 1511,5, pode-se concluir que existe evidência estatística de que a proporção da variância total explicada pela regressão é altamente significativa. Assim, o modelo de regressão linear dado por $\left\{E_{D I N}(M P a)=1,1171\right.$. $\operatorname{MOE}(M P a)+114,19\}$ é adequado.

\subsubsection{Classe Visual SS}

A Figura 42 apresenta o diagrama de dispersão e a regressão entre o $E_{\text {DIN }}$ e o MOE, para os dados da classe SS. 


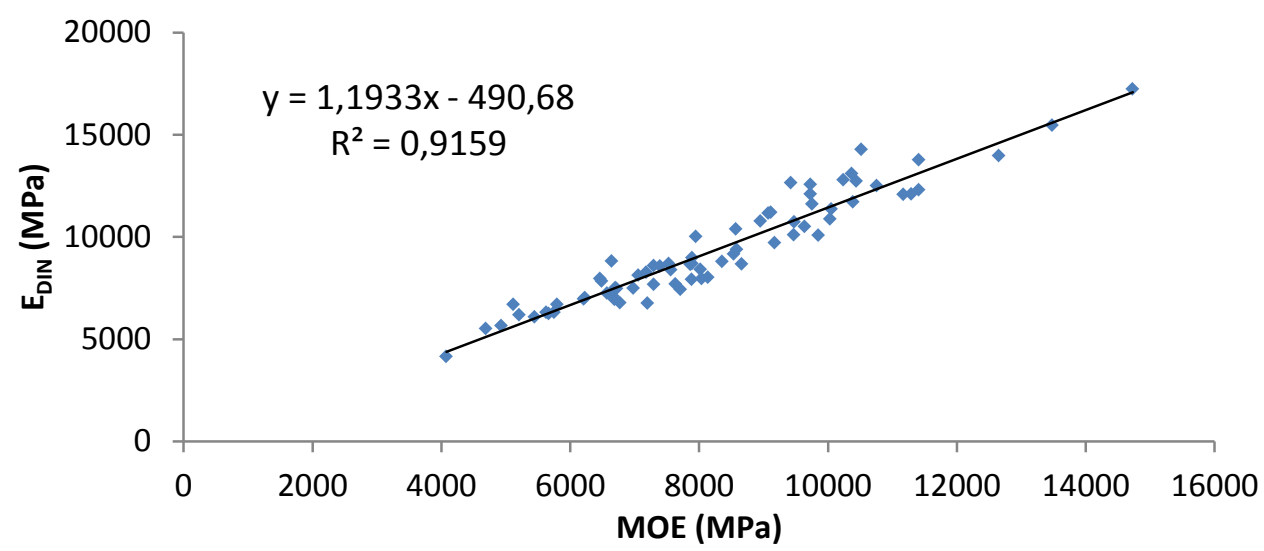

Figura 42 - Diagrama de dispersão e reta de regressão entre o MOE na flexão estática e o $\mathrm{E}_{\mathrm{DIN}}$ - Classe SS.

A Figura 43 apresenta o gráfico dos resíduos em função dos valores estimados para o $\mathrm{E}_{\mathrm{DIN}}$, podendo ser observada a homogeneidade da variância.

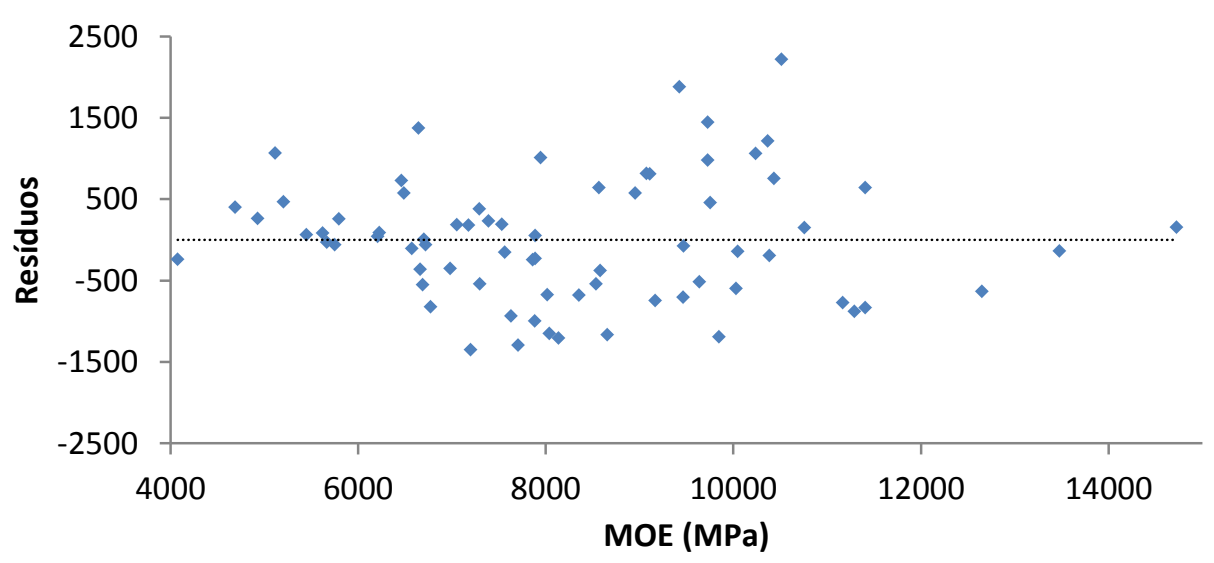

Figura 43 - Gráfico dos resíduos contra valores estimados para o $E_{\text {DIN }}$ - Classe SS.

A Figura 44 apresenta o gráfico dos resíduos padronizados contra os escores normais, observando-se, aproximadamente, uma distribuição normal.

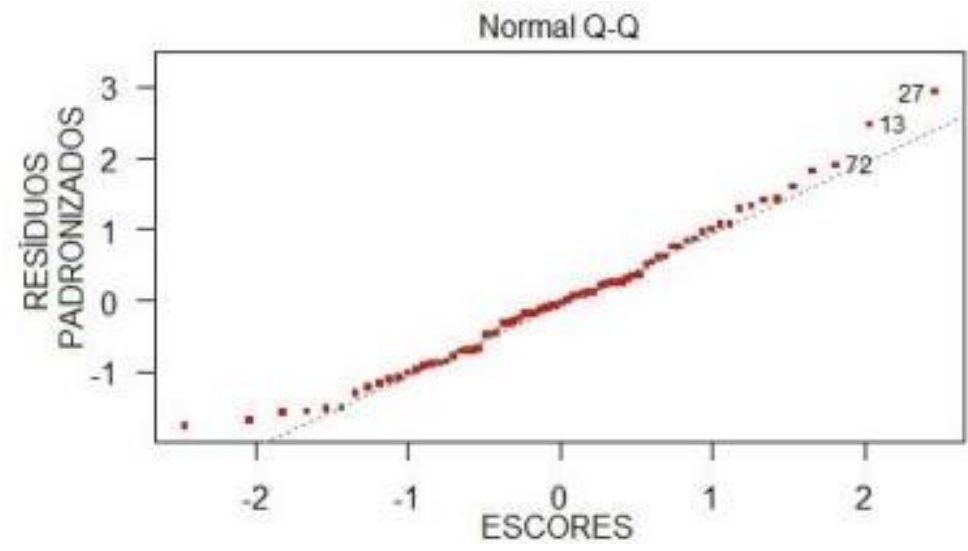

Figura 44 - Gráfico de probabilidade normal dos resíduos para o $\mathrm{E}_{\mathrm{DIN}}$ - Classe SS. 
Atendidas as suposições da regressão, a Tabela 31 apresenta os resultados da análise de variância.

Tabela 31 - Quadro de ANOVA (E $E_{\text {DIN }}$ X MOE) - Classe SS.

\begin{tabular}{lccccc}
\hline & gl & SQ & MQ & F & Valor-P \\
\hline Regressão & 1 & $4,510 \mathrm{E}+08$ & $4,510 \mathrm{E}+08$ & 762,2 & 0,0000 \\
Resíduo & 70 & $4,141 \mathrm{E}+07$ & 591626 & & \\
Total & 71 & $4,924 \mathrm{E}+08$ & & & \\
\hline
\end{tabular}

Para os graus de liberdade $(1,70)$, o valor de F, a um nível de significância de $\alpha=0,05$ é 3,91. Como o valor calculado de F é igual a 762,2, pode-se concluir que existe evidência estatística de que a proporção da variância total explicada pela regressão é altamente significativa. Assim, o modelo de regressão linear dado por $\left\{E_{D I N}(M P a)=1,1933\right.$ - $M O E(M P a)-490,68\}$ é adequado.

\subsubsection{Classe Visual S1}

A Figura 45 apresenta o diagrama de dispersão e a regressão entre o $E_{\text {DIN }}$ e o MOE, para os dados da classe $\mathrm{S} 1$.

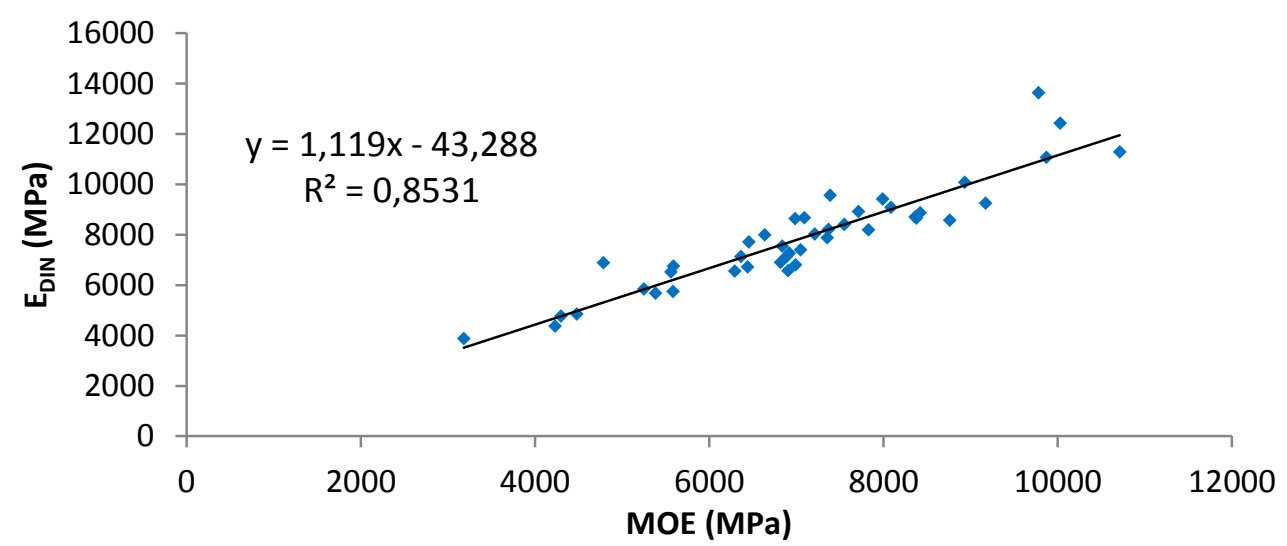

Figura 45 - Diagrama de dispersão e reta de regressão entre o MOE na flexão estática e o $\mathrm{E}_{\mathrm{DIN}}-$ Classe S1.

A Figura 46 apresenta o gráfico dos resíduos em função dos valores estimados para o $E_{\text {DIN }}$, podendo ser observada a homogeneidade da variância. 


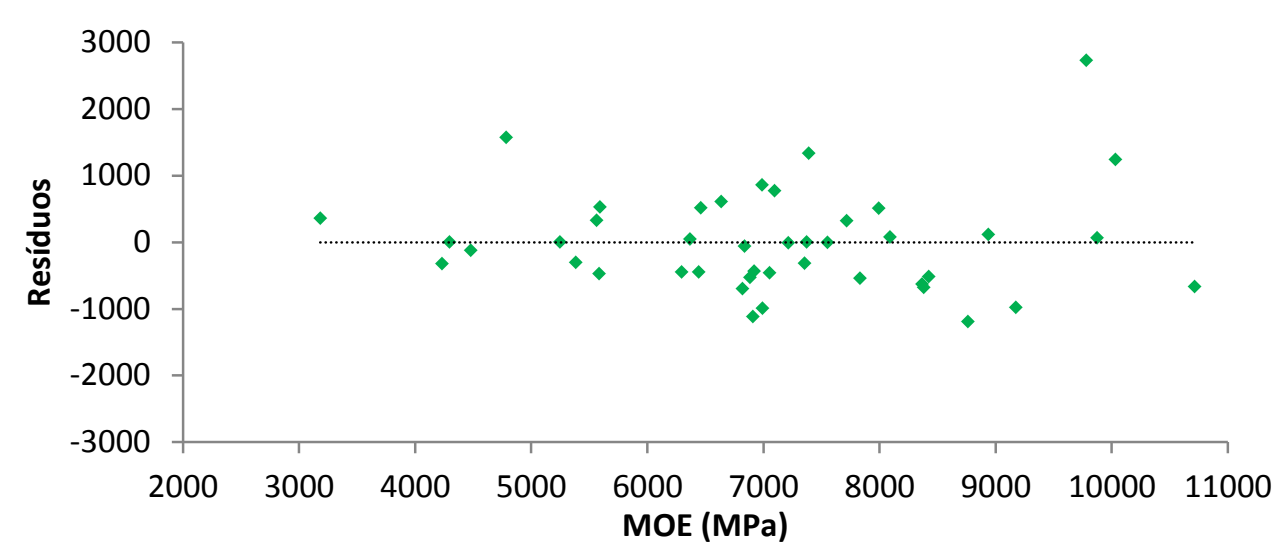

Figura 46 - Gráfico dos resíduos contra valores estimados para o $\mathrm{E}_{\mathrm{DIN}}$ - Classe S1.

A Figura 47 apresenta o gráfico dos resíduos padronizados contra os escores normais, observando-se, aproximadamente uma distribuição normal.

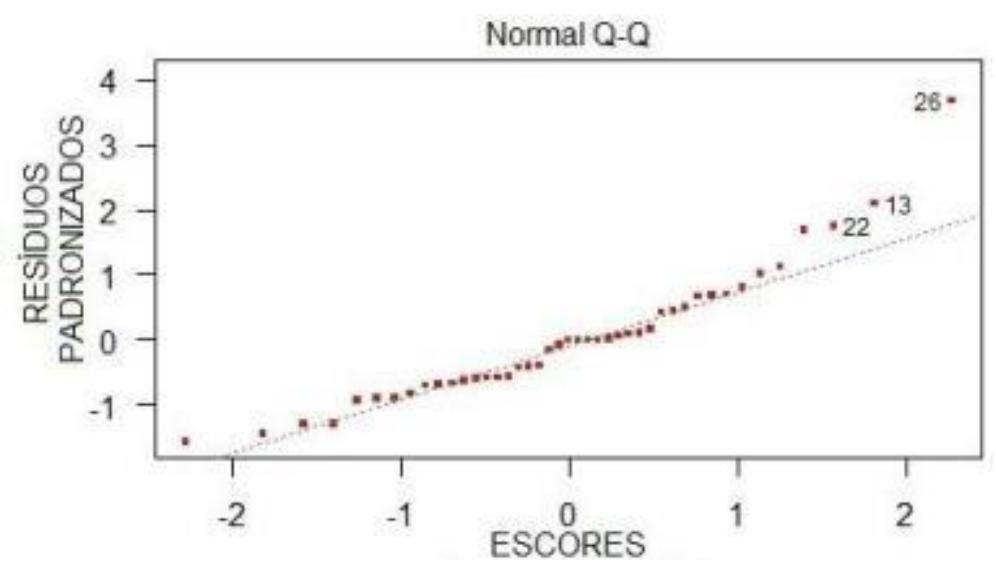

Figura 47 - Gráfico de probabilidade normal dos resíduos para o $\mathrm{E}_{\mathrm{DIN}}$ - Classe S1.

Atendidas as suposições da regressão, a Tabela 32 apresenta os resultados análise de variância.

Tabela 32 - Quadro de ANOVA (E $\mathrm{EIN}_{\mathrm{D}} \mathrm{x}$ MOE) - Classe S1.

\begin{tabular}{lccccc}
\hline & gl & SQ & MQ & F & Valor-P \\
\hline Regressão & 1 & $1,435 \mathrm{E}+08$ & $1,435 \mathrm{E}+08$ & 238,2 & 0,0000 \\
Resíduo & 41 & $2,470 \mathrm{E}+07$ & 602361 & & \\
Total & 42 & $1,682 \mathrm{E}+08$ & & & \\
\hline
\end{tabular}

Para os graus de liberdade $(1,41)$, o valor de F, a um nível de significância de $\alpha=0,05$ é 3,95. Como o valor calculado de $\mathrm{F}$ é igual a 238,2 , pode-se concluir que existe evidência estatística de que a proporção da variância total explicada pela regressão é altamente significativa. Assim, o modelo de regressão linear dado por $\left\{E_{D I N}(M P a)=1,119\right.$. $M O E(M P a)-43,288\}$ é adequado. 


\subsubsection{Classe Visual S2}

A Figura 48 apresenta o diagrama de dispersão e a regressão entre o $E_{\text {DIN }} 0$ e o MOE, para os dados da classe S2.

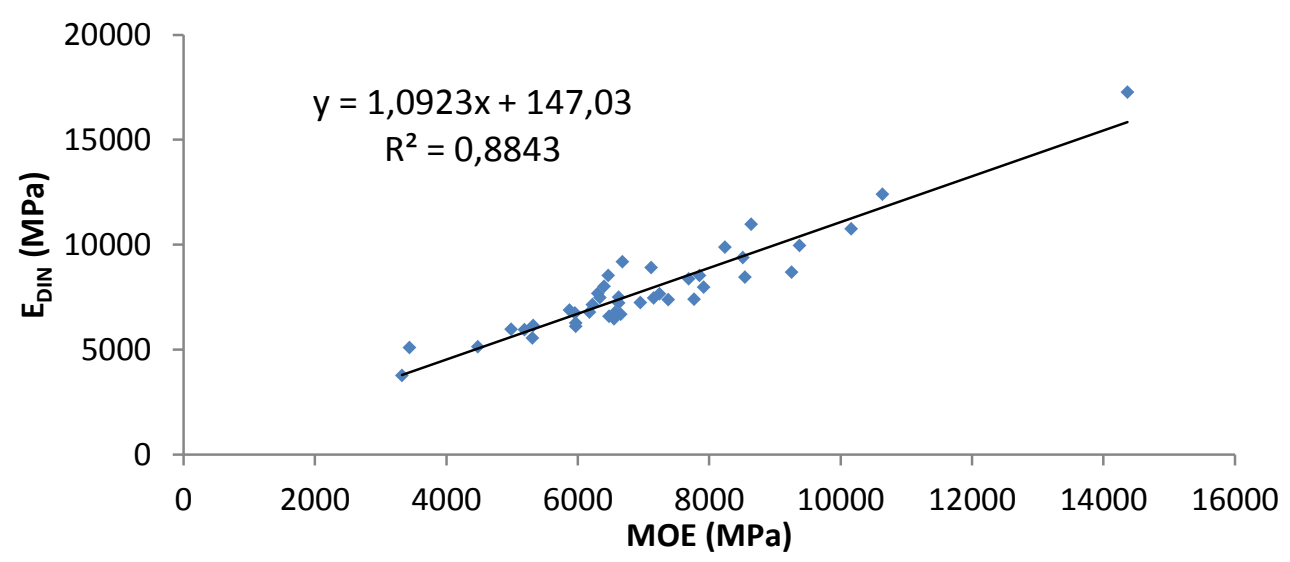

Figura 48 - Diagrama de dispersão e reta de regressão entre o MOE estático e o $\mathrm{E}_{\mathrm{DIN}}$ - Classe S2.

A Figura 49 apresenta o gráfico dos resíduos em função dos valores estimados para o $\mathrm{E}_{\mathrm{DIN}}$, podendo ser observada a homogeneidade da variância.

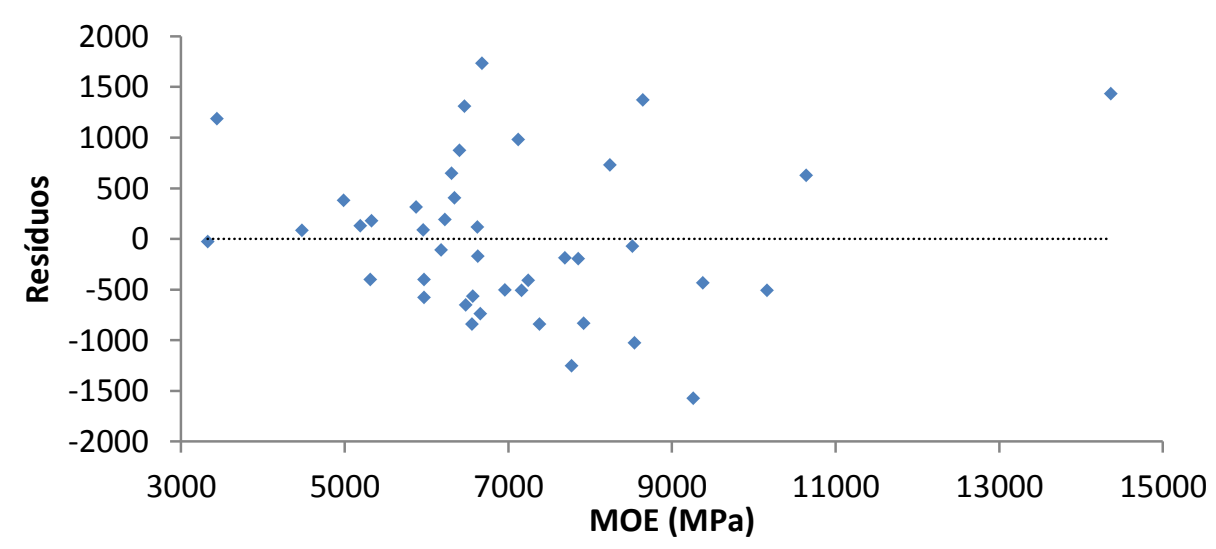

Figura 49 - Gráfico dos resíduos contra valores estimados para o $\mathrm{E}_{\mathrm{DIN}}$ - Classe S2.

A Figura 50 apresenta o gráfico dos resíduos padronizados contra os escores normais, observando-se, aproximadamente, uma distribuição normal. 


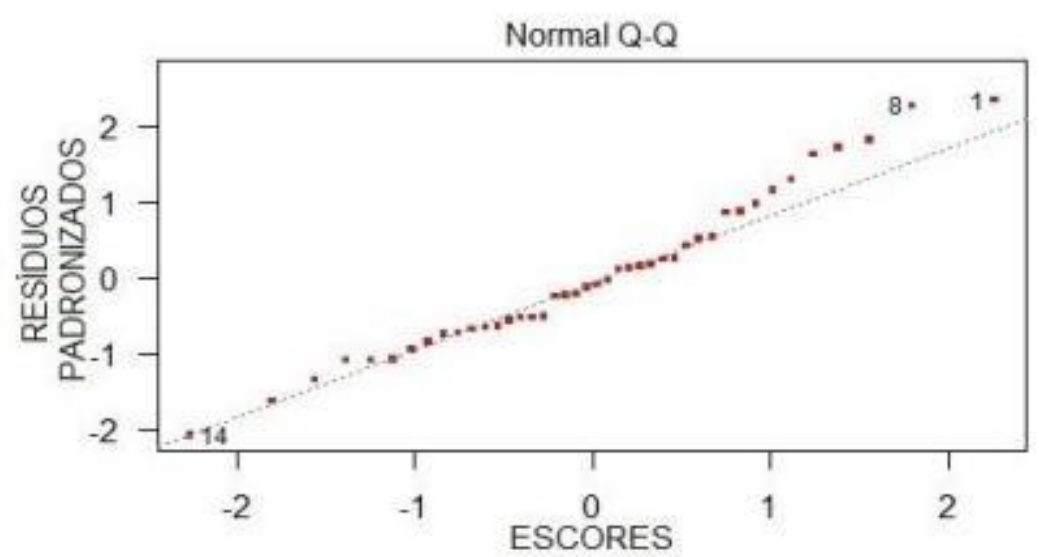

Figura 50 - Gráfico de probabilidade normal dos resíduos para o $\mathrm{E}_{\mathrm{DIN}}$ - Classe $\mathrm{S} 2$.

Atendidas as suposições da regressão, a Tabela 33 apresenta os resultados da análise de variância.

Tabela 33 - Quadro de ANOVA (E $\mathrm{E}_{\text {DIN }}$ x MOE) - Classe S2.

\begin{tabular}{lccccc}
\hline & gl & SQ & MQ & F & Valor-P \\
\hline Regressão & 1 & $1,838 \mathrm{E}+08$ & $1,838 \mathrm{E}+08$ & 305,8 & 0,0000 \\
Resíduo & 40 & $2,405 \mathrm{E}+07$ & 601219 & & \\
Total & 41 & $2,079 \mathrm{E}+08$ & & & \\
\hline
\end{tabular}

Para os graus de liberdade (1,40), o valor de F, a um nível de significância de $\alpha=0,05$ é 3,96. Como o valor calculado de $\mathrm{F}$ é igual a 305,8 , pode-se concluir que existe evidência estatística de que a proporção da variância total explicada pela regressão é altamente significativa. Assim, o modelo de regressão linear dado por $\left\{E_{D I N}(M P a)=1,0923\right.$ - $M O E(M P a)+147,03\}$ é adequado.

\subsubsection{Classe Visual S3}

A Figura 51 apresenta o diagrama de dispersão e a regressão entre o $E_{D I N}$ e o MOE, para os dados da classe S3. 


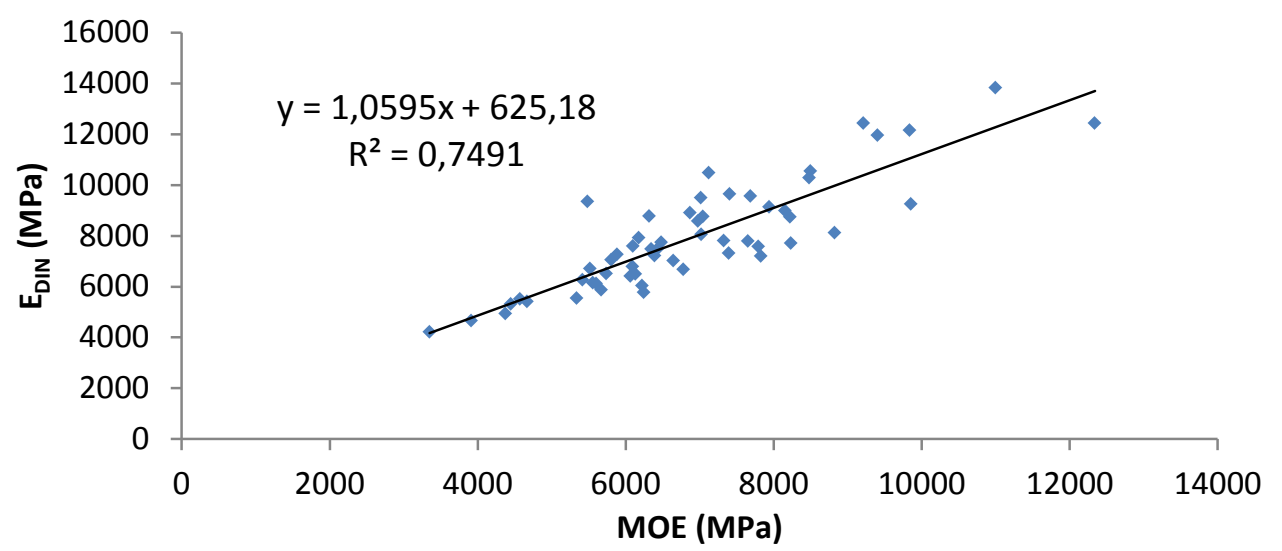

Figura 51 - Diagrama de dispersão e reta de regressão entre o MOE e o $E_{D I N}-$ Classe S3.

A Figura 52 apresenta o gráfico dos resíduos em função dos valores estimados para o $\mathrm{E}_{\mathrm{DIN}}$, podendo ser observada a homogeneidade da variância.

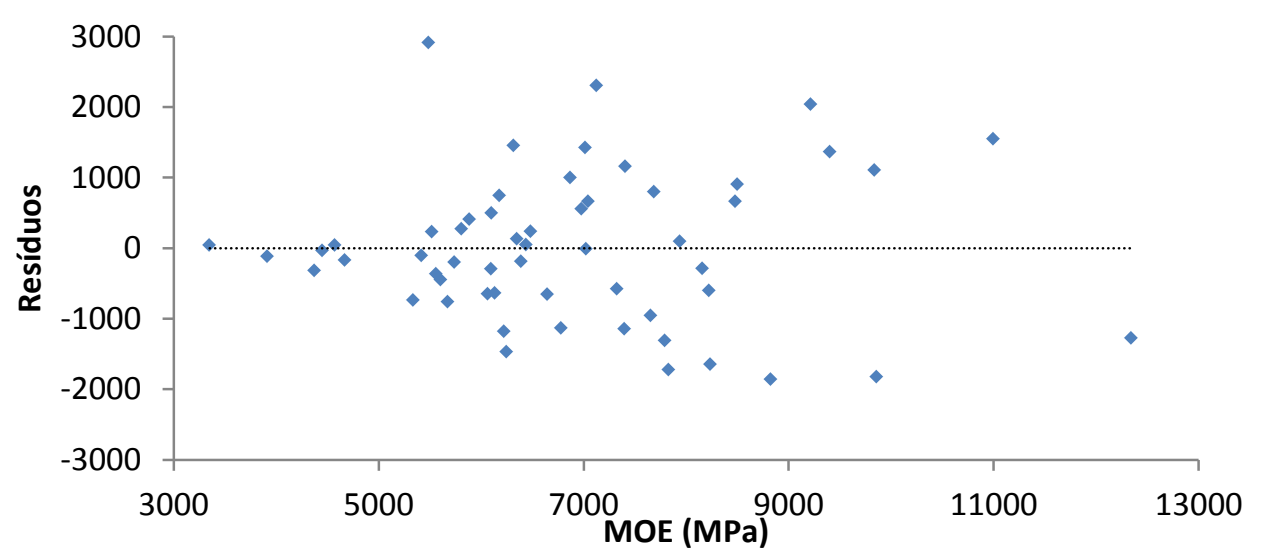

Figura 52 - Gráfico dos resíduos contra valores estimados para o $\mathrm{E}_{\mathrm{DIN}}$ - Classe S3.

A Figura 53 apresenta o gráfico dos resíduos padronizados contra os escores normais, observando-se, aproximadamente, uma distribuição normal.

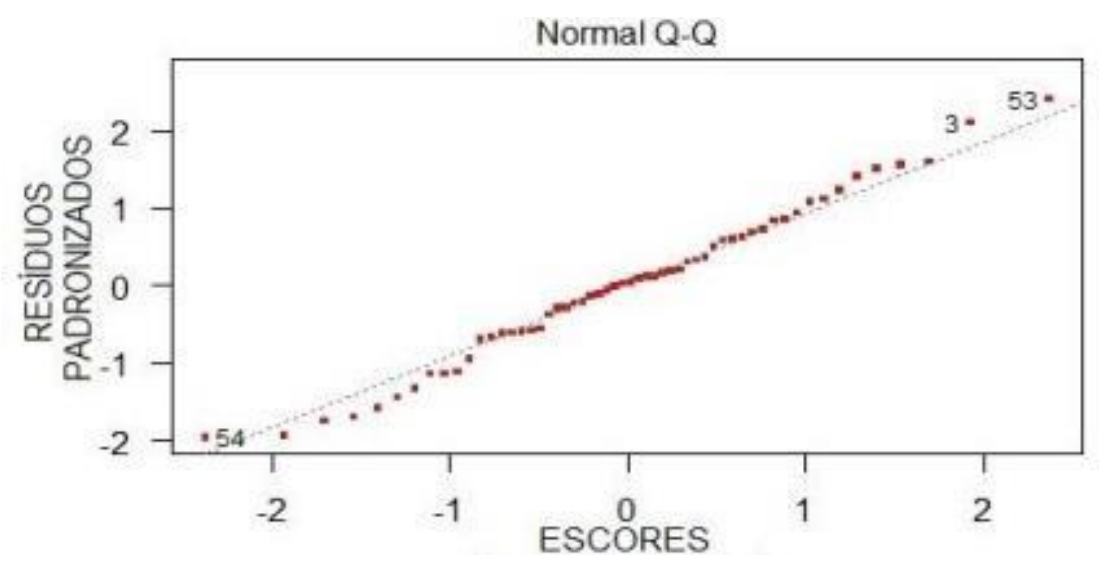

Figura 53 - Gráfico de probabilidade normal dos resíduos para o $\mathrm{E}_{\mathrm{DIN}}$ - Classe $\mathrm{S} 3$. 
Atendidas as suposições da regressão, a Tabela 34 apresenta os resultados da análise de variância.

Tabela 34 - Quadro de ANOVA (E $\mathrm{EIN}_{\mathrm{D}} \mathrm{x}$ MOE) - Classe S3.

\begin{tabular}{lccccc}
\hline & gl & SQ & MQ & F & Valor-P \\
\hline Regressão & 1 & $1,804 \mathrm{E}+08$ & $1,804 \mathrm{E}+08$ & 161,2 & 0,0000 \\
Resíduo & 54 & $6,044 \mathrm{E}+07$ & 1119199 & & \\
Total & 55 & $2,409 \mathrm{E}+08$ & & & \\
\hline
\end{tabular}

Para os graus de liberdade $(1,54)$, o valor de F, a um nível de significância de $\alpha=0,05$ é 3,93. Como o valor calculado de $\mathrm{F}$ é igual a 161,2 , pode-se concluir que existe evidência estatística de que a proporção da variância total explicada pela regressão é altamente significativa. Assim, o modelo de regressão linear dado por $\left\{E_{D I N}(M P a)=1,0595\right.$ $\cdot \operatorname{MOE}(M P a)+625,18\}$ é adequado.

\subsubsection{Resumo das Correlações do $\mathrm{E}_{\mathrm{DIN}}$}

A Tabela 35 apresenta o resumo dos valores das correlações da regressão linear entre o $E_{\text {DIN }}$ obtido pela frequência natural e o MOE na flexão estática para as diferentes classes de madeira.

Tabela 35 - Correlação da regressão linear entre o $E_{\text {DIN }}$ e o MOE.

\begin{tabular}{ccc}
\hline & Correlação do $\mathbf{E}_{\text {DIN }}$ com o MOE & \\
\hline Classe & Coeficiente de Correlação & Equação \\
Lote Completo & 0,87 & $1,1171$. MOE+114,19 \\
SS & 0,92 & $1,1933$. MOE-490,68 \\
S1 & 0,85 & $1,119$. MOE-43,288 \\
S2 & 0,88 & $1,0923$. MOE $+147,03$ \\
S3 & 0,75 & $1,0595$. MOE+625,18 \\
\hline
\end{tabular}

As regressões lineares entre o $\mathrm{E}_{\mathrm{DIN}}$ e o $\mathrm{MOE}$, apresentaram boas correlações. Foi observada uma maior correlação da regressão linear nas peças da classe SS, com menor incidência de defeitos. A presença dos defeitos naturais nas classes S1, S2 e S3, reduziu a correlação entre as propriedades. 


\subsection{CORRELAÇÃO ENTRE O MOR E O MOE}

Para a análise comparativa entre os dados do MOR e o MOE obtidos pelo ensaio estático foi utilizado o modelo de regressão linear simples, sendo o MOE a variável independente $(x)$, como variável dependente $(y)$ foi adotado o MOR.

A análise foi feita determinando a equação da regressão linear, o coeficiente de correlação e analisando os resíduos, para verificar o atendimento dos requisitos. Após, foi feita análise da variância para verificar a condição do modelo ajustado.

\subsubsection{Lote completo}

A Figura 54 apresenta o diagrama de dispersão e a regressão entre o MOR e o MOE, para os dados do lote completo.

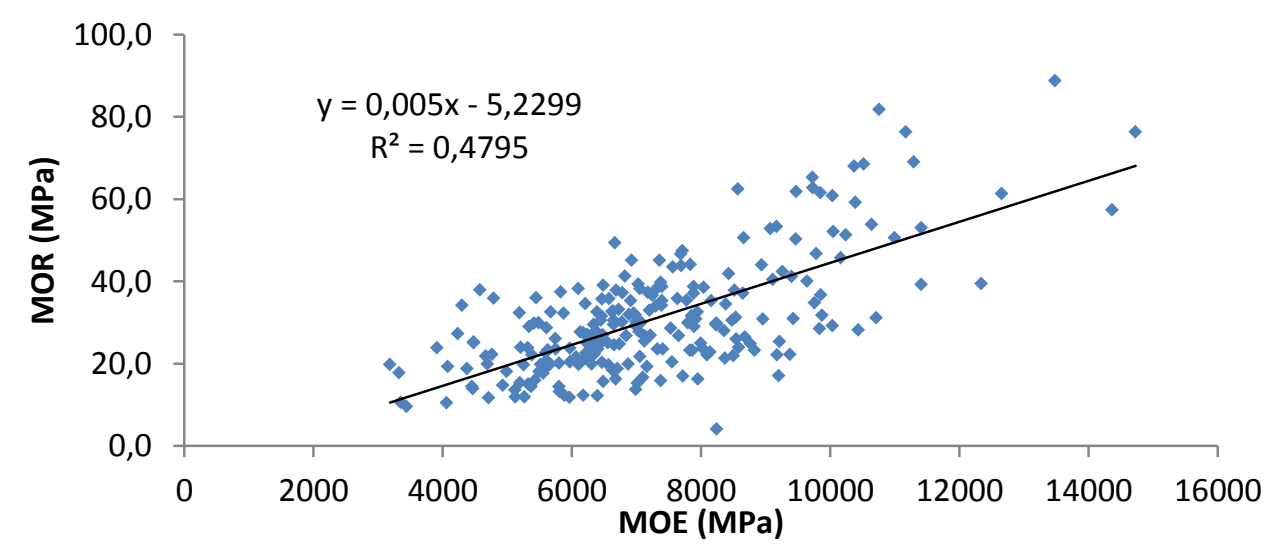

Figura 54 - Diagrama de dispersão e reta de regressão entre o MOE e o MOR do lote completo.

A Figura 55 apresenta o gráfico dos resíduos em função dos valores estimados para o MOR, podendo ser observada a homogeneidade da variância.

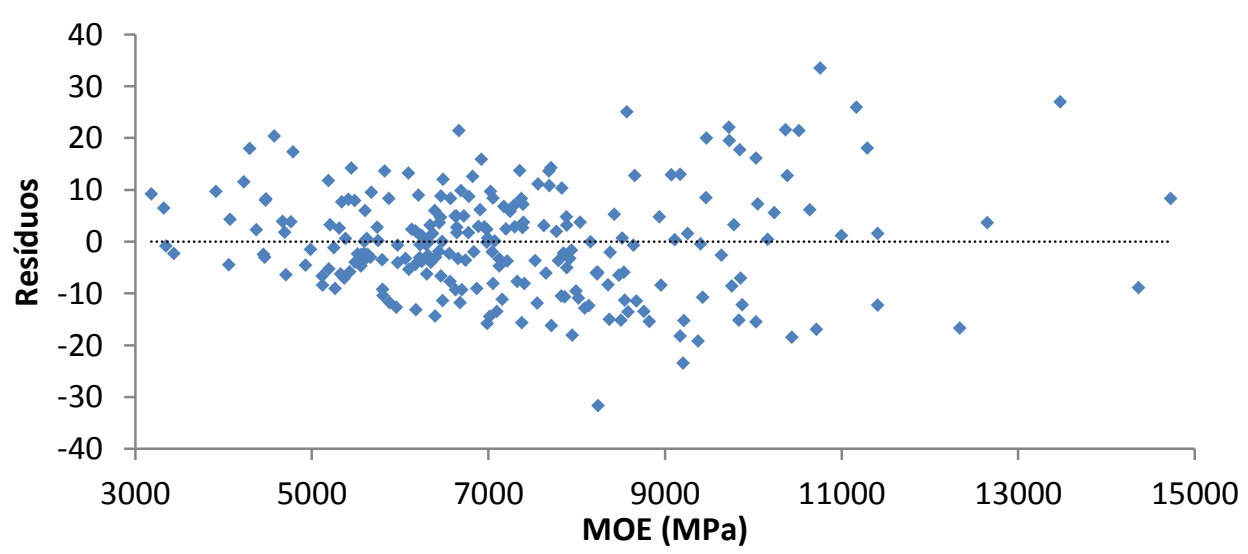

Figura 55 - Gráfico dos resíduos contra valores estimados para o MOR para o lote completo. 
A Figura 56 apresenta o gráfico dos resíduos padronizados contra os escores normais, observando-se, aproximadamente uma distribuição normal.

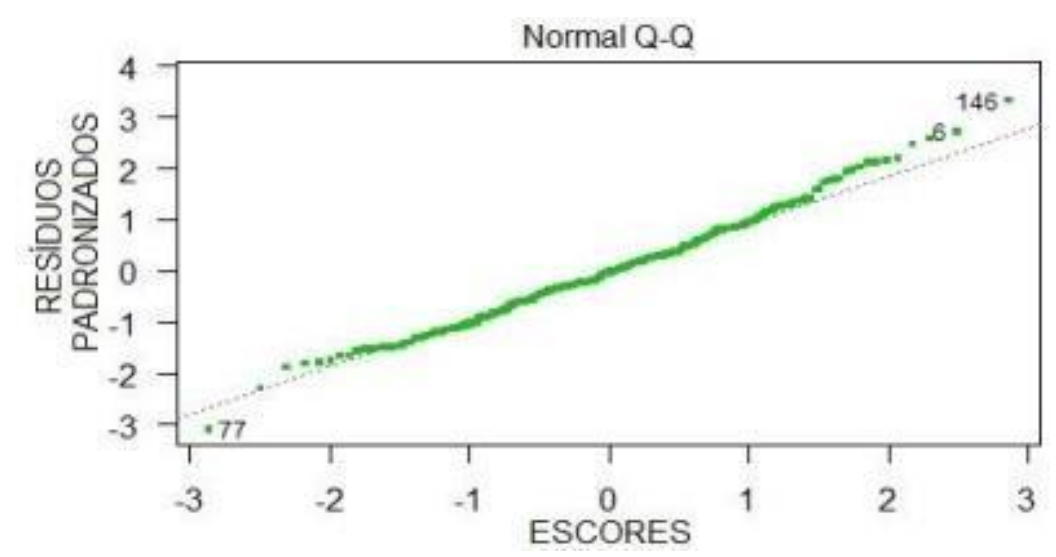

Figura 56 - Gráfico de probabilidade normal dos resíduos para o MOR do lote completo.

Atendidas as suposições da regressão, a Tabela 36 apresenta os resultados da análise de variância.

Tabela 36 - Quadro de ANOVA (MOR x MOE) - lote completo.

\begin{tabular}{lccccc}
\hline & gl & SQ & MQ & F & Valor-P \\
\hline Regressão & 1 & $2,235 \mathrm{E}+04$ & $2,235 \mathrm{E}+04$ & 215,6 & 0,0000 \\
Resíduo & 211 & $2,427 \mathrm{E}+04$ & 103,7 & & \\
Total & 212 & $4,662 \mathrm{E}+04$ & & & \\
\hline
\end{tabular}

Para os graus de liberdade $(1,211)$, o valor de F, a um nível de significância de $\alpha=0,05$ é 3,86 . Como o valor calculado de $\mathrm{F}$ é igual a 215,6 , pode-se concluir que existe evidência estatística de que a proporção da variância total explicada pela regressão é significativa. Assim, o modelo de regressão linear dado por $\{M O R(M P a)=0,005 \cdot M O E$ $(M P a)-5,2299\}$ é adequado.

\subsubsection{Classe Visual SS}

A Figura 57 apresenta o diagrama de dispersão e regressão entre o MOR e o MOE, para os dados da classe SS. 


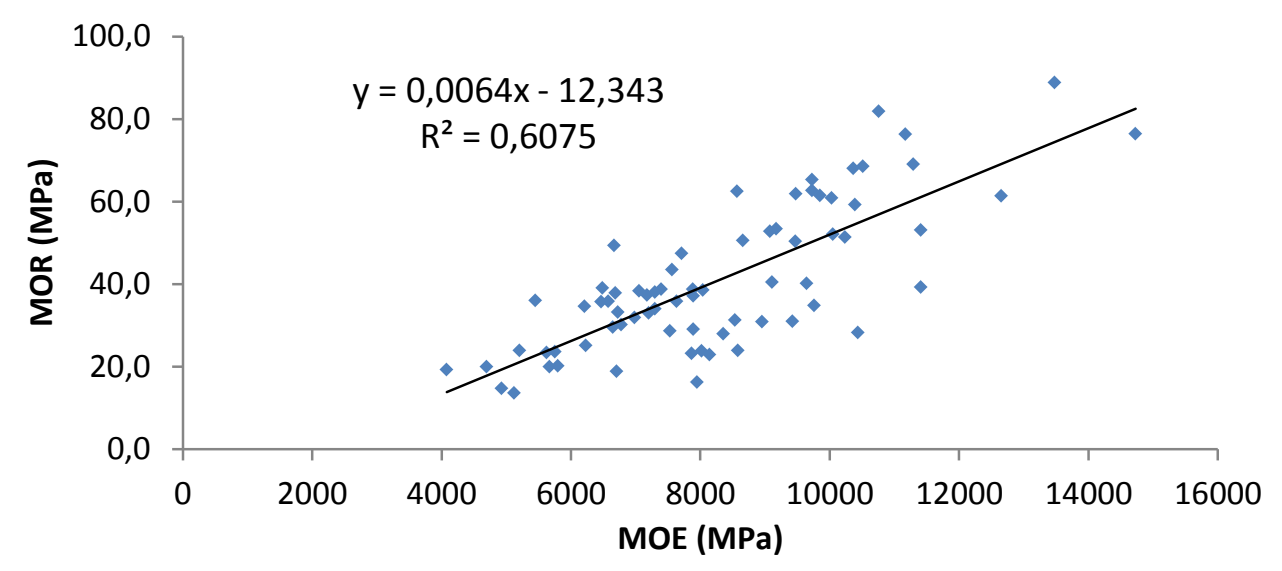

Figura 57 - Diagrama de dispersão e reta de regressão entre o MOE e o MOR - Classe SS.

A Figura 58 apresenta o gráfico dos resíduos em função dos valores estimados para o MOR, podendo ser observada a homogeneidade da variância.

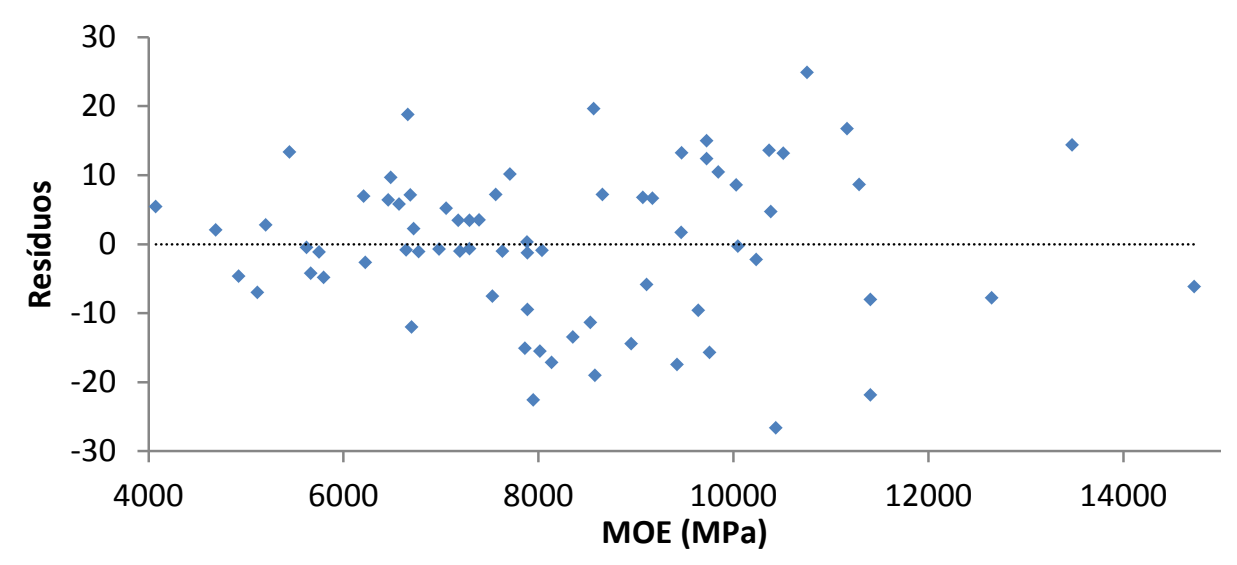

Figura 58 - Gráfico dos resíduos contra valores estimados para o MOR - Classe SS.

A Figura 59 apresenta o gráfico dos resíduos padronizados contra os escores normais, observando-se, aproximadamente uma distribuição normal.

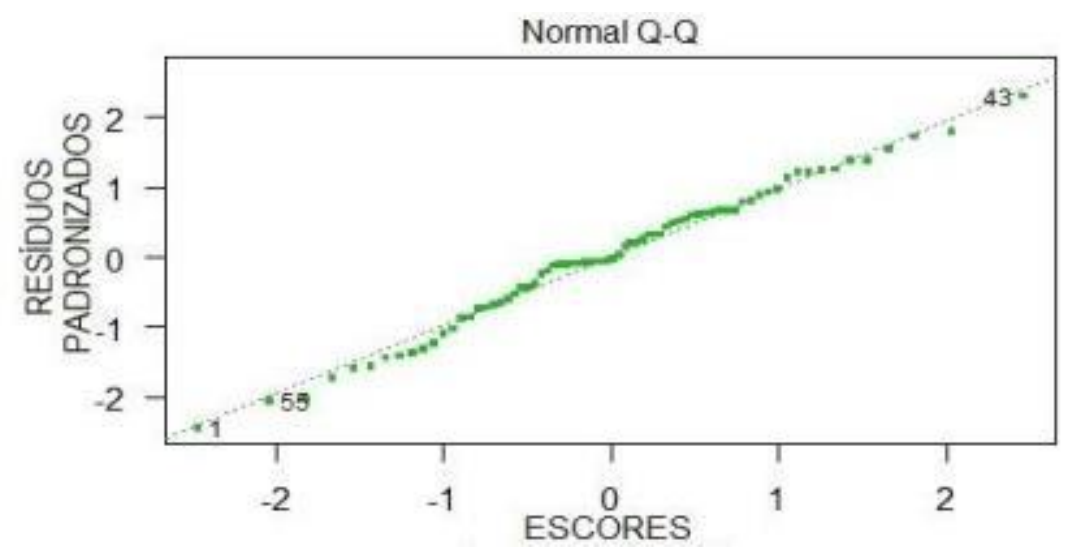

Figura 59 - Gráfico de probabilidade normal dos resíduos para o MOR - Classe SS. 
Atendidas as suposições da regressão, a Tabela 37 apresenta os resultados da análise de variância.

Tabela 37 - Quadro de ANOVA (MOR x MOE) - Classe SS.

\begin{tabular}{lccccc}
\hline & gl & SQ & MQ & F & Valor-P \\
\hline Regressão & 1 & $1,313 \mathrm{E}+04$ & $1,313 \mathrm{E}+04$ & 108,4 & 0,0000 \\
Resíduo & 70 & $8,485 \mathrm{E}+03$ & 121 & & \\
Total & 71 & $2,162 \mathrm{E}+04$ & & & \\
\hline
\end{tabular}

Para os graus de liberdade $(1,70)$, o valor de F, a um nível de significância de $\alpha=0,05$ é 3,91. Como o valor calculado de F é igual a 108,4, pode-se concluir que existe evidência estatística de que a proporção da variância total explicada pela regressão é altamente significativa. Assim, o modelo de regressão linear dado por $\{\mathrm{MOR}(\mathrm{MPa})=0,0064$ $\cdot \operatorname{MOE}(\mathrm{MPa})-12,343\}$ é adequado.

\subsubsection{Classe Visual S1}

A Figura 60 apresenta o diagrama de dispersão e a regressão entre o MOR e o MOE, para os dados da classe $\mathrm{S} 1$.

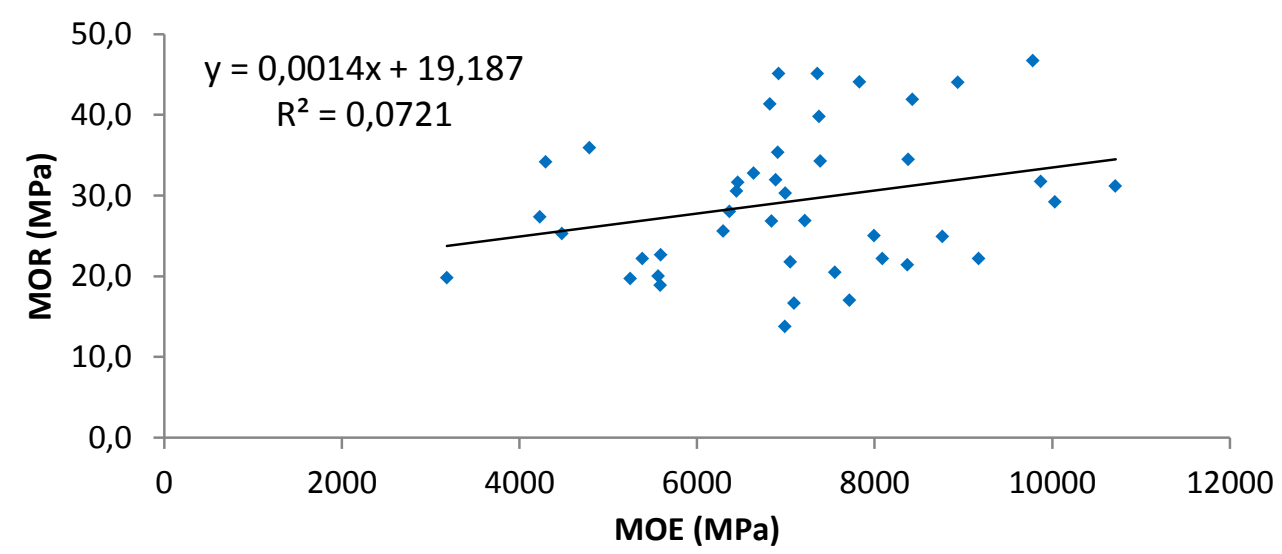

Figura 60 - Diagrama de dispersão e reta de regressão entre o MOE na flexão estática e o MOR - Classe S1.

A Figura 61 apresenta o gráfico dos resíduos em função dos valores estimados para o MOR, podendo ser observada a homogeneidade da variância. 


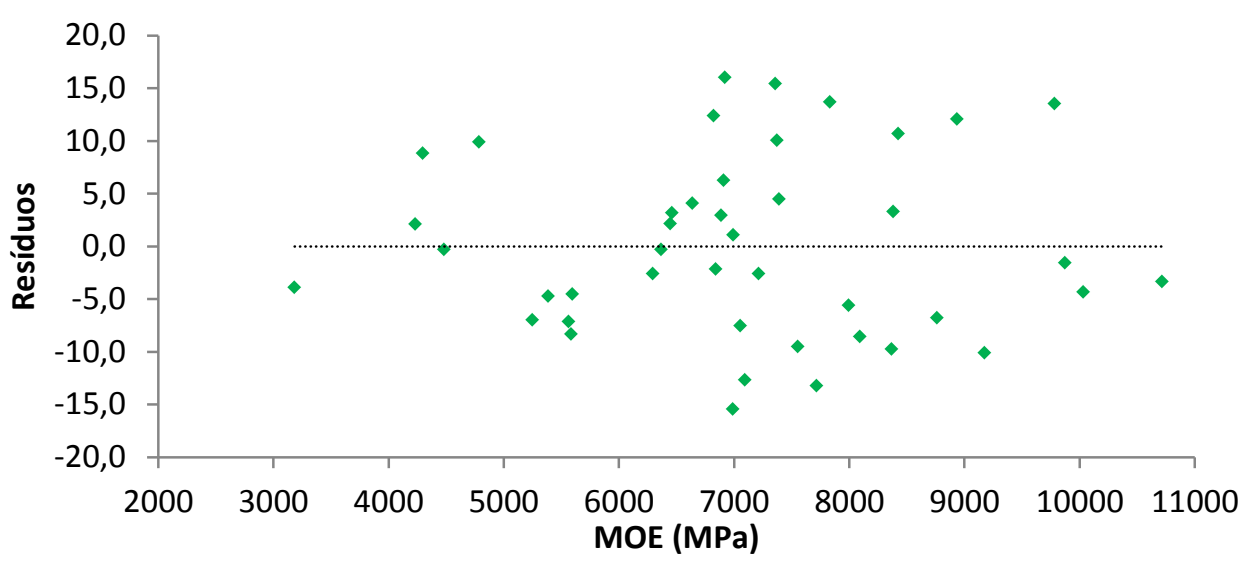

Figura 61 - Gráfico dos resíduos contra valores estimados para o MOR - Classe S1.

A Figura 62 apresenta o gráfico dos resíduos padronizados contra os escores normais, observando-se, uma oscilação na distribuição.

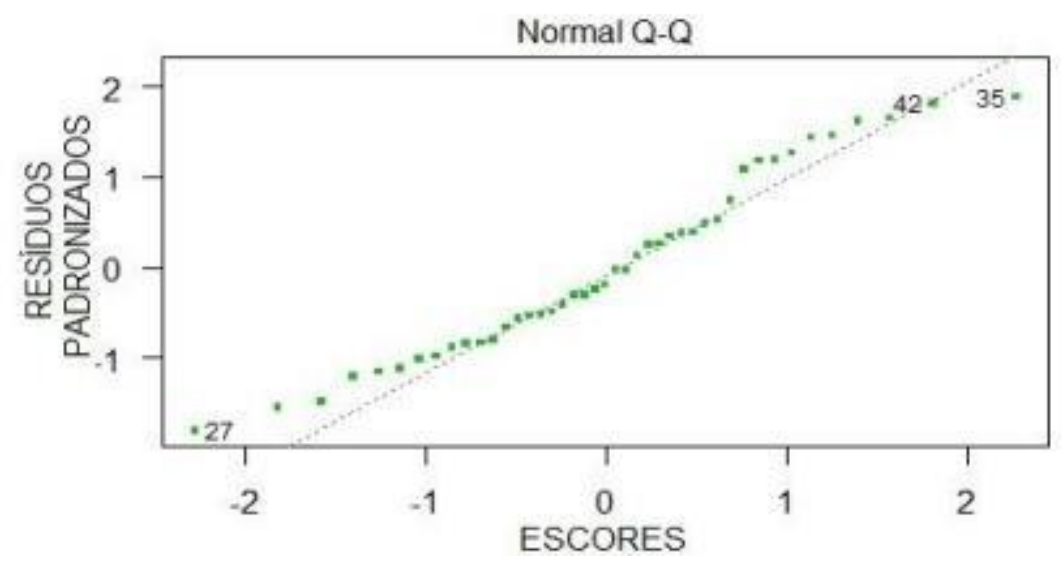

Figura 62 - Gráfico de probabilidade normal dos resíduos para o MOR - Classe S1.

As suposições da regressão atendidas, a Tabela 38 apresenta os resultados da análise de variância.

Tabela 38 - Quadro de ANOVA (MOR x MOE) - Classe S1.

\begin{tabular}{lccccc}
\hline & gl & SQ & MQ & F & Valor-P \\
\hline Regressão & 1 & $2,346 \mathrm{E}+02$ & $2,346 \mathrm{E}+02$ & 3,19 & 0,0816 \\
Resíduo & 41 & $3,019 \mathrm{E}+03$ & 74 & & \\
Total & 42 & $3,253 \mathrm{E}+03$ & & & \\
\hline
\end{tabular}

Para os graus de liberdade $(1,41)$, o valor de $\mathrm{F}$, a um nível de significância de $\alpha=0,05$ é 3,91. Como o valor calculado de $\mathrm{F}$ é igual a 3,19, pode-se concluir que não existe evidência estatística de que a proporção da variância é explicada pela regressão. Assim, o modelo de regressão linear dado por $\{M O R(M P a)=0,0014 \cdot M O E(M P a)+19,187\}$ não é adequado. 


\subsubsection{Classe Visual S2}

A Figura 63 apresenta o diagrama de dispersão e regressão entre o MOR e o MOE, para os dados da classe S2.

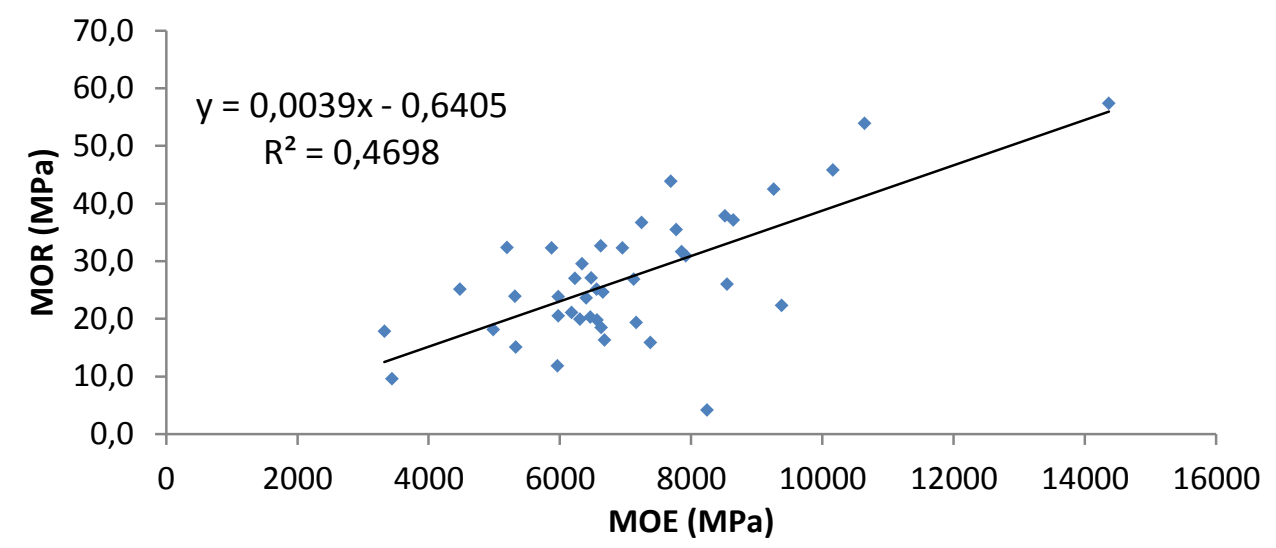

Figura 63 - Diagrama de dispersão e reta de regressão entre o MOE e o MOR - Classe S2.

A Figura 64 apresenta o gráfico dos resíduos em função dos valores estimados para o MOR, podendo ser observada a homogeneidade da variância.

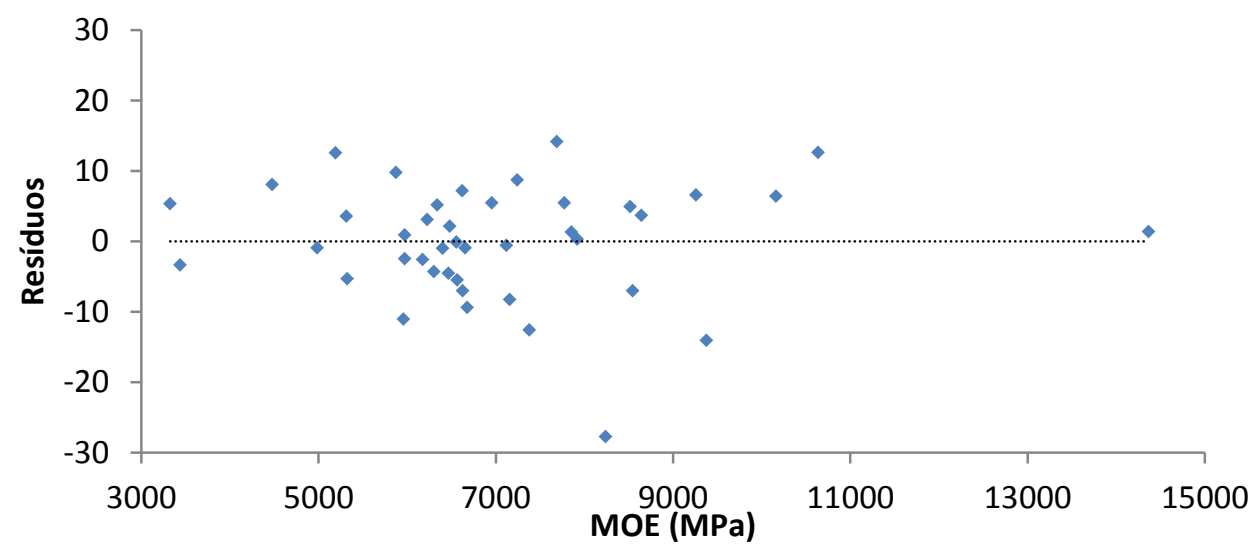

Figura 64 - Gráfico dos resíduos contra valores estimados para o MOR - Classe S2.

A Figura 65 apresenta o gráfico dos resíduos padronizados contra os escores normais, observando-se, aproximadamente, uma distribuição normal. 


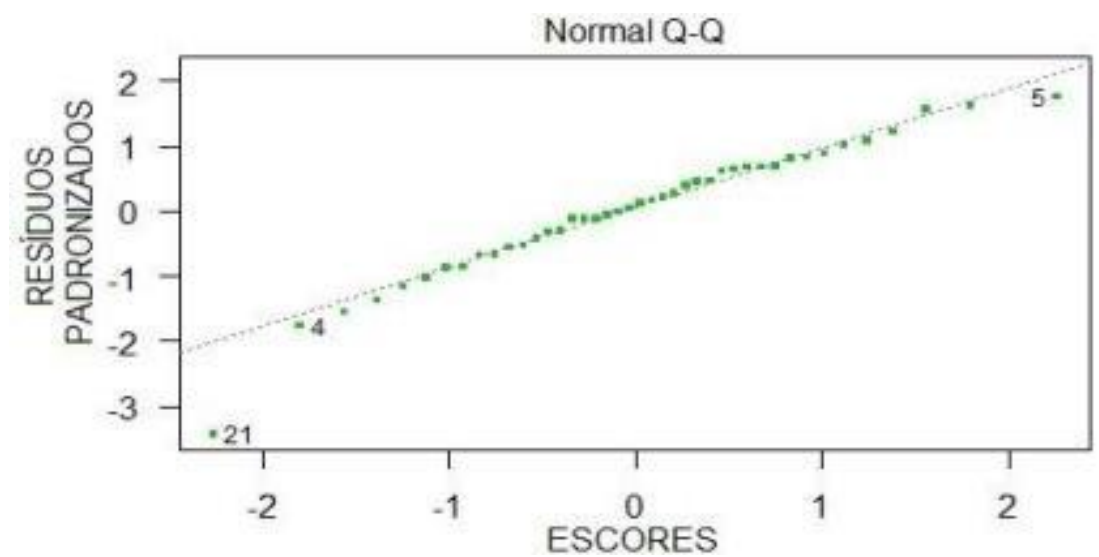

Figura 65 - Gráfico de probabilidade normal dos resíduos para o MOR - Classe S2.

Atendidas as suposições da regressão, a Tabela 39 apresenta os resultados da análise de variância.

Tabela 39 - Quadro de ANOVA (MOR x MOE) - Classe S2.

\begin{tabular}{lccccc}
\hline & gl & SQ & MQ & F & Valor-P \\
\hline Regressão & 1 & $2,394 \mathrm{E}+03$ & $2,394 \mathrm{E}+03$ & 35,4 & 0,0000 \\
Resíduo & 40 & $2,702 \mathrm{E}+03$ & 68 & & \\
Total & 41 & $5,096 \mathrm{E}+03$ & & & \\
\hline
\end{tabular}

Para os graus de liberdade $(1,40)$, o valor de $\mathrm{F}$, a um nível de significância de $\alpha=0,05$ é 3,96. Como o valor calculado de $\mathrm{F}$ é igual a 35,4, pode-se concluir que existe evidência estatística de que a proporção da variância total explicada pela regressão é significativa. Assim, o modelo de regressão linear dado por $\{M O R(M P a)=0,0039 \cdot M O E$ $(M P a)-0,6405\}$ é adequado.

\subsubsection{Classe Visual S3}

A Figura 66 apresenta o diagrama de dispersão e a regressão entre o MOR e o MOE, para os dados da classe S3. 


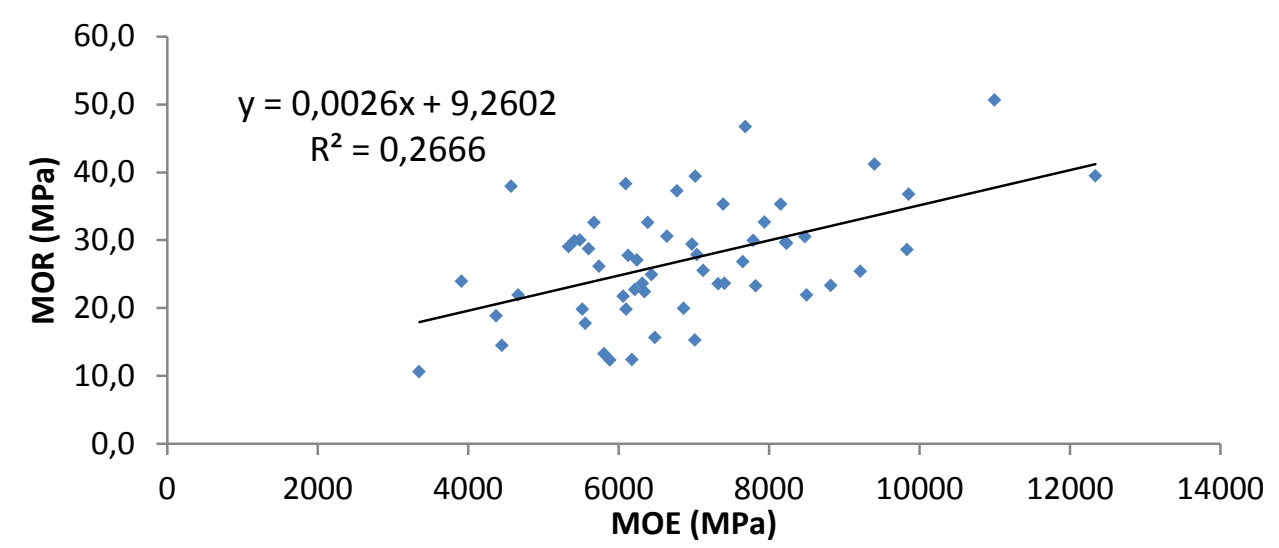

Figura 66 - Diagrama de dispersão e reta de regressão entre o MOE e o MOR - Classe S3.

A Figura 67 apresenta o gráfico dos resíduos em função dos valores estimados para o MOR, podendo ser observada a homogeneidade da variância.

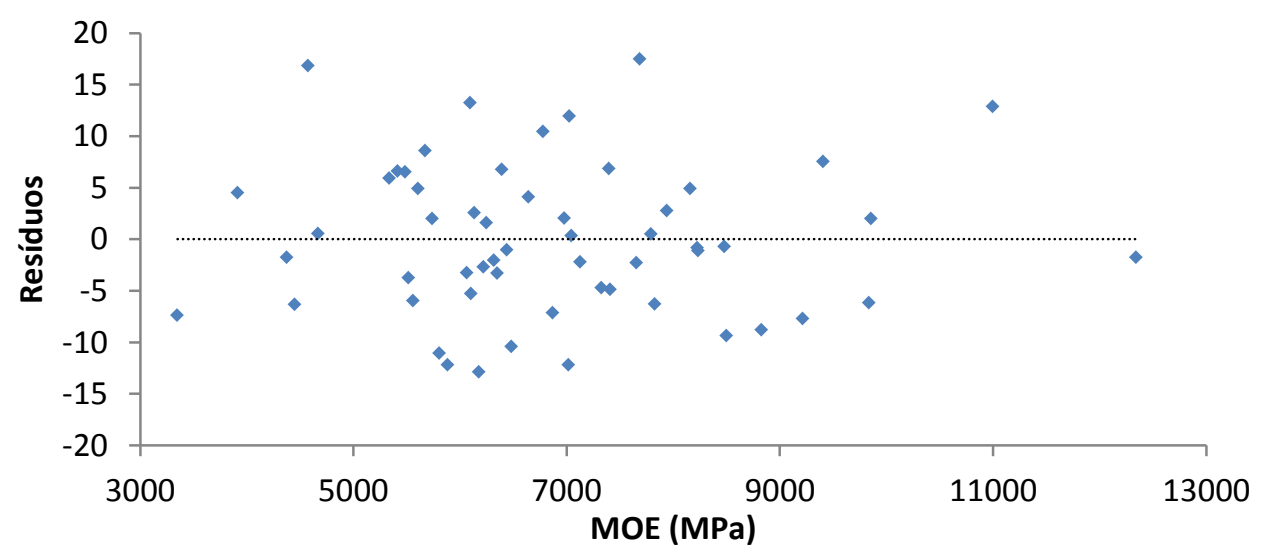

Figura 67 - Gráfico dos resíduos contra valores estimados para o MOR - Classe S3.

A Figura 68 apresenta o gráfico dos resíduos padronizados contra os escores normais, observando-se, aproximadamente, uma distribuição normal.

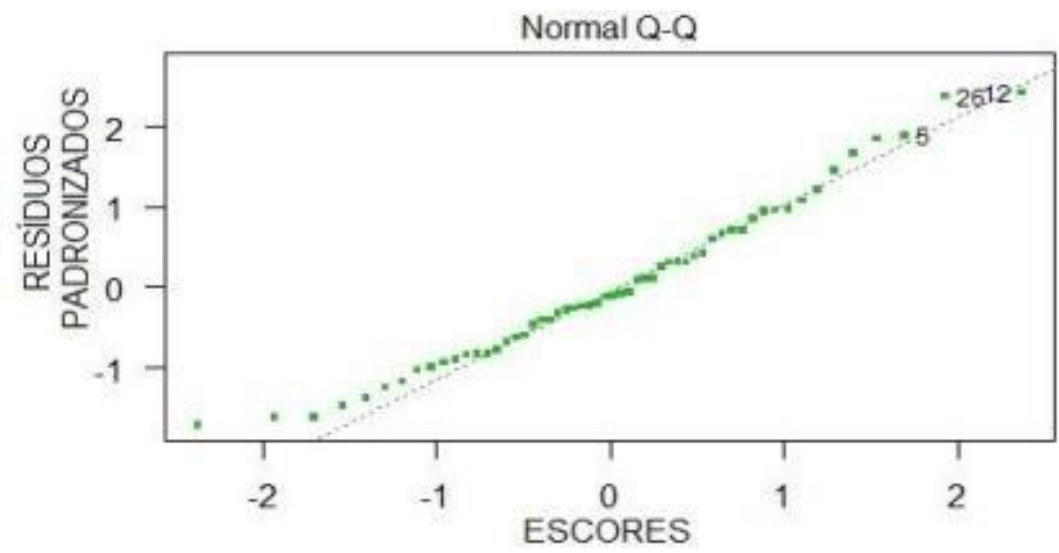

Figura 68 - Gráfico de probabilidade normal dos resíduos para o MOR - Classe S3. 
Atendidas as suposições da regressão, a Tabela 40 apresenta os resultados da análise de variância.

Tabela 40 - Quadro de ANOVA (MOR x MOE) - Classe S3.

\begin{tabular}{lccccc}
\hline & gl & SQ & MQ & F & Valor-P \\
\hline Regressão & 1 & $1,076 \mathrm{E}+03$ & $1,076 \mathrm{E}+03$ & 19,6 & 0,0000 \\
Resíduo & 54 & $2,961 \mathrm{E}+03$ & 54,8 & & \\
Total & 55 & $4,037 \mathrm{E}+03$ & & & \\
\hline
\end{tabular}

Para os graus de liberdade $(1,54)$, o valor de F, a um nível de significância de $\alpha=0,05$ é 3,93. Como o valor calculado de $\mathrm{F}$ é igual a 19,6, pode-se concluir que existe evidência estatística de que a proporção da variância total explicada pela regressão é significativa. Assim, o modelo de regressão linear dado por $\{M O R(M P a)=0,0026 \cdot M O E$ $(M P a)+9,2602\}$ é adequado.

\subsubsection{Resumo das Correlações do MOR}

A Tabela 41 apresenta o resumo dos valores das correlações da regressão linear entre a resistência (MOR) e o MOE, ambos na flexão estática, para as diferentes classes de madeira.

Tabela 41 - Correlação da regressão linear entre o MOR e o MOE.

\begin{tabular}{ccc}
\hline & Correlação do MOR com o MOE & \\
\hline Classe & Coeficiente de Correlação & Equação \\
Lote Completo & 0,48 & $0,005$. MOE-5,2299 \\
SS & 0,61 & $0,0064$. MOE-12,343 \\
S1 & 0,07 & $0,0014$. MOE+19,187 \\
S2 & 0,47 & $0,0039$. MOE-0,6405 \\
S3 & 0,27 & $0,0026$. MOE+9,2602 \\
\hline
\end{tabular}

O MOE apresentou correlações baixas para estimativa do MOR na flexão estática. Os defeitos naturais como os nós, dependendo de sua localização e dimensão, interferem mais nos valores do MOR do que nos valores do MOE, criando um ponto de fragilidade localizado na peça. Em função disto, as peças com maior incidência de defeitos, apresentaram rupturas não previsíveis, que afetaram negativamente a correlação entre as propriedades nas classes estruturais S1, S2 e S3. Foi observada uma maior correlação da regressão linear na classe SS, em comparação às classes $\mathrm{S} 1, \mathrm{~S} 2$ e $\mathrm{S} 3$. 


\subsection{CORRELAÇÃO ENTRE A DENSIDADE APARENTE E O MOE}

Para a análise comparativa entre os dados da Densidade aparente e o MOE obtido pelo ensaio de flexão estática foi utilizado o modelo de regressão linear simples, sendo a Densidade a variável independente $(x)$, como variável dependente $(y)$ foi adotado o MOE.

A análise foi feita determinando a equação da regressão linear, o coeficiente de correlação e analisando os resíduos, para verificar o atendimento dos requisitos. Após, foi feita análise da variância para verificar a condição do modelo ajustado.

\subsubsection{Lote completo}

A Figura 69 apresenta o diagrama de dispersão e regressão entre a Densidade aparente e o MOE, para os dados do lote completo.

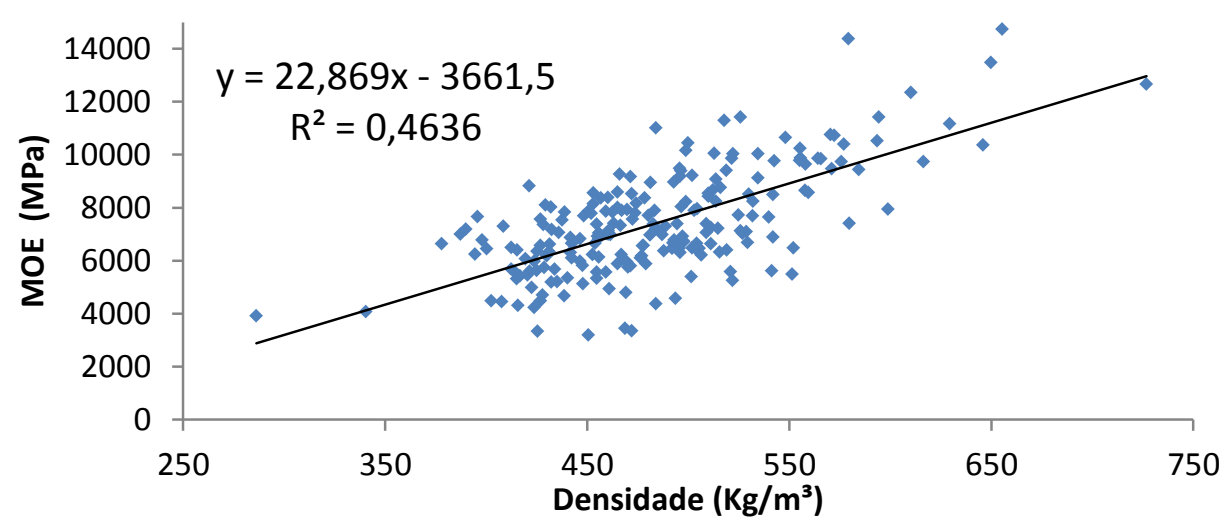

Figura 69 - Diagrama de dispersão e reta de regressão entre o MOE e a Densidade aparente do lote completo.

A Figura 70 apresenta o gráfico dos resíduos em função dos valores estimados para o MOE, podendo ser observada a homogeneidade da variância.

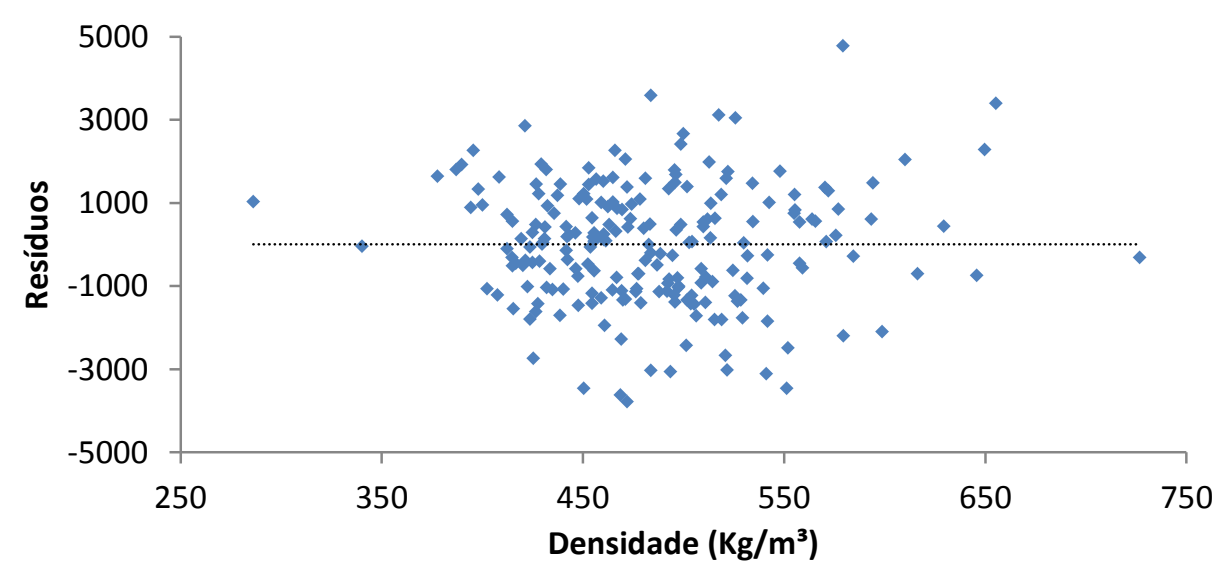

Figura 70 - Gráfico dos resíduos contra valores estimados para a Densidade aparente para o lote completo. 
A Figura 71 apresenta o gráfico dos resíduos padronizados contra os escores normais, observando-se, aproximadamente uma distribuição normal.

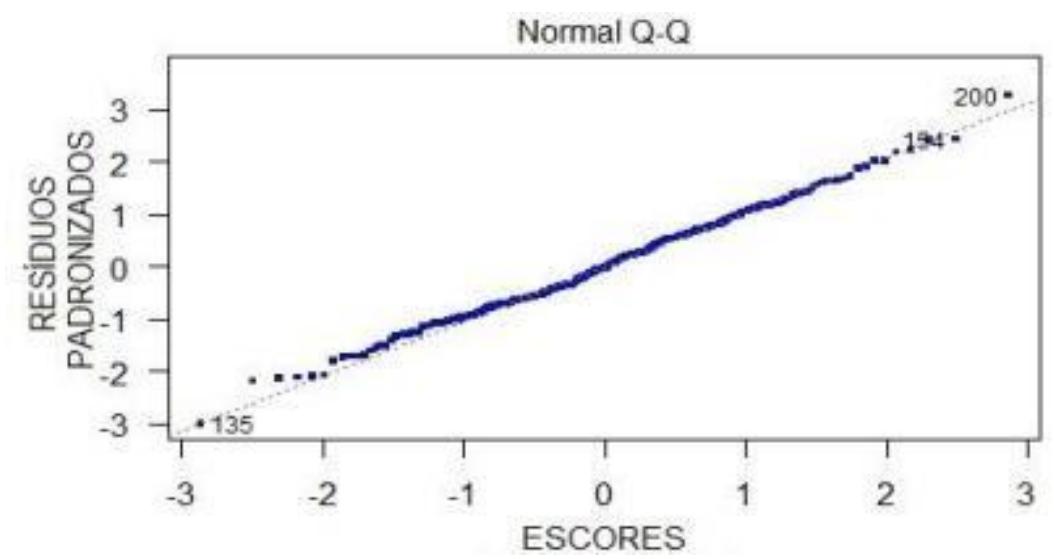

Figura 71 - Gráfico de probabilidade normal dos resíduos para a Densidade do lote completo.

Atendidas as suposições da regressão, a Tabela 42 apresenta os resultados da análise da variância.

Tabela 42 - Quadro de ANOVA (MOE x Densidade) - lote completo.

\begin{tabular}{lccccc}
\hline & Gl & SQ & MQ & F & Valor-P \\
\hline Regressão & 1 & $3,821 \mathrm{E}+08$ & $3,821 \mathrm{E}+08$ & 182,4 & 0,00 \\
Resíduo & 211 & $4,421 \mathrm{E}+08$ & 2095440 & & \\
Total & 212 & $8,242 \mathrm{E}+08$ & & & \\
\hline
\end{tabular}

Para os graus de liberdade (1,211), o valor de F, a um nível de significância de $\alpha=0,05$ é 3,86. Como o valor calculado de $\mathrm{F}$ é igual a 182,4 , pode-se concluir que existe evidência estatística de que a proporção da variância total explicada pela regressão é altamente significativa. Assim, o modelo de regressão linear dado por $\{M O E(M P a)=22,869$ - Densidade (MPa) - 3661,5\} é adequado.

\subsubsection{Classe Visual SS}

A Figura 72 apresenta o diagrama de dispersão e regressão entre a Densidade aparente e o MOE, para os dados da classe SS. 


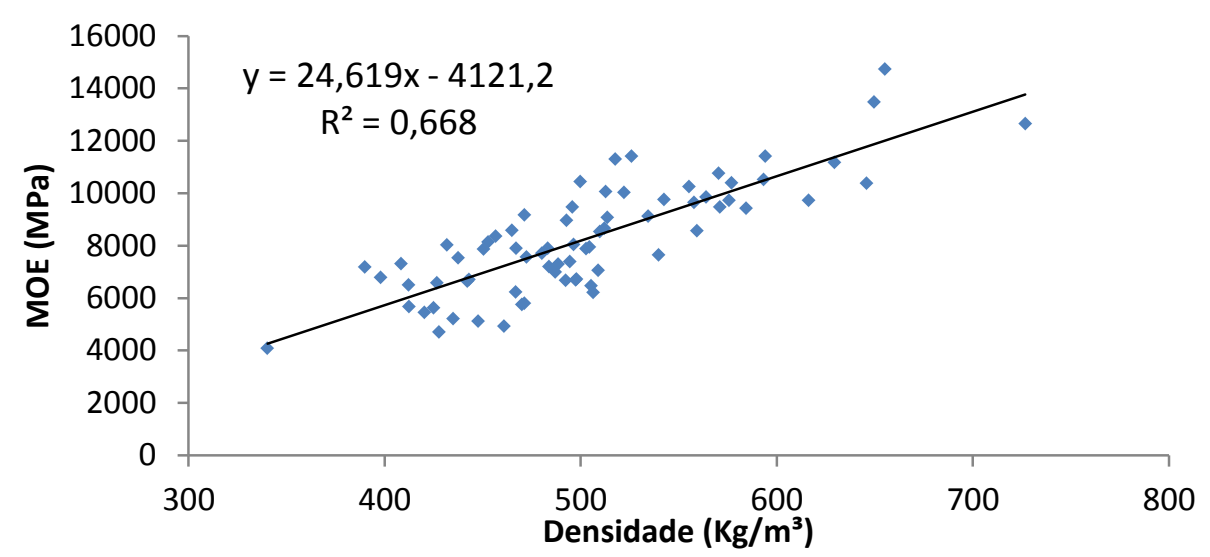

Figura 72 - Diagrama de dispersão e reta de regressão entre o MOE e a Densidade aparente - Classe SS.

A Figura 73 apresenta o gráfico dos resíduos em função dos valores estimados para o MOE, podendo ser observada a homogeneidade da variância.

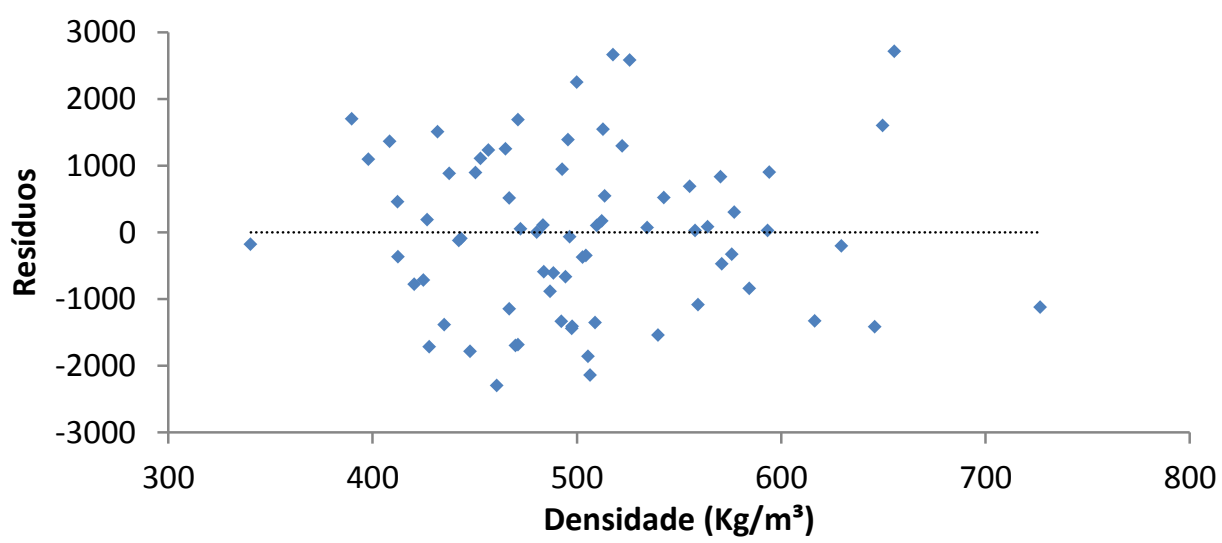

Figura 73 - Gráfico dos resíduos contra valores estimados para a Densidade aparente - Classe SS.

A Figura 74 apresenta o gráfico dos resíduos padronizados contra os escores normais, observando-se, aproximadamente uma distribuição normal.

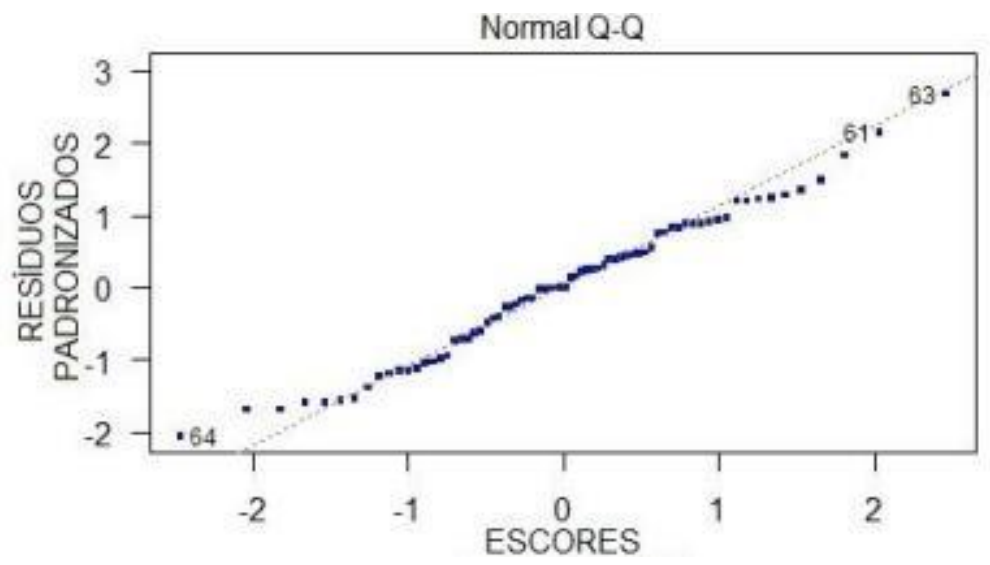

Figura 74 - Gráfico de probabilidade normal dos resíduos para a Densidade aparente - Classe SS. 
Atendidas as suposições da regressão, a Tabela 43 apresenta os resultados da análise de variância.

Tabela 43 - Quadro de ANOVA (MOE x Densidade) - Classe SS.

\begin{tabular}{lccccc}
\hline & gl & SQ & MQ & F & Valor-P \\
\hline Regressão & 1 & $2,115 \mathrm{E}+08$ & $2,115 \mathrm{E}+08$ & 140,8 & 0,0000 \\
Resíduo & 70 & $1,051 \mathrm{E}+08$ & 1502011 & & \\
Total & 71 & $3,167 \mathrm{E}+08$ & & & \\
\hline
\end{tabular}

Para os graus de liberdade $(1,70)$, o valor de F, a um nível de significância de $\alpha=0,05$ é 3,91. Como o valor calculado de $\mathrm{F}$ é igual a 140,8 , pode-se concluir que existe evidência estatística de que a proporção da variância total explicada pela regressão é altamente significativa. Assim, o modelo de regressão linear dado por $\{M O E(M P a)=24,619$ - Densidade $(\mathrm{MPa})-4121,2\}$ é adequado.

\subsubsection{Classe Visual S1}

A Figura 75 apresenta o diagrama de dispersão e a regressão entre a Densidade aparente e o MOE, para os dados da classe S1.

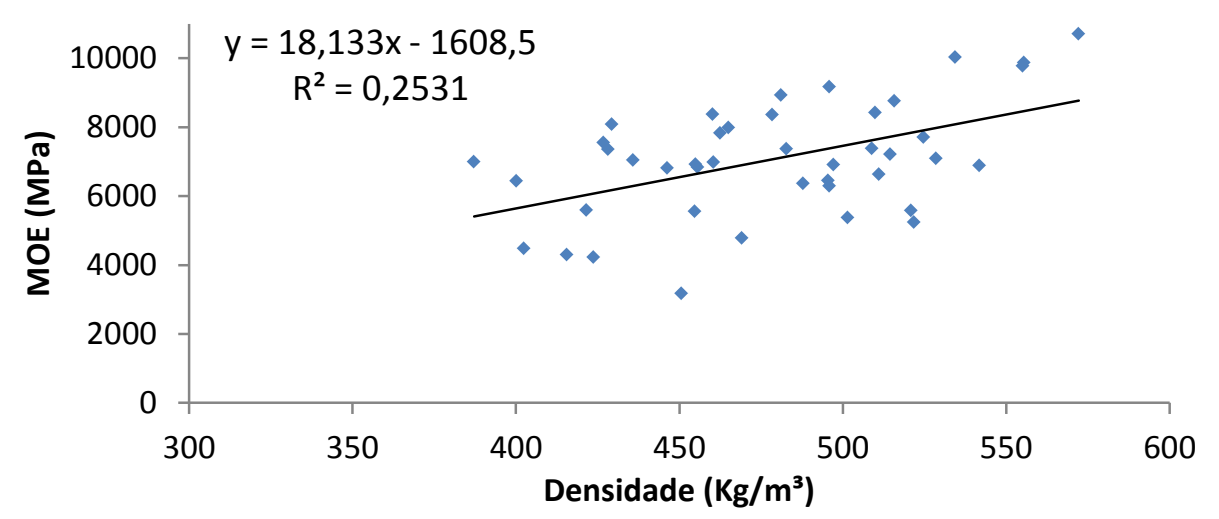

Figura 75 - Diagrama de dispersão e reta de regressão entre o MOE e a Densidade aparente - Classe S1.

A Figura 76 apresenta o gráfico dos resíduos em função dos valores estimados para a Densidade, podendo ser observada a homogeneidade da variância. 


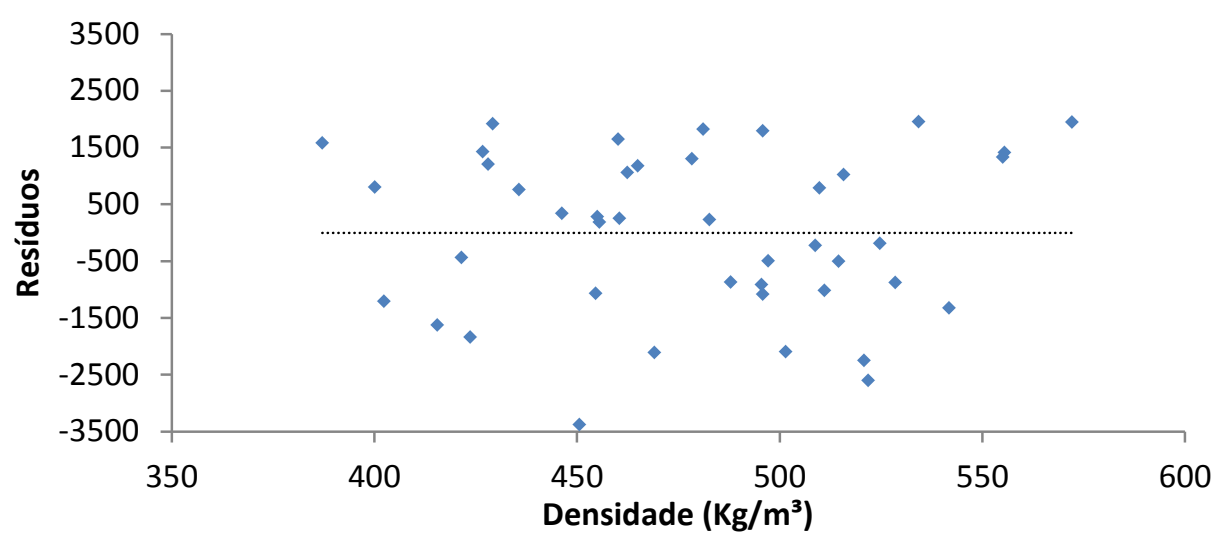

Figura 76 - Gráfico dos resíduos contra valores estimados para a Densidade aparente - Classe S1.

A Figura 77 apresenta o gráfico dos resíduos padronizados contra os escores normais, observando-se, aproximadamente uma distribuição normal.

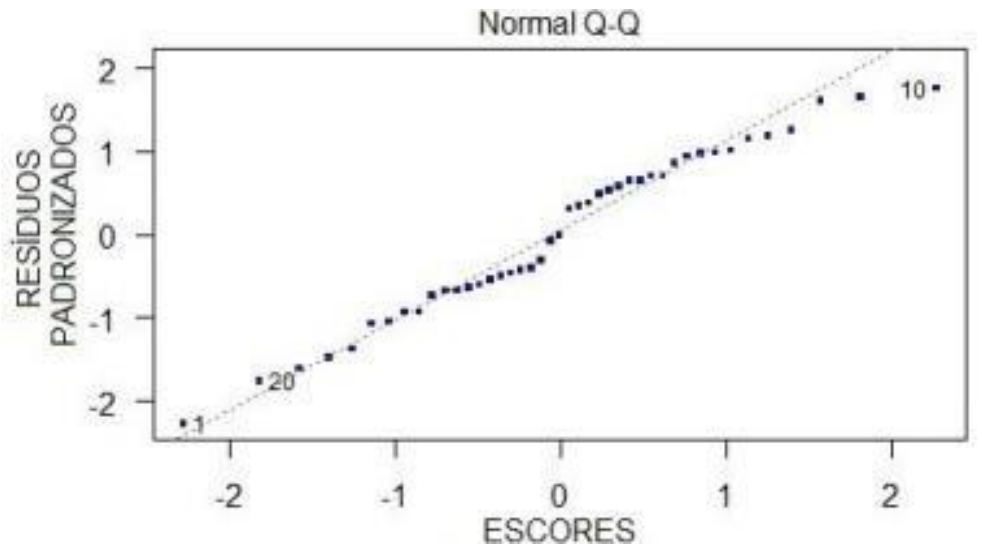

Figura 77 - Gráfico de probabilidade normal dos resíduos para a Densidade aparente - Classe S1.

Atendidas as suposições da regressão, a Tabela 44 apresenta os resultados da análise de variância.

Tabela 44 - Quadro de ANOVA (MOE x Densidade) - Classe S1.

\begin{tabular}{lccccc}
\hline & gl & SQ & MQ & F & Valor-P \\
\hline Regressão & 1 & $2,899 \mathrm{E}+07$ & $2,899 \mathrm{E}+07$ & 13,9 & 0,0006 \\
Resíduo & 41 & $8,557 \mathrm{E}+07$ & 2087056 & & \\
Total & 42 & $1,146 \mathrm{E}+08$ & & & \\
\hline
\end{tabular}


Para os graus de liberdade $(1,41)$, o valor de F, a um nível de significância de $\alpha=0,05$ é 3,95. Como o valor calculado de $\mathrm{F}$ é igual a 13,9 , pode-se concluir que existe evidência estatística de que a proporção da variância total explicada pela regressão é significativa. Assim, o modelo de regressão linear dado por $\{\operatorname{MOE}(M P a)=18,133$. Densidade $(\mathrm{MPa})-1608,5\}$ é adequado.

\subsubsection{Classe Visual S2}

A Figura 78 apresenta o diagrama de dispersão e a regressão entre a Densidade aparente e o MOE, para os dados da classe S2.

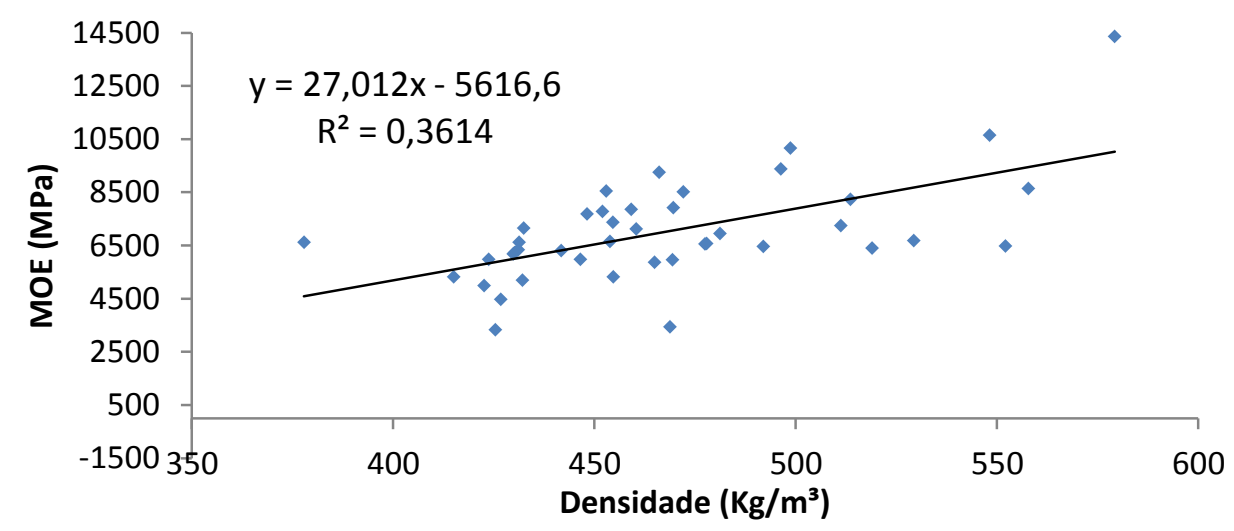

Figura 78 - Diagrama de dispersão e reta de regressão entre o MOE e a Densidade aparente - Classe S2.

A Figura 79 apresenta o gráfico dos resíduos em função dos valores estimados para o MOE, onde pode ser observada a homogeneidade da variância.

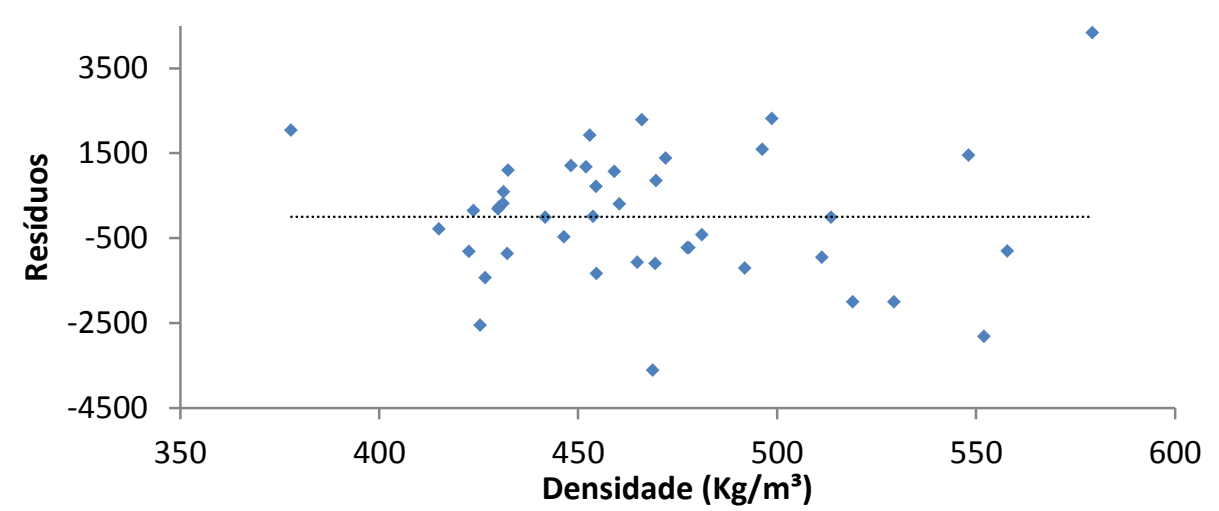

Figura 79 - Gráfico dos resíduos contra valores estimados para a Densidade aparente - Classe S2. 
A Figura 80 apresenta o gráfico dos resíduos padronizados contra os escores normais, observando-se, aproximadamente uma distribuição normal.

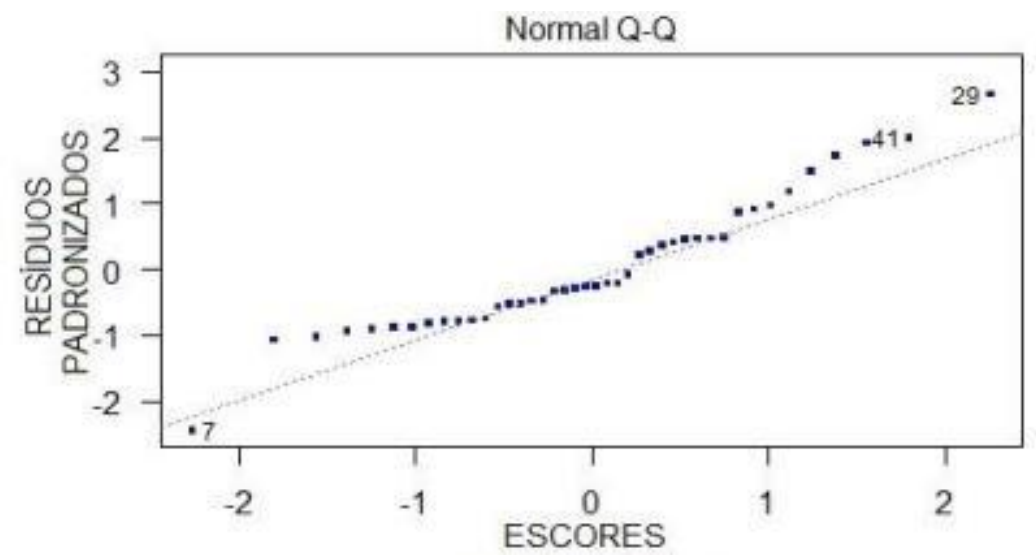

Figura 80 - Gráfico de probabilidade normal dos resíduos para a Densidade aparente - Classe S2.

Atendidas as suposições da regressão, a Tabela 45 apresenta os resultados da análise de variância.

Tabela 45 - Quadro de ANOVA (MOE x Densidade) - Classe S2.

\begin{tabular}{lccccc}
\hline & gl & SQ & MQ & F & Valor-P \\
\hline Regressão & 1 & $5,568 \mathrm{E}+07$ & $5,568 \mathrm{E}+07$ & 22,6 & 0,0000 \\
Resíduo & 40 & $9,839 \mathrm{E}+07$ & 2459746 & & \\
Total & 41 & $1,541 \mathrm{E}+08$ & & & \\
\hline
\end{tabular}

Para os graus de liberdade $(1,40)$, o valor de F, a um nível de significância de $\alpha=0,05$ é 3,95. Como o valor calculado de $\mathrm{F}$ é igual a 22,6 , pode-se concluir que existe evidência estatística de que a proporção da variância total explicada pela regressão é altamente significativa. Assim, o modelo de regressão linear dado por $\{M O E(M P a)=27,012$ - Densidade $(\mathrm{MPa})-5616,6\}$ é adequado.

\subsubsection{Classe Visual S3}

A Figura 81 apresenta o diagrama de dispersão e a regressão entre a Densidade aparente e o MOE, para os dados da classe S3. 


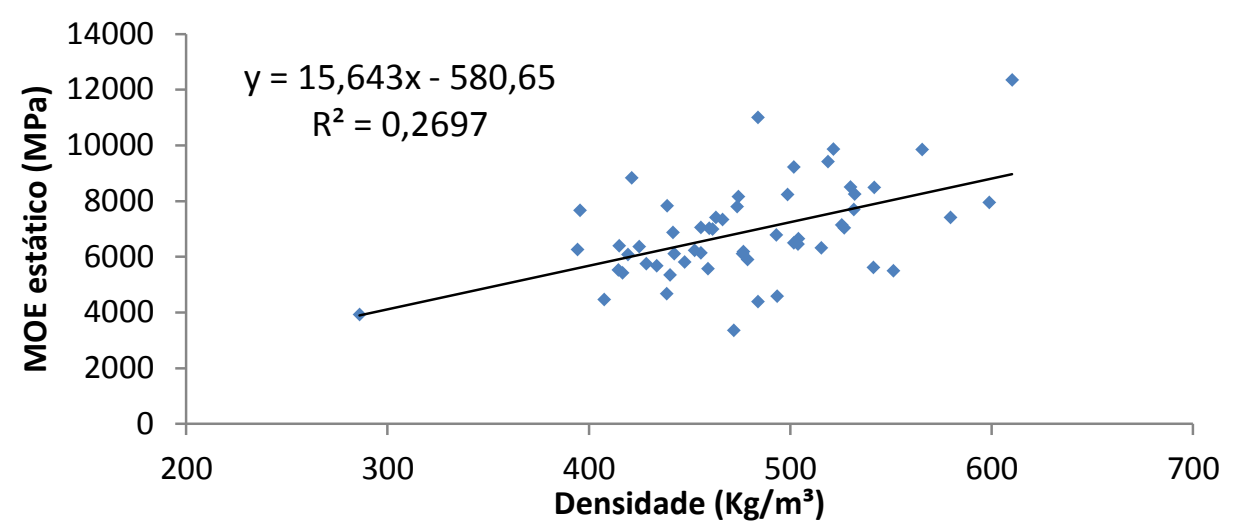

Figura 81 - Diagrama de dispersão e reta de regressão entre o MOE e a Densidade aparente - Classe S3.

A Figura 82 apresenta o gráfico dos resíduos em função dos valores estimados para o MOE, podendo ser observada a homogeneidade da variância.

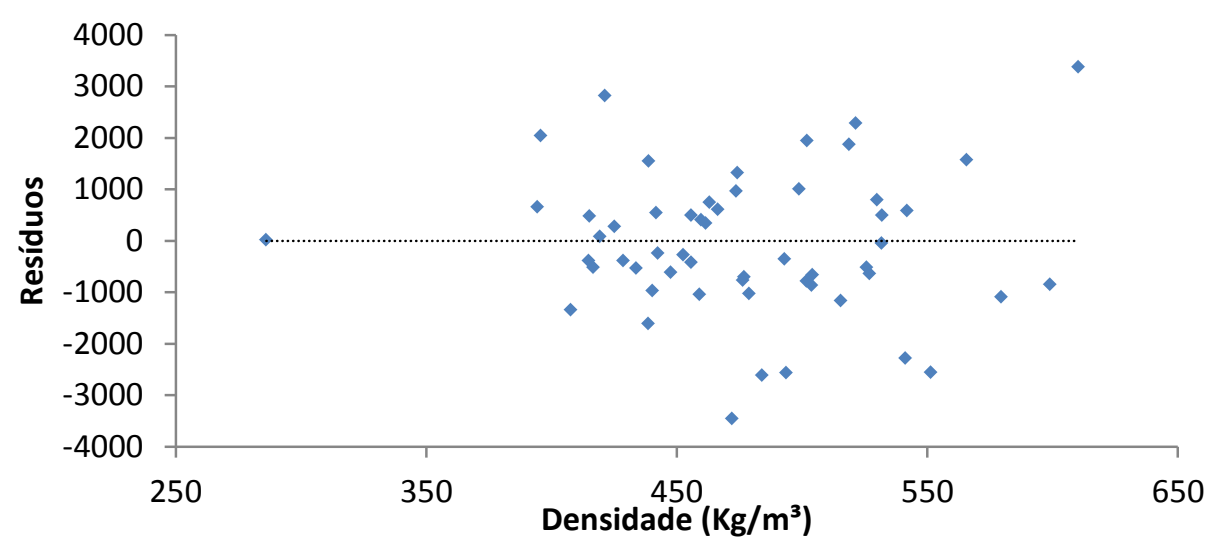

Figura 82 - Gráfico dos resíduos contra valores estimados para a Densidade aparente - Classe S3.

A Figura 83 apresenta o gráfico dos resíduos padronizados contra os escores normais, observando-se, aproximadamente uma distribuição normal.

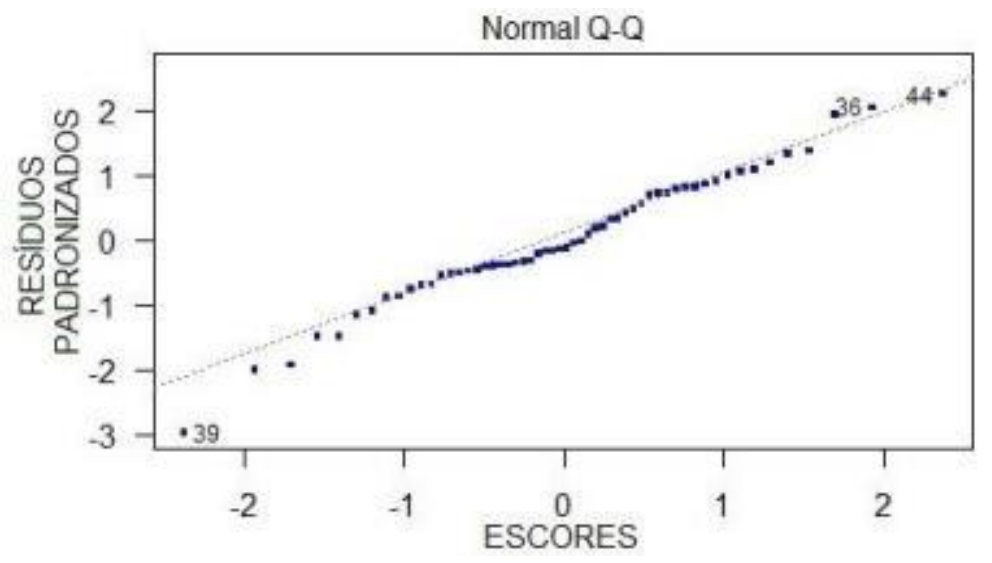

Figura 83 - Gráfico de probabilidade normal dos resíduos para a Densidade aparente - Classe S3. 
Atendidas as suposições da regressão, a Tabela 46 apresenta os resultados da análise de variância.

Tabela 46 - Quadro de ANOVA para os dados de MOE pela Densidade aparente - Classe S3.

\begin{tabular}{lccccc}
\hline & gl & SQ & MQ & F & Valor-P \\
\hline Regressão & 1 & $4,335 \mathrm{E}+07$ & $4,335 \mathrm{E}+07$ & 19,9 & 0,0000 \\
Resíduo & 54 & $1,174 \mathrm{E}+08$ & 2173553 & & \\
Total & 55 & $1,607 \mathrm{E}+08$ & & & \\
\hline
\end{tabular}

Para os graus de liberdade $(1,54)$, o valor de F, a um nível de significância de $\alpha=0,05$ é 3,93. Como o valor calculado de $\mathrm{F}$ é igual a 19,9 , pode-se concluir que existe evidência estatística de que a proporção da variância total explicada pela regressão é significativa. Assim, o modelo de regressão linear dado por $\{M O E(M P a)=15,643$. Densidade $(M P a)-580,65\}$ é adequado.

\subsubsection{Resumo das Correlações da Densidade}

A Tabela 47 apresenta o resumo dos valores das correlações da regressão linear entre a densidade aparente à $12 \%$ de umidade e o MOE na flexão estática para as diferentes classes de madeira.

Tabela 47 - Correlação da regressão linear entre a Densidade Aparente e o MOE.

\begin{tabular}{ccc}
\hline & Correlação da Densidade com o MOE \\
\hline Classe & Coeficiente de Correlação & Equação \\
Lote Completo & 0,464 & $22,869 \cdot$ Densidade $-3661,5$ \\
SS & 0,668 & $24,619 \cdot$ Densidade $-4121,2$ \\
S1 & 0,253 & $18,133 \cdot$ Densidade $-1608,5$ \\
S2 & 0,361 & $27,012 \cdot$ Densidade $-5616,6$ \\
S3 & 0,270 & $15,643 \cdot$ Densidade $-580,65$ \\
\hline
\end{tabular}

A densidade aparente não resultou um bom estimador para o MOE na flexão estática, tendo valores mais significativos para a classe SS, com menor incidência de defeitos e correlações fracas para as classes inferiores S1, S2 e S3. 


\section{CONCLUSÃO}

Do lote completo de 260 peças, após a classificação visual, 213 peças foram enquadradas para utilização estrutural, sendo $33,8 \%$ de peças na melhor categoria (SS), 39\% de peças nas classes intermediárias, sendo S1(20,2\%) e S2(19,7\%), e também 26,3\% na classe inferior (S3).

O valor médio da umidade das peças foi de 9,5\% e os valores da densidade, MOE e MOR foram corrigidos para a condição padrão de $12 \%$ de umidade em cada peça.

$\mathrm{O}$ valor médio de densidade aparente à $12 \%$ de umidade, para o lote completo foi de $484 \mathrm{~kg} / \mathrm{m}^{3}$, variando entre $470 \mathrm{~kg} / \mathrm{m}^{3}(-2,9 \%)$ e $502 \mathrm{~kg} / \mathrm{m}^{3}(+3,7 \%)$ entre as classes visuais. Pela densidade as peças apresentaram valores próximos aos da classe C20 $\left(500 \mathrm{~kg} / \mathrm{m}^{3}\right) \mathrm{da}$ NBR7190.

O Módulo de Elasticidade (MOE) característico na flexão estática à $12 \%$ de umidade apresentou valor de $5108 \mathrm{MPa}$ para o lote completo. A classe SS apresentou o maior valor, com $5801 \mathrm{MPa}, 13,6 \%$ acima do valor do lote completo. O valor do MOE para a S1 foi $4957 \mathrm{MPa}(-3,0 \%)$, para a S2 foi $4919 \mathrm{MPa}(-3,7 \%)$ e para a S3 foi $4885 \mathrm{MPa}(-4,4 \%)$. Os valores do MOE para as classes S1, S2 e S3 foram próximos. As peças, em todas as classes, foram enquadrados na classe C20 (3500 MPa) da NBR7190.

A resistência à flexão (MOR) característica para o lote completo foi 21,7 MPa. A classe SS apresentou o maior valor, 28,6 $\mathrm{MPa}, 31,8 \%$ acima do valor do lote completo. As classes S1, S2 e S3 apresentaram valores de 20,5 MPa (-5,5\%), 19,2 MPa (-11,5\%) e 18,9 $\mathrm{MPa}(-12,9 \%)$ respectivamente.

A classe SS apresentou os maiores valores característicos das propriedades de MOE e MOR, mesmo com densidade similar entre as classes. A variação média dos valores das propriedades entre as classes S1, S2 e S3 foi pequena, indicando que a junção dessas classes não teria influência significativa, para o lote avaliado.

O $E_{\text {DIN }}$ médio para o lote completo foi $13,27 \%$ superior aos valores de MOE na flexão estática. Os valores do $\mathrm{E}_{\mathrm{MTG}}$ foram em média 3,96\% acima dos valores do MOE na flexão estática.

Os valores do $\mathrm{E}_{\mathrm{DIN}}$ foram superiores aos valores de MOE nas diferentes classes visuais. Sendo $(+13,38 \%)$ na SS, $(+11,30 \%)$ na $S 1,(+11,33 \%)$ na S2 e $(+15,04 \%)$ na S3. É possível verificar que o fator de correção do software do MTG aplicado no $E_{D I N}$, para a espécie Pinus elliottii foi entre 0,9166 e 0,9206 . Resultando na estimativa mais aproximada 
dos valores do $\mathrm{E}_{\mathrm{MTG}}$ de cada classe visual em SS (+4,38\%), S1 (+2,02\%), S2 (+2,04\%) e S3 $(+5,5 \%)$, sempre superiores ao valor do MOE.

A correlação da regressão linear entre o $\mathrm{E}_{\mathrm{MTG}} \mathrm{e}$ o MOE foi 0,86 para o lote completo, sendo obtidos os seguintes valores para cada classe: 0,91 (SS), 0,85 (S1), 0,88 (S2) e 0,74 (S3). Os valores de $\mathrm{E}_{\mathrm{MTG}}$, após a aproximação definida pelo software do MTG, em função da espécie estudada, apresentaram boas correlações com o MOE na flexão estática. Foi observada uma maior correlação da regressão linear nas peças com menor incidência de defeitos, classe visual SS, havendo uma diminuição na correlação à medida que aumenta a presença dos defeitos naturais.

A correlação da regressão linear entre o $E_{\text {DIN }}$ obtido pela frequência natural e o MOE na flexão estática foi 0,87 para o lote completo, sendo obtidos os seguintes valores para cada classe: 0,92 (SS), 0,85 (S1), 0,88 (S2) e 0,75 (S3). As regressões lineares entre o $\mathrm{E}_{\mathrm{DIN}} \mathrm{e}$ o MOE, apresentaram boas correlações, sendo observada uma maior correlação da regressão linear nas peças da classe SS, com menor incidência de defeitos. Nas classes S1, S2 e S3, a presença dos defeitos naturais reduziu a correlação entre as propriedades.

A correlação da regressão linear entre o MOR e o MOE na flexão estática foi 0,48 para o lote completo, sendo obtidos os seguintes valores para cada classe: 0,61 (SS), 0,07 (S1), 0,47 (S2) e 0,27 (S3). O MOR apresentou correlações baixas para estimativa do MOE na flexão estática. Os defeitos naturais, como os nós, dependendo de sua localização e dimensão, interferem mais nos valores do MOR do que nos valores do MOE, criando um ponto de fragilidade localizado na peça. Em função disto, as peças com maior incidência de defeitos, apresentaram rupturas não previsíveis, que afetaram negativamente a correlação entre as propriedades nas classes estruturais S1, S2 e S3. Foi observada uma maior correlação da regressão linear na classe SS, em comparação às classes S1, S2 e S3.

A correlação da regressão linear entre o MOE e a densidade aparente à $12 \%$ de umidade foi 0,46 para o lote completo, sendo obtidos os seguintes valores para cada classe: 0,67 (SS), 0,25 (S1), 0,36 (S2) e 0,27 (S3). A densidade aparente não resultou um bom estimador para o MOE, com valores mais significativos para a classe SS, com menor incidência de defeitos e correlações fracas para as classes inferiores S1, S2 e S3.

O aparelho portátil de classificação estrutural MTG, por meio da vibração longitudinal apresentou bons resultados para a estimativa do MOE, e é recomendável a utilização deste método para a classificação estrutural de peças serradas de madeira. 
A técnica pode contribuir para uma maior velocidade de classificação estrutural das peças de madeira, com baixo custo de instalação e podendo ser aplicado nas serrarias, agregando valor ao produto classificado ou na pré classificação das lamelas para melhor racionalização de vigas de madeira laminada colada (MLC), contribuindo para a evolução da classificação das peças no mercado brasileiro de madeiras para uso estrutural. A classificação das peças permite um maior conhecimento das propriedades das peças utilizadas nos projetos, racionalizando a execução das estruturas. A classificação visual agregada a classificação mecânica são processos essenciais para a utilização do Pinus em vigas laminadas coladas, construções industrializadas e de woodframe, aumentando a confiabilidade no material. 


\section{REFERÊNCIAS}

AMERICAN SOCIETY FOR TESTING AND MATERIALS. ASTM D198: Standard test methods of static tests of lumber in structural sizes, Annual Book of ASTM Standards. 76 ed. West Conshohocken, 2003.

AMERICAN SOCIETY FOR TESTING AND MATERIALS. ASTM D245: Standard Practice for Establishing Structural Grades and Related Allowable Properties for Visually Graded Lumber. 00 ed. West Conshohocken: Annual Book of ASTM Standards, 2000.

AMERICAN SOCIETY FOR TESTING AND MATERIALS. ASTM D4761: Standard Test Methods for Mechanical Properties of Lumber and Wood-Base Structural Material. 02a ed. West Conshohocken: Annual Book of ASTM Standards, 2002.

ASSOCIAÇÃO BRASILEIRA DE NORMAS TÉCNICAS. NBR 7190: Projetos de estruturas de madeira. Rio de Janeiro, 1997.

ASSOCIAÇÃO BRASILEIRA DE NORMAS TÉCNICAS. NBR 11700: Madeira serrada de coníferas provenientes de reflorestamento, para uso geral. Rio de Janeiro, $1991.6 \mathrm{p}$.

ASSOCIAÇÃO BRASILEIRA DE NORMAS TÉCNICAS. NBR 12297: Madeira serrada de coníferas provenientes de reflorestamento, para uso geral: medição e quantificação de defeitos. Rio de Janeiro, 1991. 6 p.

ASSOCIAÇÃO BRASILEIRA DE PRODUTORES DE FLORESTAS PLANTADAS (Brasília) (Org.). Anuário estatístico ABRAF 2013 ano base 2012. Brasília: Abraf, 2013.

BARRETT, David et al. Comparison of Machine Grading Methods for Canadian Hemlock. SBC Industry, Madison, p.1-6, 2008.

BODIG, J.; JAYNE, B. A.. Mechanics of Wood and Wood Composites. New York: van Nostrand Reinhold, 1993. 712 p.

BUCUR, Voichita. Acoustics of Wood. Berlin: Springer-verlag Berlin Heidelberg, 2006. $394 \mathrm{p}$.

CALIL JÚNIOR, Carlito; MINÁ, Alexandre J. S.. Vibração transversal: Um método eficiente para classificação de peças estruturais de madeira. Revista Brasileira de Engenharia Agrícola e Ambiental, [s.I.], v. 7, n. 2, p.335-338, ago. 2003. FapUNIFESP (SciELO). http://dx.doi.org/10.1590/s1415-43662003000200025.

CARREIRA, Marcelo Rodrigo. Critérios para classificação visual de peças estruturais de Pinus sp. 2003. 182 f. Dissertação (Mestrado) - Curso de Engenharia de Estruturas, Escola de Engenharia de São Carlos, Universidade de São Paulo, São Carlos, 2003. 
CARREIRA, Marcelo Rodrigo; DIAS, Antônio Alves. Critérios para classificação visual de peças estruturais de Pinus sp. Cadernos de Engenharia de Estruturas, São Carlos, v. 8, n. 34, p.17-43, out. 2006. Bimestral. ISSN: 1806-6907.

EUROPEAN COMMITTEE FOR STANDARDIZATION. 14081-2: Timber structures Strength graded structural timber with rectangular cross section - Part 2: Machine grading; additional requirements for initial type testing. Bruxelas: Cen, 2010. 25 p.

EUROPEAN COMMITTEE FOR STANDARDIZATION. 14081-3: Timber structures Strength graded structural timber with rectangular cross section - Part 3: Machine grading; additional requirements for factory production control. Bruxelas: Cen, 2010. $19 \mathrm{p}$.

EUROPEAN COMMITTEE FOR STANDARDIZATION. 14081-4: Timber structures Strength graded structural timber with rectangular cross section - Part 4: Machine grading; grading machine settings for machine controlled systems. Bruxelas: Cen, 2010. $16 \mathrm{p}$.

FREITAS, Roberto Ramos de. Classificação de peças estruturais de pinus spp pela MSR (Machine Stress Rate). 2004. 185 f. Dissertação (Mestrado) - Área de Interunidades em Ciências e Engenharia de Materiais, Escola de Engenharia de São Carlos, Universidade de São Paulo, São Carlos, 2004.

GATTO, Darci Alberto et al. Qualidade da madeira serrada na região da quarta colônia de imigração italiana do rio grande do sul. Ciência Florestal, Santa Maria, v. 14, n. 1, p.223-233, 2004.

GAUNT, Douglas; VAN WYK, Louw. Literature review on machine stress grading accuracy check methods: Manufacturing \& Products. 02.1905 Victoria, Australia: Fwpa, 2003. 67 p. ISBN: 1920883045.

HALABE, Udaya B. et al. Nondestructive Evaluation of Green Wood Using Stress Wave and Transverse Vibration Techniques. Materials Evaluation, Columbus, v. 55, n. 9, p.1013-1018, set. 1997.

HERZOG, Thomas et al. Timber Construction Manual. Berlin: Friedemann Zeitler, 2008. $375 \mathrm{p}$.

HOFFMEYER. Styrkesortering ger mervärde: Parte 2 - Tillgaenglig teknik. Dinamarca: Laboratory Of Bygningsmaterialer, 1995.

HORÁCEK, Petr; TIPPNER, Jan. Nondestructive Evaluation of Static Bending Properties of Scots Pine Wood using stress wave technique. Wood Research, Brno, República Checa, v. 57, n. 3, p.359-366, 2012.

INDUSTRIA BRASILEIRA DE ARVORES (Df). Indústria Brasileira de Árvores. Relatório Anual IBA: 2015 base 2014. Brasília, 2015. 80 p.

JANKOWSKY, Ivaldo Pontes. Fundamentos de secagem de madeiras. Documentos Florestais, Piracicaba, n. 10, p.1-10, jun. 1990. 
JOHANSSON, Carl-johan. Grading of Timber with Respect to Mechanical Properties. In: THELANDERSSON, Sven. Timber Engineering: Part One - Basic Properties of Wood-Based Structural Elements. West Sussex: Wiley, 2003. Cap. 3. p. 23-43.

KOLLMANN, Frans F.P.; COTE, Wilfred A.. Physics of Wood. In: KOLLMANN, Frans F.p.. Principles of Wood Science and Technology: Solid Wood. Heidelberg: Springer-verlag, 1968. Cap. 6. p. 160-291.

KOLLMANN, Frans F.P.; COTE, Wilfred A.. Mechanics and Rheology of Wood. In: KOLLMANN, Frans F.P.. Principles of Wood Science and Technology: Solid Wood. Heidelberg: Springer-verlag, 1968. Cap. 7. p. 292-419.

KRETSCHMANN, David E.. Stress Grades and Design Properties for Lumber, Round Timber, and Ties. In: FOREST PRODUCTS LABORATORY (Org.). Wood handbook: Wood as an engineering material. Washington: U.s. Department Of Agriculture, 2010. Cap. 7. p. 172-187.

KRETSCHMANN, David E.. Mechanical Properties of Wood. In: FOREST PRODUCTS LABORATORY (Org.). Wood handbook: Wood as an engineering material. Washington: U.s. Department Of Agriculture, 2010. Cap. 5. p. 100-145.

LARSSON, Daniel. Mechanical characterization of engineering materials by modal testing. 1997. 97 f. Tese (Doutorado) - Curso de Engenharia de Estruturas, Chalmers University Of Technology, Gotemburgo, Suécia, 1997.

MADSEN, B.. Duration of loadest for wet lumber in bending. Forest Products Journal, Peachtree Corners, v. 25, n. 5, p.33-40, 1975.

MILLER, D. G.. Selection efficiencies of non-destructive strength tests. Forest Products Journal, Peachtree Corners, v. 12, n. 8, p.358-363, 1962.

NOGUEIRA, Marcelo; BALLARIN, Adriano W.. Sensibilidade dos ensaios de ultrasom à ortotropia elástica da madeira. In: CONFERêNCIA PAN-AMERICANA DE ENSAIOS NÃO-DESTRUTIVOS, 3., 2003, Rio de Janeiro. Anais... . Rj: ABENDE, 2003.

O'HALLORAN, M. R.; BODIG, J.; BOWDEN, D. C.. Nondestructive parameters of lodge pole pine dimension lumber in bending. Forest Products Journal, Peachtree Corners, v. 22, n. 2, p.44-51, 1972.

OLIVEIRA, Fabiana Goia R.; CAMPOS, Janaina Anadia Goes de; SALES, Almir. Ultrasonic Measurements In Brazilian Hardwood. Materials Research, São Carlos, v. 5 , n. 1, p.51-55, 2002.

ROCCO LAHR, Francisco Antônio. Sobre a Determinação de Propriedades de Elasticidade da Madeira. 1983. 221 f. Tese (Doutorado) - Curso de Engenharia de Estruturas, Escola de Engenharia de São Carlos, Universidade de São Paulo, São Carlos, 1983. 
ROZEMA, Peter. Timber Grader MTG: Operational instructions. Holanda: Enschede Institutenweg, 2013.93 p.

SCHWEITZER, Roland. Wood as a Building Material - from the beginnings to the 19th century. In: HERZOG, Thomas. Timber Construction Manual. New York: Friedemann Zeitler, 2008. Cap. 1. p. 24-30.

SEGUNDINHO, Pedro Gutemberg de Alcantara et al. Aplicação do método de ensaio das frequências naturais de vibração para obtenção do módulo de elasticidade de peças estruturais de madeira. Revista Arvore, Viçosa, v. 36, n. 6, p.1155-1162, jun. 2012.

TARGA, Luiz A.; BALLARIN, Adriano W.; BIAGGIONI, Marco A. M.. Avaliação do módulo de elasticidade da madeira com uso de método não-destrutivo de vibração transversal. Engenharia Agrícola, Jaboticabal, v. 25, n. 2, p.291-299, maio/ago. 2005.

THELANDERSSON, Sven. Wood as a Construction Material. Timber Engineering: PartOne - Basic Properties of Wood-Based Structural Elements. West Sussex: Wiley, 2003. Cap. 2. p. 15-23.

WEGENER, Gerd; ZIMMER, Bernhard. Building with wood is building for the future. In: HERZOG, Thomas. Timber Construction Manual. Berlin: Friedemann Zeitler, 2008. Cap. 2. p. 47-53.

WIEGAND, Tobias. Grading an improvement of solid timber products. In: HERZOG, Thomas. Timber Construction Manual. Berlin: Friedemann Zeitler, 2008. Cap. 3. p. 55-59. 